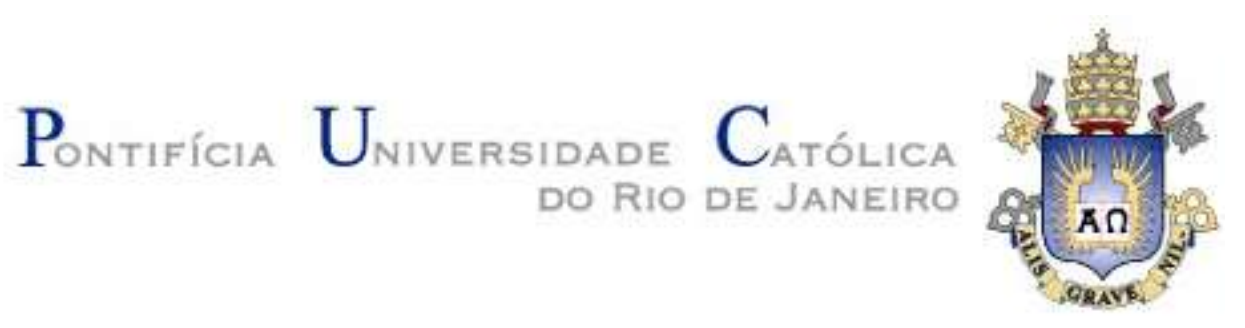

Thaís Motta da Silva

\title{
Aplicação da Integral-J em Aços de Diferentes Limites de Escoamento
}

\author{
Dissertação de Mestrado
}

Dissertação apresentada como requisito parcial para obtenção do grau de Mestre pelo Programa de PósGraduação em Engenharia de Materiais e de Processos Químicos e Metalúrgicos do Departamento de Engenharia Química e de Materiais.

Orientador: Prof. Marcos Venicius Soares Pereira Co-orientador: Prof. André Luis Moreira de Carvalho 


\title{
Pontifícia U Uiversidade C $_{\text {atóllica }}$

Thaís Motta da Silva

\section{Aplicação da Integral-J em Aços de Diferentes Limites de Escoamento}

\begin{abstract}
Dissertação apresentada como requisito parcial para obtenção do grau de Mestre pelo Programa de PósGraduação em Engenharia de Materiais e de Processos Químicos e Metalúrgicos do Departamento de Engenharia Química e de Materiais. Aprovada pela Comissão Examinadora abaixo assinada
\end{abstract}

Prof. Marcos Venicius Soares Pereira Orientador Departamento de Engenharia Química e de Materiais - PUC Rio

Prof. André Luis Moreira de Carvalho Co-Orientador Departamento de Engenharia de Materiais - UEPG

Prof. Ana Rosa Fonseca de Martins Departamento de Engenharia Química e de Materiais - PUC Rio

Prof. Fathi Aref Ibrahim Darwish Universidade Federal Fluminense - UFF RJ

Prof. Marcio da Silveira Carvalho Coordenador Setorial do Centro Técnico Científico - PUC - Rio 
Todos os direitos reservados. É proibida a reprodução total ou parcial do trabalho sem autorização do autor, do orientador e da universidade

Thaís Motta da Silva

Graduou-se em Engenharia Mecânica na Fundação Técnico-Educacional Souza Marques em 2014. Possui ensino médio técnico em mecânica industrial pela Escola Técnica do Rio de Janeiro

Ficha Catalográfica

Silva, Thaís Motta da

Aplicação da Integral-J em aços de diferentes limites de escoamento / Thaís Motta da Silva ; orientador: Marcos Venicius Soares

Pereira ; co-orientador: André Luis Moreira de Carvalho. - 2018.

109 f. : il. color. ; $30 \mathrm{~cm}$

Dissertação (mestrado)-Pontifícia Universidade Católica do Rio de Janeiro, Departamento de Engenharia Química e de Materiais, 2018.

Inclui bibliografia

1. Engenharia de Materiais - Teses. 2. Engenharia Química Teses. 3. DIN 42CrMo4. 4. Geometria SEN(T). 5. Integral-J. 6. Método compliance. 7. ASTM A36. I. Pereira, Marcos Venicius Soares. II. Carvalho, André Luis Moreira de. III. Pontifícia Universidade Católica do Rio de Janeiro. Departamento de Engenharia Química e de Materiais. IV. Título. 
Para meus pais, Carlos Roberto e Regina Maria, pelo constante incentivo, apoio e amor demonstrado a mim. 


\section{Agradecimentos}

A minha família, em especial aos meus pais, Carlos Roberto e Regina Maria, por estarem sempre ao meu lado e me incentivando a ir em busca dos meus objetivos. Vocês são minha motivação e inspiração para seguir em frente com determinação e consistência. Serei sempre grata.

Ao meu namorado, André Henrique, que confiou em mim e me impulsionou em cada momento de incerteza e indecisão. Obrigada por estar ao meu lado.

Ao meu orientador Prof. Marcos Venicius Soares Pereira pela competente orientação e parceria para realização desta pesquisa.

Ao meu co-orientador Prof. André Luís Moreira de Carvalho pelo auxílio durante os ensaios preliminares e pelo exemplo de persistência perante as dificuldades encontradas.

A CAPES e a PUC-RJ, pelos auxílios concedidos, sem os quais esta pesquisa não poderia ter sido realizada.

Aos meus colegas da PUC-RJ pela parceria durante o período que estivemos juntos.

Aos professores que participaram da Comissão Organizadora.

A todos os professores e funcionários do Departamento e dos laboratórios da PUCRio pela disponibilidade, competência e por compartilhar conhecimentos. 


\section{Resumo}

Silva, Thaís Motta da; Soares Pereira, Marcos Venicius. Aplicação Da Integral-J Em Aços De Diferentes Limites De Escoamento. Rio de Janeiro, 2018. 109p. Dissertação de Mestrado - Departamento de Engenharia Química e de Materiais, Pontifícia Universidade Católica do Rio de Janeiro.

O estudo da resistência à fratura dos materiais é de grande importância para desenvolvimentos de projetos, seleção de materiais e avaliação do comportamento dos materiais perante a presença de um defeito no componente. Há inúmeras normas que envolvem geometrias padronizadas para determinação desta propriedade mecânica, no entanto nem todo componente em serviço possui as mesmas condições encontradas nas geometrias padronizadas, como é o caso de materiais dúcteis empregados em estruturas com espessuras de paredes finas e elevada pressão interna. Nesta dissertação foram estudados dois materiais com diferentes limites de escoamento confeccionados conforme geometria tipo SEN(T) de fixação por garras, a qual não é padronizada pela ASTM. Com isso, foi realizada uma pesquisa com o emprego desta geometria com variação de 0,2 a 0,8 da relação de $a_{0} / \mathrm{W}$ e entalhes laterais com redução de $20 \%$ foram confeccionados nos corpos de prova do material mais dúctil. Após, foi realizada a pré-trinca de fadiga e iniciado o ensaio de tenacidade à fratura. Este último foi desenvolvido adotando o método compliance, o qual permite que com apenas um corpo de prova seja realizado descarregamentos parciais permitindo assim a determinação de $\mathrm{J}$ e incremento de trinca em cada posição, possibilitando plotar a curva-R Os resultados obtidos determinaram que mesmo com $\mathrm{a} / \mathrm{W}$ diferente daqueles indicados por norma para levantamento da curva-R, é possível obter uma curva-R para a/W=0,2. Existe uma limitação em aplicar a geometria $\operatorname{SEN}(\mathrm{T})$ que não possuem extensa ductilidade.

\section{Palavras-chave}

Resistência à fratura; geometria $\mathrm{SEN}(\mathrm{T})$; integral $\mathrm{J}$; método compliance; ASTM A36; DIN 42CrMo4 


\section{Abstract}

Silva, Thaís Motta da; Soares Pereira, Marcos Venicius (Advisor). Application Of J-Integral In Steels Of Different Yield Limits. Rio de Janeiro, 2018. 109p. Dissertação de Mestrado - Departamento de Engenharia Química e de Materiais, Pontifícia Universidade Católica do Rio de Janeiro.

The study of resistance to fracture of the materials is very important for developing new projects, making materials specifications and also for evaluating materials behaviour under presence of a crack in a component. There are uncountables standards which apply normalized specimens due to determine this mechanical property, however some components in service doesn't act under same conditions as the specimen chosen, for instance ductile materials applied in components with thin thickness and high intern pressure. In this dissertation was studied two diferente of materials with distinct yield limits fabricated according to SEN(T) geometry with clamped fixing, which one is not acceptable by ASTM. Thus, a research has been carried out using this geomerty with a variation of 0,2 to 0,8 in $a_{0} / \mathrm{W}$ ratio and side-grooves with $20 \%$ reducted were made in the specimens with higher ductility. After that, the procedure for doing fatigue pre-crack was initialized, followed by fracture toughness test. This last one was developed adopting the unloading compliance technique, which one allows that more than one aplications of force and displacement can be realized in only one specimen then the value of $\mathrm{J}$ and crack extension can be calculated and the R-curve will be plotted. The results obtained showed even with a a/W ratio diferente of those indicated by standards, is possible to constructo a qualified $\mathrm{R}$-curve for $\mathrm{a} / \mathrm{W}=0,2$. In additon to the results, there is a limitation in applying a $\operatorname{SEN}(\mathrm{T})$ geometry in materials that don't present extensive ductility.

\section{Keywords}

Resistance to fracture; SEN(T) specimen; J-integral ; unloading compliance method; ASTM A 36; DIN 42CrMo4 


\section{Sumário}

$\begin{array}{ll}\text { 1. Introdução } & 23\end{array}$

2. Revisão bibliográfica 29

2.1 Fundamentos da Mecânica da Fratura 29

2.1.1 Comportamento de fratura do material 31

2.1.2 Comportamento de resistência e deformação do material 35

2.1.3 Constrição plástica 36

$\begin{array}{lll}2.2 & \text { Curva-R } & 38\end{array}$

2.3 Integral-J 42

$\begin{array}{lll}2.4 & \text { Corpo de prova SENT } & 49\end{array}$

2.4.1 Método DNV-RF-108 50

2.4.2 Método CanMet 50

2.5 Integral- J e corpo de prova SENT 51

3. Materiais e métodos 55

3.1 Materiais 55

3.2 Ensaio de tração 56

3.3 Ensaio de tenacidade à fratura 57

3.3.1 Dimensões da geometria SENT 57

$\begin{array}{ll}3.3 .2 \text { Entalhe de letroerosão } & 61\end{array}$

3.3.3 Side-groove ou entalhe lateral 62

3.3.4 Classificação dos corpos de prova SENT 63

3.3.5 Pré-trinca de fadiga 64

3.3.6 Procedimento do ensaio 66

3.3.6.1 Processamento de dados 68

4. Resultados e discussão $\quad 71$

$\begin{array}{lll}4.1 & \text { Ensaio de tração } & 71\end{array}$

$\begin{array}{lll}4.2 & \text { Pré-trinca de fadiga } & 73\end{array}$

$\begin{array}{lll}4.3 & \text { Tenacidade à fratura } & 77\end{array}$ 
5. Conclusões 102

6. Sugestões para trabalhos futuros 103

7. Referências bibliográficas 104 


\section{Lista de figuras}

Figura 1 - Geometrias mais aplicadas nos ensaios de 24 resistência à fratura

Figura 2 - Exemplos de equipamentos e estruturas que 25 possuem baixa restrição plástica e apresentam condições distintas as geometrias padronizadas

Figura 3 - Diagrama relacionando a pressão para falha e 25 comprimento da trinca em duto

Figura 4 - llustração esquemática de condições de 26 carregamentos para um duto pressurizado.

Figura 5 - Vários comprimentos escalares, disciplinas 29 científicas e abordagens de modelagens relevantes para análises de trincas

Figura 6 - Adaptação da abordagem de resistência dos 30 materiais

Figura 7 - Esquemático das três variáveis pincipais na análise da mecânica da fratura

Figura 8 - Característica microscópica de fratura frágil

Figura 9 - Análise macroscópica de fratura frágil de um aço doce

Figura 10 - Registro esquemático do gráfico tensão $\mathrm{x}$ deformação apresentando 0 comportamento macroscópico de um material dúctil

Figura 11 - Imagens esquemáticas da formação de alvéolos

Figura 12 - Ilustração esquemática representando a influência da constrição plástica e geometria do corpo de prova

Figura 13 - Carga versus COD

Figura 14 - Esquema da curva de resistência em termos de $\mathrm{J}$ mostrando diferentes estágios do crescimento da trinca

Figura 15 - Definição dos parâmetros para qualificação dos pontos na curva-R

Figura 16 - Contorno arbitrário ao redor da ponta da trinca

Figura 17 - Definição da área plástica para calcular J usando o método básico

Figura 18 - Definição da área plástica para calcular J usando o 


\section{método compliance}

Figura 19 - Desenho esquemático das amostras SENT 50

Figura 20 - Diagrama do fator de intensidade de tensão 52 adimensional com razão a/W e variação H/W

Figura 21 - Variação do compliance normalizado, $\mu$, para diferentes razões a/W

Figura 22 - Variação do fator $\eta$ plástico para diferentes razões a/W derivados de CMOD para o corpo de prova SENT

Figura 23 - Representação esquemática do corpo de prova reduzido para ensaios de tração com seção transversal circular

Figura 24 - Modo de fixação do corpo de prova para ensaio de tração

Figura 25 - Representação esquemática dos corpos de prova SENT de fixação por garras para o material DIN 42CrMo4

Figura 26 - Representação esquemática dos corpos de prova SENT de fixação por garras para o ASTM A36

Figura 27 - Esquemático da representação referente ao tamanho inicial e largura do corpo de prova

Figura 28 - Detalhe da dimensão do entalhe conforme norma ASTM A36

Figura 29 - Equipamento para realização do entalhe de eletroerosão

Figura 30 - Esquemático ilustrando o efeito do crescimento de trinca dúctil em um corpo de prova sem e com sidegroove

Figura 31 - Disposição do corpo de prova para realização da pré-trinca de fadiga em modo de flexão em três apoios

Figura 32 - Equipamentos do sistema de ensaio de tenacidade à fratura

Figura 33 - Segunda máquina utilizada para desenvolvimento do ensaio de tenacidade à fratura

Figura 34 - Detalhamento dos pontos adotados para desenvolvimento matemático do método compliance 
Figura 35 - Medição do tamanho médio real de trinca inicial do CP_D_0.2

Figura 36 - Medição do tamanho médio real de trinca inicial do CP_D_0.3

Figura 37 - Medição do tamanho médio real de trinca inicial do CP_D_0.45

Figura 38 - Medição do tamanho médio real de trinca inicial do CP_D_0.6

Figura 39 - Medição do tamanho médio real de trinca inicial do CP_D_0.7

Figura 40 - Medição do tamanho médio real de trinca inicial do CP_A_0.6

Figura 41 - Análise fractográfica do CP_D_0.2

Figura 42 - Ampliação da região entre a pré-trinca de fadiga e 86 a frente da trinca do CP_D_0.3

Figura 43 - Medição da extensão dúctil de trinca do CP_D_0.45 90

Figura 44 - Microestrutura da região de extensão dúctil 91

Figura 45 - Determinação dos pontos de medição para 93 determinação da extensão dúctil de trinca

Figura 46 - Imagem micrográfica da extensão de trinca do 96 CP_D_0.7

Figura 47 - Fractografia do CP_D_0.6 101

Figura 48 - Evidência de estado plano de tensão na 101 propagação da pré trinca de fadiga 


\section{Lista de tabelas}

\begin{tabular}{|c|c|c|}
\hline Tabela I & - & $\begin{array}{l}\text { Produção de petróleo segundo regiões } \\
\text { geográficas, países e blocos econômicos }\end{array}$ \\
\hline Tabela II & - & $\begin{array}{l}\text { Produção de gás natural segundo regiões } \\
\text { geográficas, países e blocos econômicos }\end{array}$ \\
\hline Tabela III & - & Composição química do aço ASTM A36 \\
\hline Tabela IV & - & Composição química do aço DIN 42CrMo4 \\
\hline Tabela V & - & $\begin{array}{l}\text { Nomenclatura dos corpos de prova SENT do } \\
\text { material ASTM A36 }\end{array}$ \\
\hline Tabela VI & - & $\begin{array}{l}\text { Nomenclatura dos corpos de prova SENT do } \\
\text { material DIN } 42 \text { CrMo } 4\end{array}$ \\
\hline Tabela VII & - & $\begin{array}{l}\text { Tamanho da pré-trinca estimada para } \\
\text { diferentes tamanhos de entalhes }\end{array}$ \\
\hline Tabela VIII & - & Coeficientes $\beta_{n}$ para SENT de fixação por garras \\
\hline Tabela IX & - & $\begin{array}{l}\text { Resultado do ensaio de tração para os aços } \\
\text { ASTM A36 e DIN } 42 \text { CrMo } 4\end{array}$ \\
\hline Tabela X & - & $\begin{array}{l}\text { Valores de cargas máximas aplicadas para } \\
\text { realização da pré-trinca de fadiga }\end{array}$ \\
\hline Tabela XI & - & $\begin{array}{l}\text { Dados das dimensões físicas das pré-trincas de } \\
\text { fadiga e do entalhe total nos nove pontos } \\
\text { equidistantes mensurados }\end{array}$ \\
\hline Tabela XII & - & $\begin{array}{l}\text { Dimensão média do entalhe inicial mensurado, } \\
\text { ам(i). }\end{array}$ \\
\hline Tabela XIII & - & Valor encontrado de a $\mathrm{m(i)} / \mathrm{W}$ \\
\hline Tabela XIV & - & Parâmetros do ensaio do CP_D_0.2 \\
\hline Tabela XV & - & Parâmetros da curva J- $\Delta$ a do CP_D_0.2 \\
\hline Tabela XVI & - & $\begin{array}{l}\text { Comparação entre a dimensão da trinca } \\
\text { mensurada com a calculada do CP_D_0.2 }\end{array}$ \\
\hline Tabela XVII & - & Determinação do valor de Jıc do CP_D_0.2 \\
\hline Tabela XVIII & - & Parâmetros do ensaio do CP_D_0.3 \\
\hline Tabela XIX & - & Parâmetros da curva J- $\Delta$ a do CP_D_0.3 \\
\hline Tabela XX & - & $\begin{array}{l}\text { Comparação entre a dimensão da trinca } \\
\text { mensurada com a calculada do CP_D_O.3 }\end{array}$ \\
\hline Tabela XXI & - & Parâmetros do ensaio do CP_D_0.45 \\
\hline Tabela XXII & - & Parâmetros da curva J- $\Delta$ a do CP_D_0.45 \\
\hline Tabela XXIII & - & $\begin{array}{l}\text { Comparação entre as dimensões da trinca } \\
\text { mensurada do CP_D_0.45 com a calculada }\end{array}$ \\
\hline
\end{tabular}


Tabela XXIV - Valor ideal dos parâmetros do ensaio para 90 CP_D_0.45

Tabela XXV - Parâmetros do ensaio do CP_D_0.6 91

Tabela XXVI - Parâmetros da curva J- $\triangle$ a do CP_D_0.6 92

Tabela XXVII - Comparação entre a dimensão da trinca 93 mensurada com a calculada do CP_D_0.6

Tabela XXVIII - Valor ideal dos parâmetros de ensaio para 93 CP_D_0.6

Tabela XXIX - Parâmetros do ensaio do CP_D_0.7 94

Tabela XXX - Parâmetros da curva J- $\Delta$ a do CP_D_0.7 95

Tabela XXXI - Valor de JIC determinado a partir da curva J-R 95 para o CP_D_0.7

Tabela XXXII - Comparação entre a dimensão da trinca 96 mensurada com a calculada do CP_D_0.7

Tabela XXXIII - Parâmetros do ensaio do CP_A_0.6 97

Tabela XXXIV - Parâmetros da curva J- $\triangle$ a do CP_A_0.6 98

Tabela XXXV - Valor de JIc determinado a partir da curva J-R 100 para o CP_A_0.6

Tabela XXXVI - Comparação entre a dimensão da trinca 101 mensurada com a calculada do CP_A_0.6 


\section{Lista de gráficos}

Gráfico 1 - Tensão x deformação dos materiais 72

Gráfico 2 - Curva P vs. CMOD referente ao CP_D_0.2 77

Gráfico 3 - Ampliação da região mais relevante do registro do 78 ensaio de tenacidade à fratura do CP_D_0.2

Gráfico 4 - Curva J-R do CP_D_0.2 82

Gráfico 5 - Mesmo conjunto de dados apresentado no gráfico 82 4 analisado após deslocamento do zero até próximo ao primeiro valor de $\Delta$ a qualificado

Gráfico 6 - Curva P vs. CMOD referente ao CP_D_0.3 83

Gráfico 7 - Curva P vs. CMOD referente ao CP_D_0.45 88

Gráfico 8 - Curva P vs. CMOD referente ao CP_D_0.6 91

Gráfico 9 - Curva P vs. CMOD referente ao CP_D_0.7 94

Gráfico 10 - Plotagem dos pares J e $\Delta$ a para o CP_D_0.7 96

Gráfico 11 - Curva P vs. CMOD referente ao CP_A_0.6 97

Gráfico 12 - Plotagem dos pares J e $\Delta$ a para o CP_A_0.6 100 


\section{Lista de abreviaturas e siglas}

ASTM American Society Testing and Materials

BS British Standard

DIN Deutsches Institut für Normung - Instituto Alemão para Normatização

C(T) Corpo de Prova Compacto com aplicação de carga trativa para ensaio de tenacidade à fratura

SE(B) Corpo de Prova de Flexão em Três Pontos para ensaio de tenacidade à fratura

SENT Single Edge-Notched Tension - Corpo de Prova de Tração para ensaio de tenacidade à fratura

$\mathrm{D}(\mathrm{T}) \quad$ Corpo de Prova Compacto de geometria circular para ensaio de tenacidade à fratura sob carga de tração

DNV Det Norske Veritas

SAE Society of Automotive Engineering-Sociedade de Engenharia Automotiva.

AISI American Iron and Steel Intitute - Intituto Americano de ferro e aço

CANMET Center for material and Energy Technology

ANTT Agência Nacional de Transportes Terrestres

ANP Agência Nacional de Petróleo

MEV Microscópio Eletrônico de Varredura

MFLE Mecânica da Fratura Linear-Elástica

MFEP Mecânica da Fratura Elasto-Plástica

SSY Small-Scale Yielding 


$\begin{array}{ll}\text { LSY } & \text { Large-Scale Yielding } \\ \text { CTOD } & \text { Crack-Tip Opening Displacement }- \text { Deslocamento da } \\ & \text { Abertura da Ponta da Trinca } \\ \text { CMOD } & \text { Crack Mouth Opening Displacement - Deslocamento da } \\ & \text { Abertura da Boca da Trinca } \\ \text { LLD } & \text { Load-Line Displacement - Deslocamento da Linha de Carga } \\ \text { LE } & \text { Limite de Escoamento } \\ \text { LRM } & \text { Limite de Resistência Mecânica } \\ \text { PA } & \text { Porcentagem de Alongamento } \\ \text { PRA } & \text { Porcentagem de Redução de Área }\end{array}$




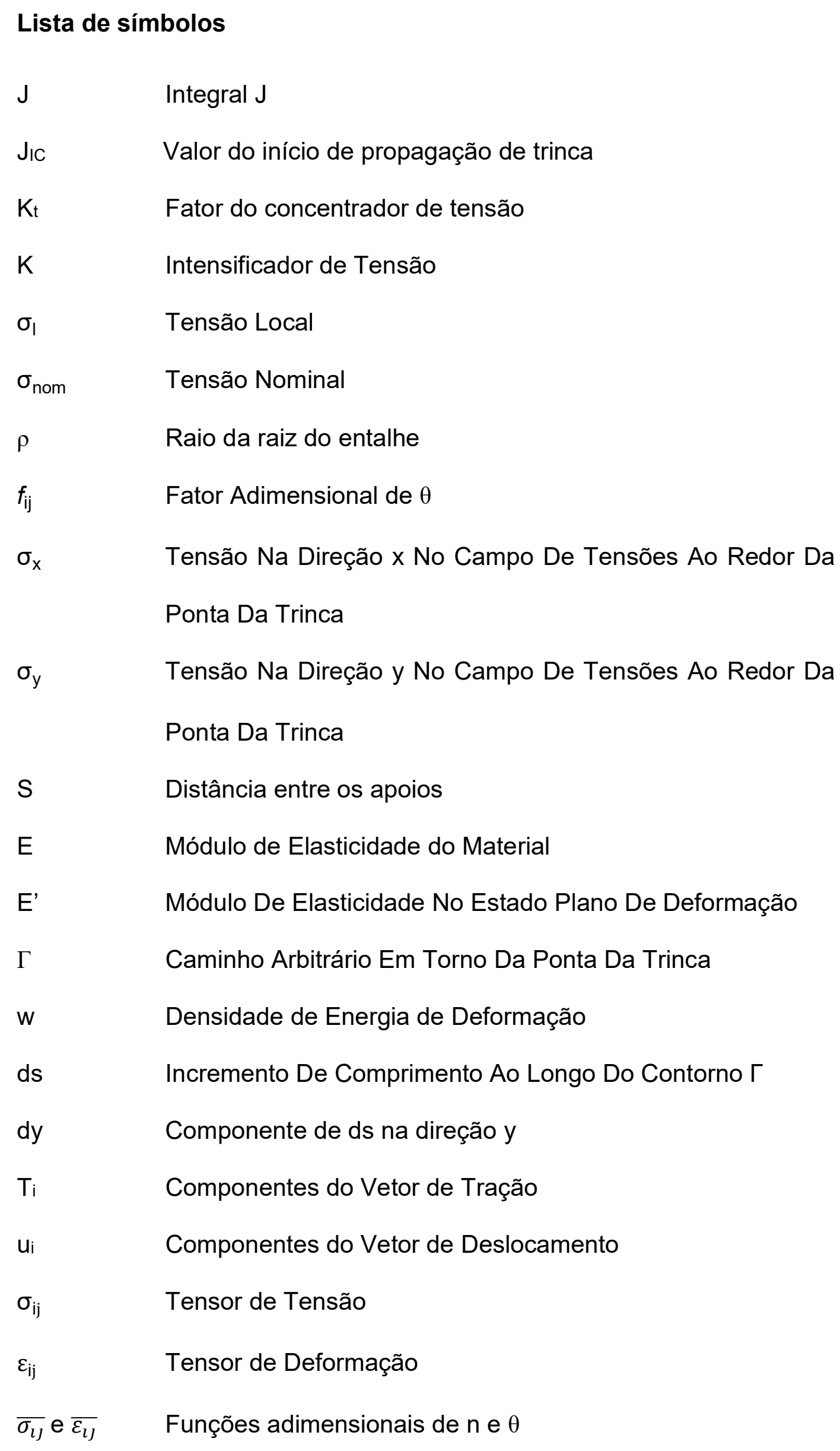


In Constante de Integração que depende do expoente de encruamento

Distância da ponta da trinca

Ângulo em relação ao plano de propagação da trinca

$\Delta a_{p} \quad$ Incremento físico da trinca

$\Delta$ aprevisto Incremento da extensão de trinca obtido pelo método compliance

$\mathrm{H}$

Distância Entre Os Pontos De Aplicação Da Carga no Corpo de Prova

b Ligamento remanescente a frente da ponta da trinca

B Espessura do corpo de prova

W Largura do corpo de prova

Q Influência geométrica

a

Dimensão do entalhe usinado

$a_{0}$

Dimensão idealizada inicialmente para a trinca

$\mathrm{a} 0 \mathrm{q}$

Dimensão inicial de trinca prevista pelo método compliance

aм(i)

Tamanho médio físico inicial da trinca

$a_{p}$

Tamanho médio físico final da trinca

$a_{i}$

Tamanho da trinca na posição $i$ pelo método compliance

a(i-1) Tamanho da trinca na posição anterior

$\mathrm{b}_{0} \quad$ Ligamento remanescente inicial à frente da ponta da trinca

bм(i) Ligamento inicial médio a frente da ponta da trinca

$b_{f} \quad$ Ligamento remanescente final à frente da ponta da trinca

$\mathrm{bm}_{\mathrm{M}(\mathrm{f})} \quad$ Ligamento final médio a frente da ponta da trinca

$\mathrm{M}^{*} \quad$ Dimensão da pré-trinca de fadiga 

$\mathrm{B}_{\mathrm{N}} \quad$ Espessura líquida do corpo de prova na raiz do side-groove
Be Espessura efetiva
Po $\quad$ Carga cíclica inicial máxima
$P_{f} \quad$ Carga cíclica final máxima
$R \quad$ Razão entre $P_{0}$ e $P_{f}$
$\sigma_{y} \quad$ Média entre $\sigma_{\mathrm{LE}}$ e $\sigma_{\mathrm{LRM}}$
$\sigma_{Y S} \quad$ Tensão Limite de Escoamento
$\sigma_{\mathrm{TS}} \quad$ Tensão Limite de Resistência Mecânica
$v \quad$ Coeficiente de Poisson
$\mathrm{Lf}_{\mathrm{f}} \quad$ Comprimento Final
Lo $\quad$ Comprimento Inicial
A $\quad$ Área final da seção do corpo de prova de tração
Ao Área inicial da seção do corpo de prova de tração
S Distância entre os apoios
$\eta$ e $\gamma \quad$ Fatores geométricos plásticos dependentes de a/W
$\mathrm{Jpl} \quad$ Componente plástica da Integral-J
Jel Componente elástica da Integral J
$\Delta \quad$ Deslocamento da linha de carga (LLD)
V Deslocamento da abertura da boca da trinca (CMOD)
$\Delta$ amáx $\quad$ Máxima Extensão de trinca
$\mathrm{C}_{(\mathrm{i})} \quad$ Compliance medido na posição $i$
Apl(i) Área plástica na posição $i$ do ensaio
$\mathrm{P}_{(\mathrm{i})} \quad$ Carga aplicada máxima na posição $i$ do ensaio
$V_{\mathrm{pl}(\mathrm{i})} \quad$ Parte plástica do deslocamento da boca da trinca
z $\quad$ Espessura da faca 
Compliance normalizado

$\mathrm{K}_{(\mathrm{i})}$

Fator de intensidade de tensão na posição $i$ 
No que diz respeito ao sucesso, as pessoas não são medidas em polegadas, libras, niveis de escolaridade ou histórico familiar; elas são medidas pelo tamanho de seus pensamentos.

David Schwartz 


\section{INTRODUÇÃO}

Procedimentos convencionais de avaliação da resistência à fratura sob condições elasto-plástica, Integral J, como por exemplo ASTM E1820 [1], ASTM E1290 [2], BSI 7448 [3] indicam metodologias experimentais e determinam critérios a serem adotados para validação dos ensaios e resultados. A padronização dos corpos de prova perante estas normas envolve basicamente seis geometrias de corpos de prova diferentes, que variam em seu formato dimensional e modo de aplicação do carregamento durante o ensaio. Dentre as seis geometrias, encontramse os compactos, $\mathrm{C}(\mathrm{T})$, de flexão em três pontos, $\mathrm{SE}(\mathrm{B})$, os com entalhe no meio, $\mathrm{M}(\mathrm{T})$, os compactos com formato de disco, $\mathrm{DC}(\mathrm{T})$, os com formato de arco com carga trativa, $\mathrm{A}(\mathrm{T})$ e os com formato de arco com carga flexiva, $\mathrm{A}(\mathrm{B})$. Usualmente os corpos de prova $\mathrm{C}(\mathrm{T})$ e $\mathrm{SE}(\mathrm{B})$, dispostos na Figura 1, com trincas profundas, a/W $\geq 0,5$, são os mais empregados no estudo de resistência à fratura dos materiais [4][5]. Na maioria dos casos, os resultados obtidos a partir de ambas destas amostras, podem ser correlacionados e comparados um ao outro. Entretanto, as geometrias $\mathrm{C}(\mathrm{T})$ ou $\mathrm{SE}(\mathrm{B})$ fornecem condições de elevada restrição plástica na ponta da trinca com quantidade limitada de plasticidade, diferente daquelas apresentadas por alguns materiais em serviço, resultando num valor conservativo de tenacidade à fratura ou curva-R [6]. Ainda que, fisicamente, o conservadorismo represente um fator extra de segurança, por outro lado ele motiva a ação de medidas inadequadas e precipitadas quanto a reparos ou substituições dos componentes estruturais, gerando um alto custo operacional. Exemplos de materiais usualmente encontrados nesta situação são os vasos de pressão e dutos com espessuras relativamente finas e com elevada pressão interna. Estes componentes mecânicos interagem e são expostos a ambientes agressivos, como ilustrado nas imagens dispostas na Figura 2. Em complemento ao risco mencionado anteriormente, há também uma grande perspectiva de formação de defeitos superficiais nestes componentes durante o processo de fabricação ou operacionais, tais fatos geralmente precedidos a uma sequência de eventos que progridem à falha do componente, que tem como variáveis a tenacidade do material, comprimento do 
defeito e pressão interna de serviço envolvida. Consequentemente, pode-se gerar transtornos externos a integridade do material, exemplo disso são os danos ambientais e sociais impactados pela gravidade do fluido armazenado ou transportado no momento da falha.

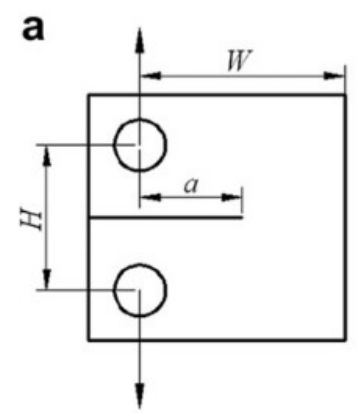

CT

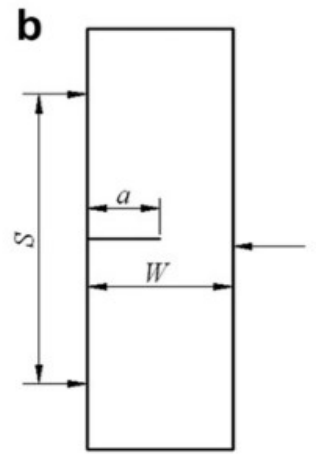

SENB

Figura 1 - Geometrias mais aplicadas nos ensaios de resistência à fratura: (a) corpo de prova $\mathrm{C}(\mathrm{T})$, e (b) corpo de prova SE(B). [4]

Como pode ser interpretado através da Figura 3, referente a um diagrama de comprimento de trinca versus pressão de falha, um defeito tipo trinca incialmente não passante, pode vir a se tornar passante, elevando exponencialmente o grau de importância no acompanhamento do tamanho do defeito diante da condição de pressão interna de trabalho, como é o caso de dutos e vasos de pressão, e a propriedade de tenacidade à fratura do material. Nota-se que para um duto com presença de trinca passante, $\mathrm{d} / \mathrm{t}=1,0$, à medida que o comprimento da trinca cresce menor pressão interna o material vai suportar, até atingir uma pressão de falha crítica, ocorrerá o vazamento do fluído, a partir deste ponto o componente irá se romper. Com base nisso, o acompanhamento dos defeitos de um componente e suas condições são de elevada importância.

Outro ponto relevante é que os dutos e vasos de pressão apresentam uma baixa restrição plástica, ou baixo nível de triaxialidade de tensão, associado à sua espessura fina e ao LSY, não favorecendo a existência de um estado plano de deformação a frente da ponta do defeito. Além do que, sob aumento do carregamento, estes materiais desenvolvem extensiva deformação plástica na ponta da trinca antes de ocorrer a fratura [5], característico de materiais com elevada ductilidade. 

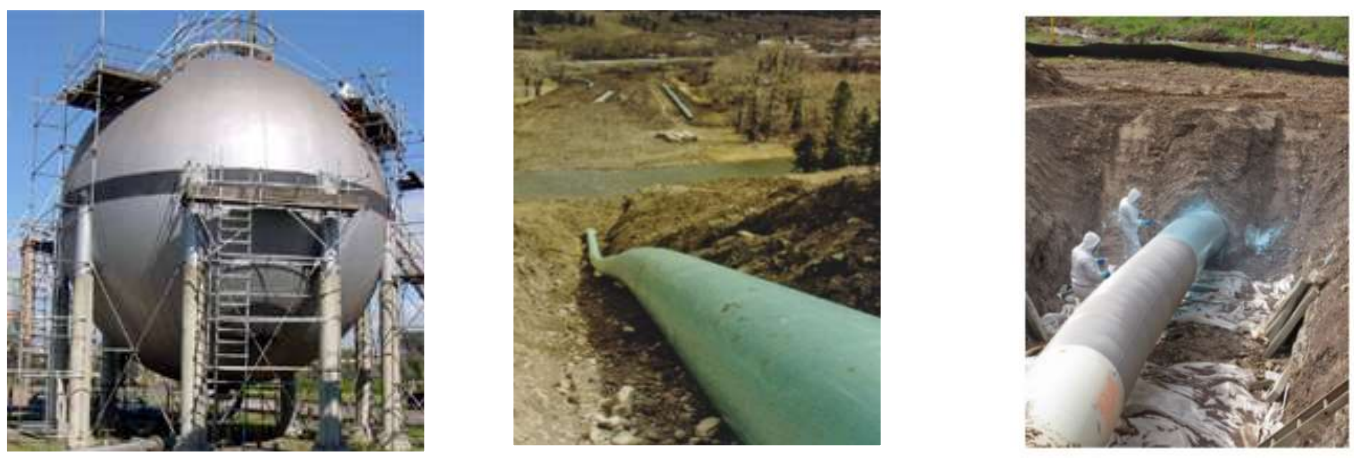

Figura 2 - Exemplos de equipamentos e estruturas que possuem baixa restrição plástica e apresentam condições distintas as geometrias padronizadas. [7]

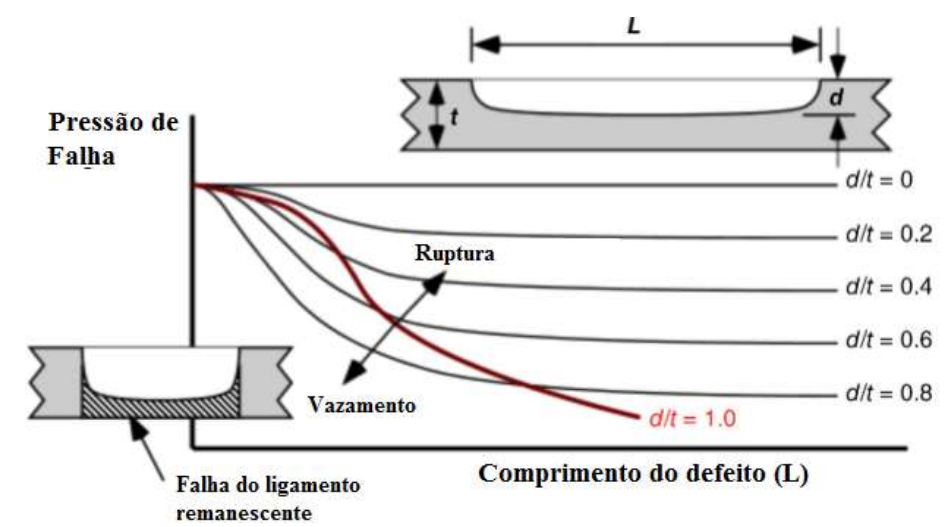

Figura 3 - Diagrama relacionando pressão para falha e comprimento da trinca. Adaptado de [7]

Diante dos argumentos mencionados anteriormente, quanto mais condizente a determinação do valor de resistência à fratura do material em relação ao componente estrutural, melhor análise e transfereabilidade poderá ser realizada na caracterização de materiais, desenvolvimento de projetos e levantamento da tolerância à falha. Sendo assim, um considerável interesse por esta área de pesquisa foi desenvolvido a fim de implementar uma nova geometria que representasse melhor as condições na ponta da trinca entre os ensaios laboratoriais e os componentes estruturais com estas características. Diversos estudos foram realizados [8-11], os quais concluíram que o uso da geometria SENT - Single Edge Notched Tension, Figura 4b, é uma forma alternativamente comum para avaliação da tenacidade à fratura de materiais com maior ductilidade, isso porque a amostra SENT e defeitos superficiais tipo trincas em dutos, por exemplo, possuem condições de carregamentos, tensão na ponta da trinca e campo de deformação que controlam o início de fratura frágil similares [5], por possuírem profundidade de trinca rasa e serem dominados por forças trativas, conforme ilustrado na Figura 4a. 
$\mathrm{Na}$ ausência de uma norma vigente que abordasse a geometria SENT, a DNV especificou no ano de 2006 o procedimento DNV-RP-F108 [12] o qual passou a ser utilizado como uma metodologia interna de grandes empresas que a adotaram como uma prática de controle a fratura para instalação de dutos, e também como método para lidar com a severidade de um defeito permitindo que este seja relacionado com as condições operacionais em termos de carregamento ou tamanho crítico de trinca com aplicações nas áreas onshore e offshore.

No ano de 2008, outro procedimento típico da indústria direcionado ao corpo de prova SENT foi desenvolvido pelo maior centro de pesquisas dedicado a fabricação, processamento e avaliação de metais e materiais do Canadá, o Canadian Center for Material and Energy Technology (CANMET) [13]. Tal prática envolve uma metodologia de ensaio mais viável, que consiste na obtenção da integral J baseada na curva J-R utilizando apenas um corpo de prova, abordagem conhecida como método compliance, e fixando um único clip-gage para medição do CMOD. Dois anos depois a publicação no CANMET, a ExxonMobil Upstream Research Company [14], multinacional de petróleo e gás sediada nos Estados Unidos, criou seu próprio procedimento, este fundamentado no ensaio de CTOD abordando o uso de um único corpo de prova com o uso de duplo clip-gage como método de medição. Com foco na grande demanda industrial pela geometria SENT, a BSI constatou a necessidade de desenvolver uma norma padronizada voltada a este corpo de prova, e então em dezembro de 2014 baseada no procedimento da DNV [12], publicou a norma BS 8571:2014 [15]. Em, 2012 a ASTM atualizou a norma ASTM E2472 [16] que passou a englobar condições de baixa restrições plásticas, porém destinadas apenas para as geometrias $\mathrm{C}(\mathrm{T})$ e $\mathrm{M}(\mathrm{T})$, sendo assim, até o presente estudo a geometria SENT não é reconhecida como padronizada pela ASTM.

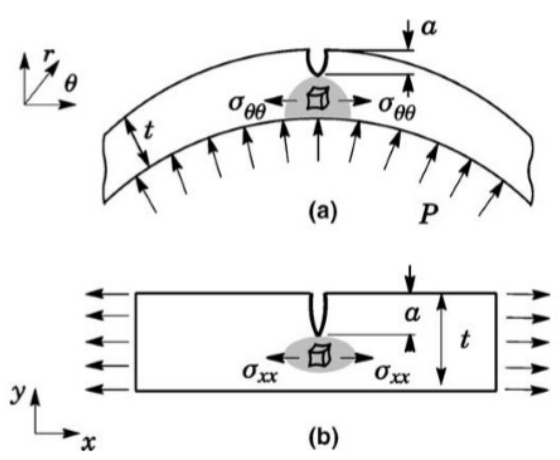

Figura 4 - Ilustração esquemática de condições de carregamento para um duto pressurizado com uma trinca axial externa (a) e uma amostra de fratura SENT (b). [5] 
Com o objetivo de enfatizar a importância do corpo de prova SENT para a área na qual ele é destinado, foi realizado um levantamento de dados e informações sobre dutos para breve associação a esta pesquisa. Segundo a ANTT, 4\% dos transportes são realizados por dutovias. Hoje o Brasil possui cerca de $20000 \mathrm{~km}$ de malha dutoviária, dentre oleodutos e gasodutos, instalada em seu território o que permite o transporte de fluidos entre duas ou mais áreas por quilômetros de distância, movimentando produtos extraídos offshore, por exemplo, a píer marítimos, terminais terrestres e aquaviários, e refinarias. De acordo com a ANP [17][18], na última década, o Brasil produziu 40\% a mais de petróleo, dados na Tabela 1, pertencendo ao $12^{\circ}$ lugar no ranking dos países com maior produção de petróleo gerando um volume de 2,5 milhões de barris/dia, equivalente a 2,8\% da produção mundial. Na linha de gasodutos, o Brasil teve um acréscimo de cerca de $62 \%$ no aumento de produção de gás natural na última década, dados na Tabela 2 .

Tabela I - Produção de petróleo segundo regiões geográficas, países e blocos econômicos. [18]

\begin{tabular}{|c|c|c|c|c|c|c|c|c|c|c|c|}
\hline \multirow{2}{*}{$\begin{array}{c}\text { REGIÕES } \\
\text { GEOGRÁFICAS, } \\
\text { PAÍSES E } \\
\text { BLOCOS } \\
\text { ECONÔMICOS }\end{array}$} & \multicolumn{10}{|c|}{ PRODUÇÃO DE PETRÓLEO (MIL BARRIS/DIA) } & \multirow{2}{*}{$\begin{array}{r}15 / 14 \\
\%\end{array}$} \\
\hline & 2006 & 2007 & 2008 & 2009 & 2010 & 2011 & 2012 & 2013 & 2014 & 2015 & \\
\hline $\begin{array}{l}\text { América Central e } \\
\text { do Sul }\end{array}$ & 7.463 & 7.295 & 7.376 & 7.322 & 7.348 & 7.401 & 7.322 & 7.344 & 7.605 & 7.712 & 1,41 \\
\hline Argentina & 838 & 798 & 772 & 716 & 704 & 649 & 652 & 643 & 636 & 637 & 0,08 \\
\hline Brasil • & 1.809 & 1.833 & 1.899 & 2.029 & 2.137 & 2.193 & 2.149 & 2.114 & 2.346 & 2.527 & 7,70 \\
\hline Colômbia & 523 & 531 & 588 & 671 & 786 & 915 & 944 & 1.004 & 990 & 1.008 & 1,74 \\
\hline Equador & 538 & 513 & 507 & 507 & 488 & 501 & 505 & 527 & 557 & 543 & $-2,42$ \\
\hline Peru & 97 & 96 & 99 & 99 & 113 & 109 & 110 & 112 & 124 & 113 & $-9,12$ \\
\hline Trinidad e Tobago & 177 & 154 & 152 & 152 & 147 & 139 & 118 & 118 & 116 & 110 & $-4,87$ \\
\hline Venezuela & 3.336 & 3.230 & 3.222 & 3.033 & 2.838 & 2.758 & 2.701 & 2.678 & 2.685 & 2.626 & $-2,18$ \\
\hline
\end{tabular}

Tabela II - Produção de gás natural segundo regiões geográficas, países e blocos econômicos. [18]

\begin{tabular}{|c|c|c|c|c|c|c|c|c|c|c|c|}
\hline \multirow{2}{*}{$\begin{array}{c}\text { REGIÕES } \\
\text { GEOGRÁFICAS, } \\
\text { PAÍSES E } \\
\text { BLOCOS } \\
\text { ECONÔMICOS }\end{array}$} & \multicolumn{10}{|c|}{ PRODUÇÃO DE GÁS NATURAL (BILHÕES M³) } & \multirow{2}{*}{$\begin{array}{r}15 / 14 \\
\% \\
\end{array}$} \\
\hline & 2006 & 2007 & 2008 & 2009 & 2010 & 2011 & 2012 & 2013 & 2014 & 2015 & \\
\hline $\begin{array}{l}\text { América Central } \\
\text { e do Sul }\end{array}$ & 154,1 & 162,1 & 163,0 & 157,7 & 166,2 & 167,0 & 173,6 & 175,9 & 177,1 & 178,5 & 0,75 \\
\hline Argentina & 46,1 & 44,8 & 44,1 & 41,4 & 40,1 & 38,8 & 37,7 & 35,5 & 35,5 & 36,5 & 2,93 \\
\hline Brasil $\bullet$ & 12,9 & 13,8 & 14,3 & 12,3 & 14,2 & 15,6 & 17,8 & 20,3 & 21,0 & 20,9 & $-0,74$ \\
\hline Colômbia & 11,2 & 11,2 & 14,0 & 11,9 & 14,6 & 16,7 & 19,3 & 21,3 & 22,6 & 22,9 & 1,27 \\
\hline Equador & 7,0 & 7,5 & 9,1 & 10,5 & 11,3 & 11,0 & 12,0 & 12,6 & 118,0 & 11,0 & $-6,51$ \\
\hline Peru & 1,8 & 2,7 & 3,4 & 3,5 & 7,2 & 11,3 & 11,9 & 12,2 & 12,9 & 12,5 & $-3,32$ \\
\hline Trinidad e Tobago & 40,1 & 42,2 & 42,0 & 43,6 & 44,8 & 43,1 & 42,7 & 42,8 & 42,1 & 39,6 & $-5,80$ \\
\hline Venezuela & 31,5 & 36,2 & 32,8 & 31,0 & 30,6 & 27,6 & 29,5 & 28,4 & 28,6 & 32,4 & 13,22 \\
\hline
\end{tabular}


Estes dados mostram o crescimento do ramo da indústria de óleo e gás no Brasil, que se estende também a outras nações mundiais, como o Reino Unido e Estados Unidos, que representam 12,9 \% e 8,8 \%, respectivamente, da produção de petróleo mundial. A partir destas considerações, há uma profunda exigência quanto aos níveis de aceitação dos parâmetros de integridade estrutural dos materiais que são submetidos e empregados para estas finalidades.

Sendo assim, o principal objetivo deste trabalho é levantar as curvas-R de dois aços com diferentes limites de escoamento, adotando o método compliance (inverso de rigidez) em corpos de prova de geometria do tipo SENT com variações na razão $\mathrm{a}_{0} / \mathrm{W}$. No Capítulo 2 será abordado um levantamento bibliográfico de mecânica da fratura, o surgimento do corpo de prova SENT e descrição da curvaR. Subsequentemente, no Capítulo 3, materiais empregados, procedimentos experimentais e metodologia adotada nesta pesquisa serão dissertados. Os resultados dos ensaios encontram-se detalhados no Capítulo 4. E por fim, a conclusão e sugestões para trabalhos futuros são descritos no Capítulo 5 e Capítulo 6 , respectivamente. 


\section{REVISÃO BIBLIOGRÁFICA}

\subsection{Fundamentos da Mecânica da Fratura}

A mecânica da fratura é o estudo de componentes ou materiais que possuem uma descontinuidade em sua estrutura. A determinação da tenacidade à fratura é significativamente importante para descrever a resistência do material contra falhas de uma estrutura contendo um defeito, pois correlaciona a extensão do defeito comparando o ensaio efetuado em uma amostra laboratorial com uma estrutura de engenharia, baseando-se na similaridade entre ambas quanto ao campo de tensões e de deformações na ponta da trinca [19]. Em geral, descontinuidade é definida como sendo uma interrupção na homogeneidade de características físicas mecânicas ou metalúrgicas do material [20], e a não-homogeneidade está, inevitavelmente, presente na grande parte dos componentes estruturais. Todavia, o método de análise de uma descontinuidade pode ser efetuado de diferentes maneiras, considerando basicamente o comprimento escalar para a qual o problema da fratura está sendo tratado, como na Figura 5.

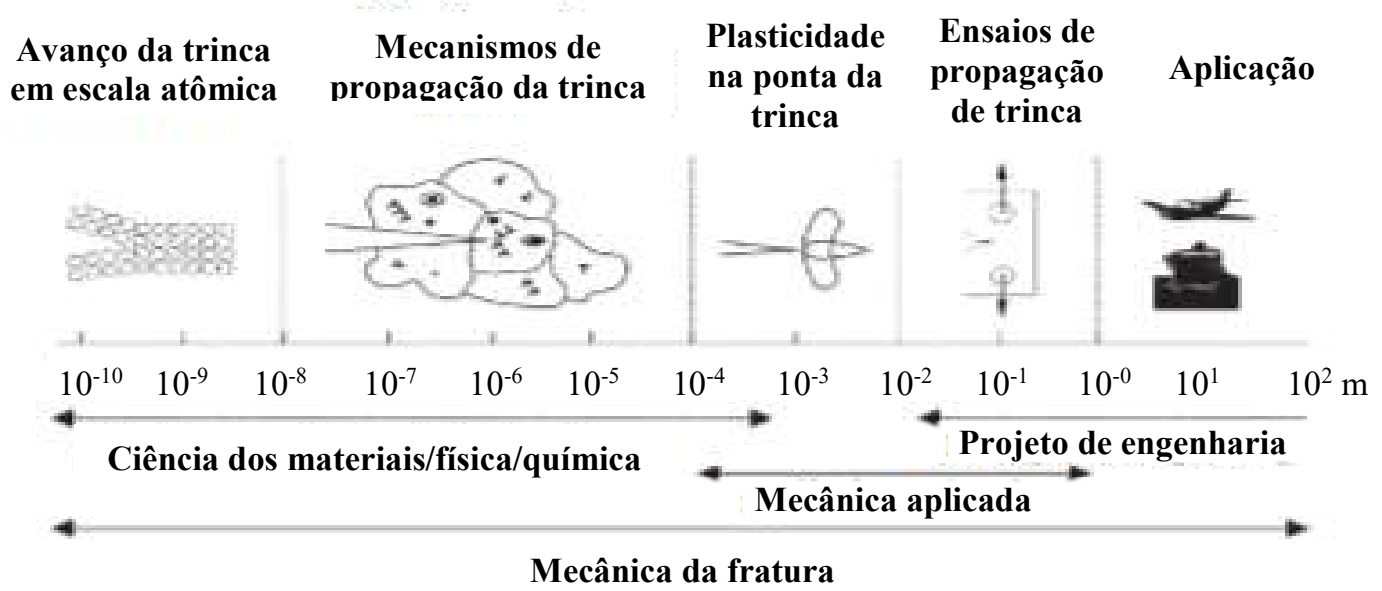

Figura 5 - Vários comprimentos escalares, disciplinas científicas e abordagens de modelagens relevantes para análise de trincas. Adaptado de [21]

Muitas vezes, o mecanismo considerado fundamental para propagação de uma descontinuidade, em destaque as trincas, é o distanciamento de átomos que ocorre pela separação da força coesiva entre as camadas atômicas como a formação 
de novas superfícies no material. Através do resultado oriundo da interpretação das ligações interatômicas nos sólidos, é permissível, na grande maioria das situações, definir o tipo de ligação e associar a uma propriedade de material. Sucedendo esta análise, determina-se fatores de plasticidade, mecanismo de propagação e o tipo de ensaio de resistência à fratura, conduzindo o material para a aplicação prática. Para cumprimento de tal sequência objetivando a determinação qualitativa das limitações e níveis aceitáveis das descontinuidades, é imprescindível a ampliação de conhecimentos e tecnologias para lidar da melhor maneira com a integridade e comportamento mecânico de materiais distintos.

Historicamente, antes ao aparecimento da mecânica da fratura, a maioria dos componentes eram fundamentados sob o conceito da mecânica dos sólidos clássica. Por esta abordagem, o estudo da integridade estrutural é baseado nos princípios da estática para determinar a relação entre cargas externas aplicadas a um componente deformável e a intensidade das forças internas que agem no componente [22]. Ou seja, a capacidade de resistência do material duela com a tensão externa aplicada, relação apresentada na Figura 6, e considera o componente 100\% homogêneo, livre de imperfeições e descontinuidades, além de não cogitar a ação externa do meio ambiente. Compreende-se então que a falha do material só ocorrerá se sua capacidade de resistir for inferior a tensão empregada, ao contrário, o material falhará.

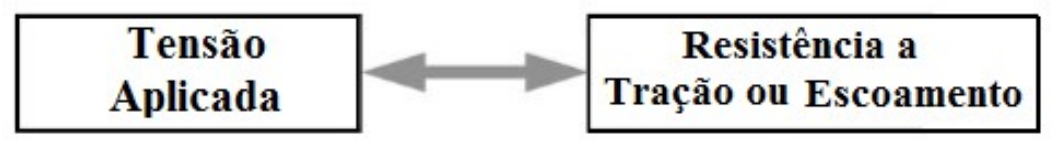

Figura 6 - Adaptação da abordagem de resistência dos materiais. [22]

No entanto, a metodologia de análise da mecânica clássica representa uma condição não encontrada frequentemente em estruturas de engenharia, especialmente pelo fato de componentes sólidos conterem geralmente defeitos. Sendo assim, o estudo dos materiais foi desenvolvido para uma área da engenharia mais avançada, conhecida como mecânica da fratura que é considerada atualmente a ferramenta indispensável para o estudo da integridade dos materiais.

As análises sob a abordagem da mecânica da fratura, diferentemente da mecânica clássica, consistem em avaliar três variáveis importantes, que envolve a relação entre tensão, tamanho da falha e da tenacidade à fratura. A tensão e tamanho 
do defeito possuem influência na força motriz pela resposta do material a propagação da falha, enquanto que no quesito de resistência do material a tenacidade à fratura serve como base para avaliação da tolerância de uma estrutura a falha, podendo então ser definida como um termo para determinação da resistência do material a extensão de uma trinca medida a partir da energia absorvida antes e durante o processo de fratura. Conhecendo duas das três variáveis é possível determinar a terceira variável do processo de fratura, porém se sabe que a fratura de um material trincado está mais propensa de ocorrer quando tanto a tensão ou tamanho do defeito aumentam a modo de superar o valor de resistência do material.

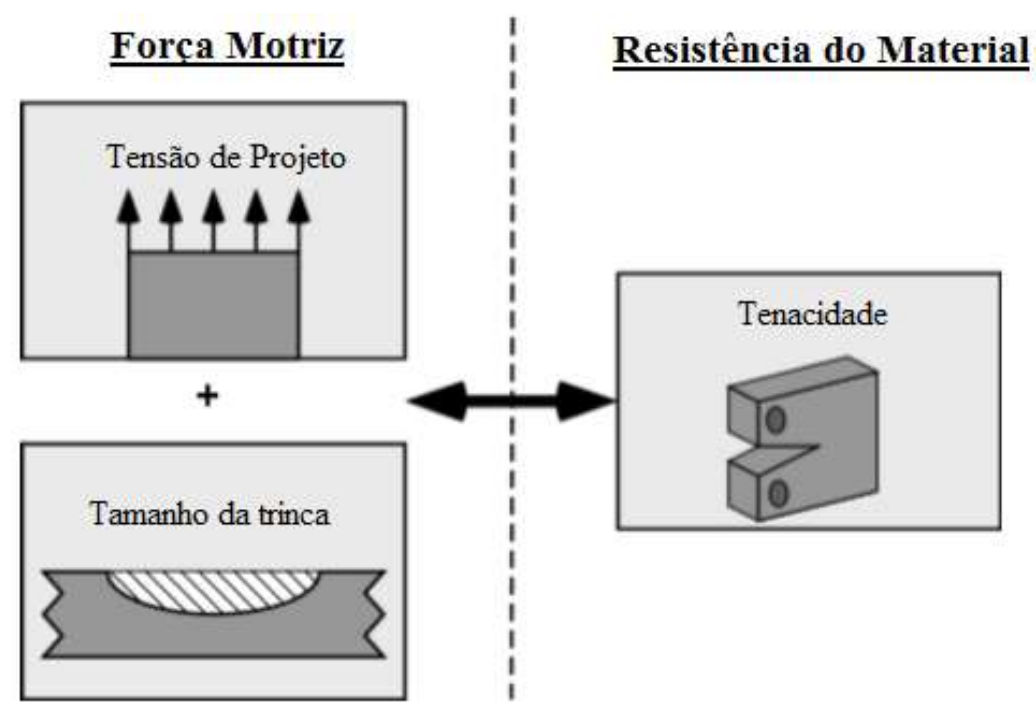

Figura 7 - Esquemático das três variáveis principais na análise da mecânica à fratura. Adaptado de [23]

Em adição, sabe-se que quando se analisa o comportamento de um material metálico durante a qualificação de sua resistência à fratura, outros três fatores devem também ser levados em consideração para a condição particular empregada, são estes: o comportamento de fratura do material, o comportamento de resistência e deformação do material e o efeito de constrição plástica geométrica [24].

\subsubsection{Comportamento de fratura do material}

Este primeiro fator abordado relaciona o micromecanismo e macromecanismo de fratura, usualmente descrito como frágil ou dúctil e associado com a criação de duas novas superfícies que não existiam no componente. Neste 
fator, a fratura e as marcas formadas pela ruptura do componente são estudadas com o emprego de um microscópio eletrônico de varredura (MEV) ou microscópio óptico. O termo frágil, no âmbito da fratura, significa a presença de uma deformação pequena ou nula precedido ao fenômeno de ruptura. Este comportamento é usualmente encontrado em materiais de elevada rigidez e resistência, porém com baixa tolerância a presença de defeitos. Do ponto de vista microscópico, uma das formas de interpretação de um material frágil é através da decorrência da ruptura pela separação de dois planos cristalográficos com total ausência de deformação plástica generalizada, apresentando fratura sucessiva e repetida das ligações atômicas ao longo dos planos cristalográficos do material. Este processo é configurado como facetas de clivagem e também denominado como fratura transgranular, disposto na Fig.8a. O material pode vir a apresentar outras características microscópicas neste tipo de fratura que são as que indicam a origem da região que se iniciou a falha, determinadas como "marcas de sargento", mostrada na Fig. 8b, e linhas de rio, visualizadas na Fig. 8c.
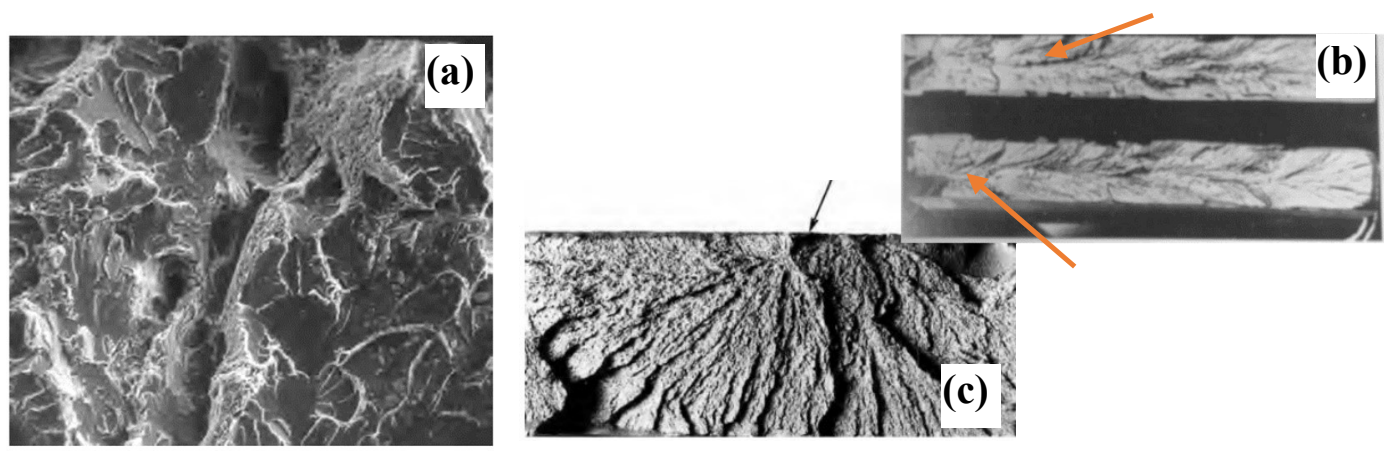

Figura 8 - Características microscópicas de fratura frágil. (a) Fractografia eletrônica de varredura apresentando facetas de clivagem; (b) Fractografia apresentando "marcas de sargento" em forma de $\mathrm{V}$; e (c) linhas radiais indicando a origem e movimento da trinca. [25]

Macroscopicamente, a fratura frágil apresenta uma superfície plana, perpendicular a tensão trativa aplicada, e brilhosa, e não é perceptível a olho nu presença de deformação plástica na região de fratura do componente, como pode ser observado na Figura 9. Este caso de fratura é considerado o mais crítico por não apresentar indício prévio a ocorrência da fratura, progredindo de forma catastrófica e em condições com baixa quantidade de energia absorvida pelo material. 


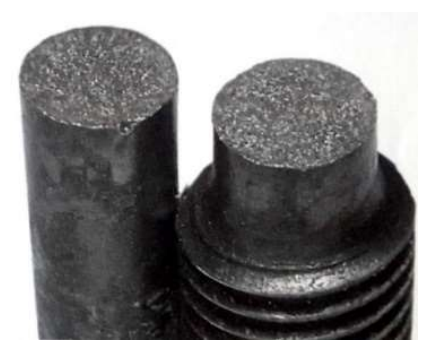

Figura 9 - Análise macroscópica de fratura frágil de um aço doce [25]

Já a definição do termo dúctil provém da capacidade de um material suportar a aplicação de uma carga excessiva e de se deformar permanentemente antes de fraturar. Após atingir sua capacidade de resistência mecânica, o componente apresenta, macroscopicamente, uma redução em sua seção transversal, desenvolvida pela resposta do material a solicitação de deformação ou alongamento em direção ao eixo de aplicação da carga. Na figura esquemática 10 , há a representação de um gráfico tensão-deformação, no qual pode-se observar os estágios evidentes do comportamento dúctil de um material. Em materiais de engenharia, há presença de uma superfície com plano orientado a $45^{\circ}$ na extremidade da superfície do material o que representa a ação de uma tensão cisalhante nesta região. Este tipo de fratura é conhecido como tipo taça e cone. Já em materiais extremamente puros, dificilmente aplicados, como por exemplo ouro e chumbo à temperatura ambiente, a seção do material ensaiado pode reduzir até um ponto afiado, resultando em deformações plásticas extremamente grandes e com uma redução de área próxima a $100 \%$. Sob o ponto de vista macroscópico, um material dúctil apresenta, geralmente, a superfície de fratura opaca e fibrosa característica causada da deformação precedida à fratura.

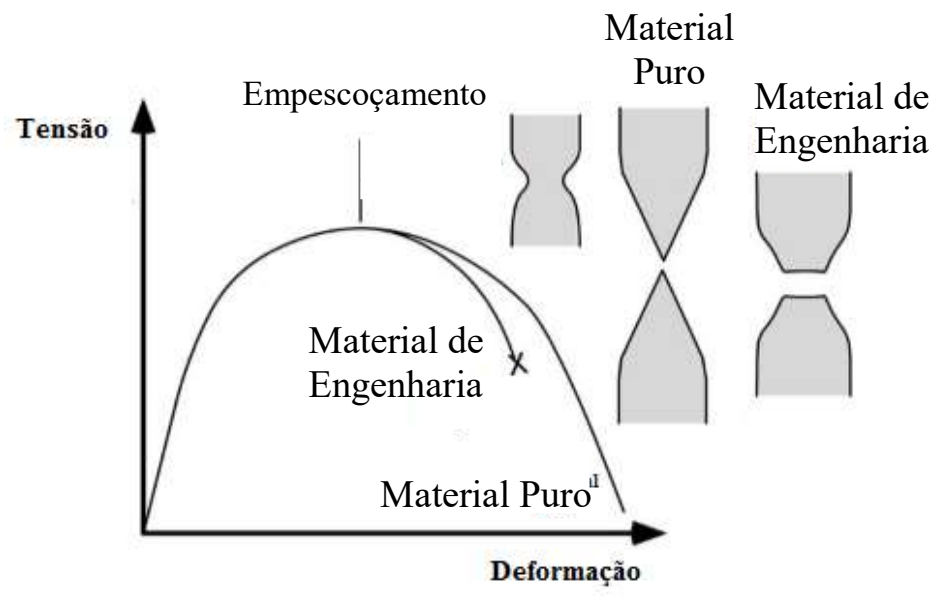

Figura 10 - Registro esquemático do gráfico tensão x deformação apresentando o comportamento macroscópico de um material dúctil. Adaptado de [23] 
Do ponto de vista microscópico, a fratura dúctil é conduzida em várias etapas, envolvendo a combinação da nucleação, crescimento e coalescência de microcavidades, o que leva a formação de grandes vazios esféricos, conhecidos como alvéolos ou dimples, que são formados ao redor de uma partícula de segunda fase ou inclusões, tanto por desconexão da interface da matriz das partículas ou por fratura da partícula. Geralmente, a fratura dúctil está relacionada a propagação estável do defeito pois acontece de forma lenta e estável. O formato dos alvéolos possui grande influência da direção da carga aplicada no momento do processo de rasgamento dúctil do material. Conforme pode-se visualizar na Figura 11a, os alvéolos aparentam estar essencialmente arredondados e na mesma distância, isso se dá pela aplicação de uma carga uniaxial trativa na região analisada. Enquanto na Figura 11b, os alvéolos são formados com a aplicação de uma carga cisalhante, ou seja, deslizante, o que leva a apresentar microscopicamente alvéolos alongados.
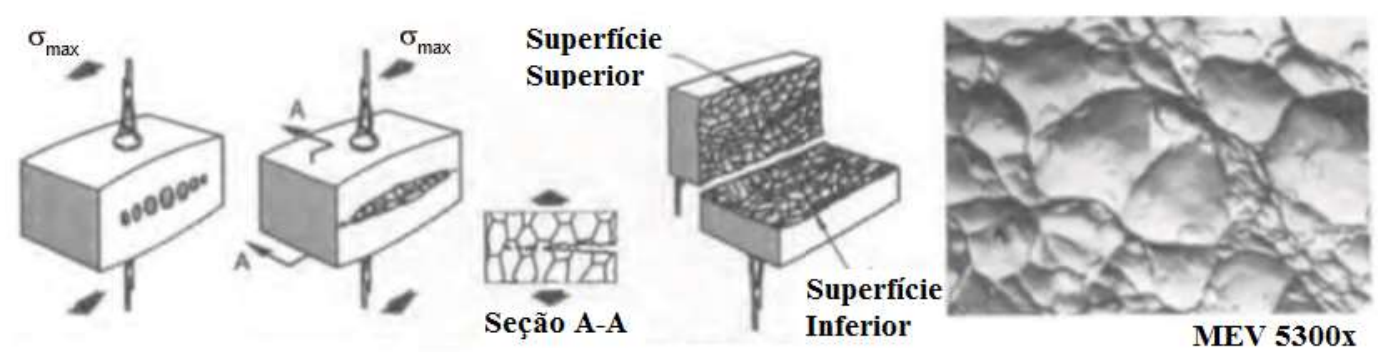

(a) Alvéolos Equidistantes

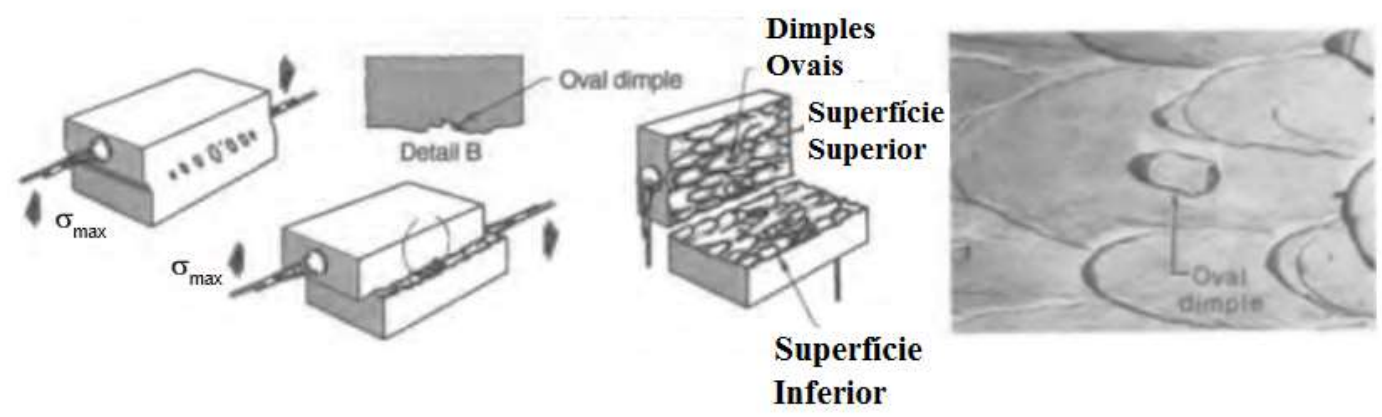

(b) Alvéolos Alongados

Figura 11 - Imagens esquemáticas da formação de alvéolos. (a) Imagem do MEV apresentado microcavidades esféricas resultantes de uma carga uniaxial; e (b) microcavidades alongadas na superfície de fratura com a presença de tensão cisalhante atuante. Adaptado de [21]

No entanto, há casos como em condições de temperaturas muito baixas que materiais dúcteis apresentam características de fratura frágil. Por este motivo é importante considerar características como microestrutura, taxa de deformação, 
temperatura, meio ambiente e estado de tensão durante a análise do material e amostras fractográficas, além de fatores extras como concentradores de tensões presentes na estrutura, tensão aplicada maior que a capacidade de resistência do material e temperatura de trabalho relativamente baixa. [24]

\subsubsection{Comportamento de resistência e deformação do material}

O segundo fator envolvido na característica da resistência à fratura do material está relacionado ao comportamento de deformação do mesmo, a qual a análise é caracterizada como sendo linear elástica ou elasto-plástica. O surgimento da abordagem da mecânica da fratura linear-elástica (MFLE) levou a ampliação dos estudos para mecânica da fratura elasto-plástica (MFEP).

A MFLE foi desenvolvida a partir de diversos estudos, inicialmente, Inglis [27], em 1913, trouxe em evidência a severidade de uma trinca em uma estrutura ressaltando sua presença como um fator negativo no comportamento resistivo do material, uma observação que ocasionou a primeira observação quantitativa do efeito de um concentrador de tensões, $K_{t}$, na falha de um componente, o qual permite estimar a medida do grau que uma tensão externa é amplificada constantemente na extremidade de um determinado formato de defeito. Após Inglis, Griffith [28] foi o primeiro pesquisador que acrescentou uma contribuição sensível a mecânica da fratura no ano de 1920, introduzindo o conceito da taxa de absorção de energia, $G$, ele idealizou o equilíbrio termodinâmico entre o aumento da taxa de energia superficial, a diminuição da energia potencial e o trabalho externo, resumindo o seu estudo a quantidade de energia fornecida a uma trinca e como a mesma iria se movimentar diante a aplicação desta energia, e a partir desta análise foi capaz de desenvolver sua segunda grande contribuição a MFLE, a eq. (2.1).

$$
\sigma \sqrt{\mathrm{a}}=\left(\frac{2 \gamma_{e} \mathrm{E}}{\pi}\right)
$$

Porém, a aplicação da teoria da trinca de Griffith é limitada sendo válida apenas para materiais com SSY (small-scale yelding) na ponta da trinca, os quais valores de resistência à fratura qualificam essencialmente uma fratura frágil controlada por tensão e ainda nesta condição a zona plástica é pequena e altamente 
localizada na ponta do defeito em comparação as dimensões relativas da estrutura na qual ela está contida. Com isso, sua aplicação não se estende a materiais dúcteis e ligas que por serem materiais capazes de absorver muito mais energia aplicada do que energia superficial apresentando desta maneira deformação plástica significante na ponta do defeito que envolve o embotamento na ponta da trinca antes do crescimento real, adotando a teoria de Griffith subestimaria severamente a resistência a fratura dos materiais metálicos.

Ainda abrangendo a MFLE, há o aparecimento do fator de intensidade de tensão K apresentado em 1957 pelo pesquisador Irwin [29] através da eq. (2.2).

$$
\mathrm{K}=\sigma \sqrt{\pi \mathrm{a}}
$$

Que parametriza o campo de tensões elástico na ponta da trinca, este fator apresenta geralmente valores no sub índice que indica o modo de carregamento aplicado e o mesmo não é considerado um parâmetro do material, significando que materiais distintos podem conduzir campos de tensões e tamanho da zona plástica na ponta da trinca iguais resultando em um mesmo valor de K. De forma geral, a eq. (2.2) é a mais utilizada para determinação do fator de intensidade de tensões, porém há a possibilidade de adicionar um fator dependente da configuração geométrica sendo encontrado nas principais literaturas. [23] [30-34]

Em sequência a análise efetuada na MFLE, dois novos parâmetros, CTOD e integral-J, originaram, respectivamente, por estudos desenvolvidos por Wells [35] em 1961 e Rice [36] em 1968, que modificaram a caracterização da tenacidade à fratura de materiais que apresentam considerável deformação plástica associada com um rasgamento dúctil, surgindo assim a mecânica da fratura elasto-plástica, MFEP. O conceito e desenvolvimento da integral-J será abordada mais adiante desta dissertação.

\subsubsection{Constrição Plástica}

O terceiro fator considerado para qualificação da resistência à fratura do material é a constrição plástica. Este é um efeito gerado ao componente que limita a capacidade do material de se deformar plasticamente e que se refere também ao grau de triaxialidade de tensão [37]. O grau de restrição plástica não só está 
associado diretamente com a espessura, tamanho e configuração das amostras como também com a profundidade do defeito existente e comprimento absoluto do ligamento remanescente não trincado [38] [39]. E quando se aplica os resultados da resistência à fratura em componentes em serviço espera-se que ele apresente as mesmas características quanto ao nível de constrição plástica e mecanismos de falhas.

O gráfico desenvolvido por Nyhus [40] apresenta a influência geométrica, Q, associado a constrição plástica no resultado do parâmetro de tenacidade à fratura do material. Pode-se observar na Figura 12 que a constrição plástica é dependente da geometria dos corpos de prova e o modo de carregamento aplicado, ambos conduzem a perda de restrição no material, ressaltado no aumento na resistência à fratura do material. Como mencionado nos itens anteriores desta dissertação, as geometrias altamente compactadas, $\mathrm{SE}(\mathrm{B})$ e $\mathrm{C}(\mathrm{T})$ com trincas profundas, $\mathrm{a} / \mathrm{W}=0,5$, fornecem estimativas inferiores a medida de resistência à fratura que um duto seria capaz de suportar, por gerarem tensões triaxiais significativas, aumentam a resistência local no material, reduzindo sua habilidade de escoar ao redor da ponta da trinca. Em amostras $\mathrm{SE}(\mathrm{B})$ com $\mathrm{a} / \mathrm{W}=0,3$, o conservadorismo no valor da tenacidade à fratura é menor, porém ainda subestimado quanto a capacidade de uma estrutura tubular. Ao gerar a curva-R, este conservadorismo é representado com a obtenção de curvas maiores para amostras de baixa constrição plástica e curvas mais baixas para amostras de alta constrição plástica. Sabe-se que é difícil gerar alta triaxialidade em estruturas finas, especialmente no caso de dutos onde a deformação plástica em serviço pode exceder amplamente o limite de escoamento do material, portanto, a restrição é significativamente menor (e a dureza maior) para as trincas presentes nestes componentes do que nas trincas em amostras normalizadas. Além do mais, o valor da tenacidade à fratura em condições de baixo nível de triaxialidade de tensão pode alcançar um resultado duas vezes maior do que a tenacidade obtida através de uma amostra que representa alto nível de triaxialidade de tensão [26]. Sob esta observação, reforça a teoria que a geometria SENT é a que mais se equipara no valor de tenacidade à fratura e as condições de serviço das estruturas de um duto. 


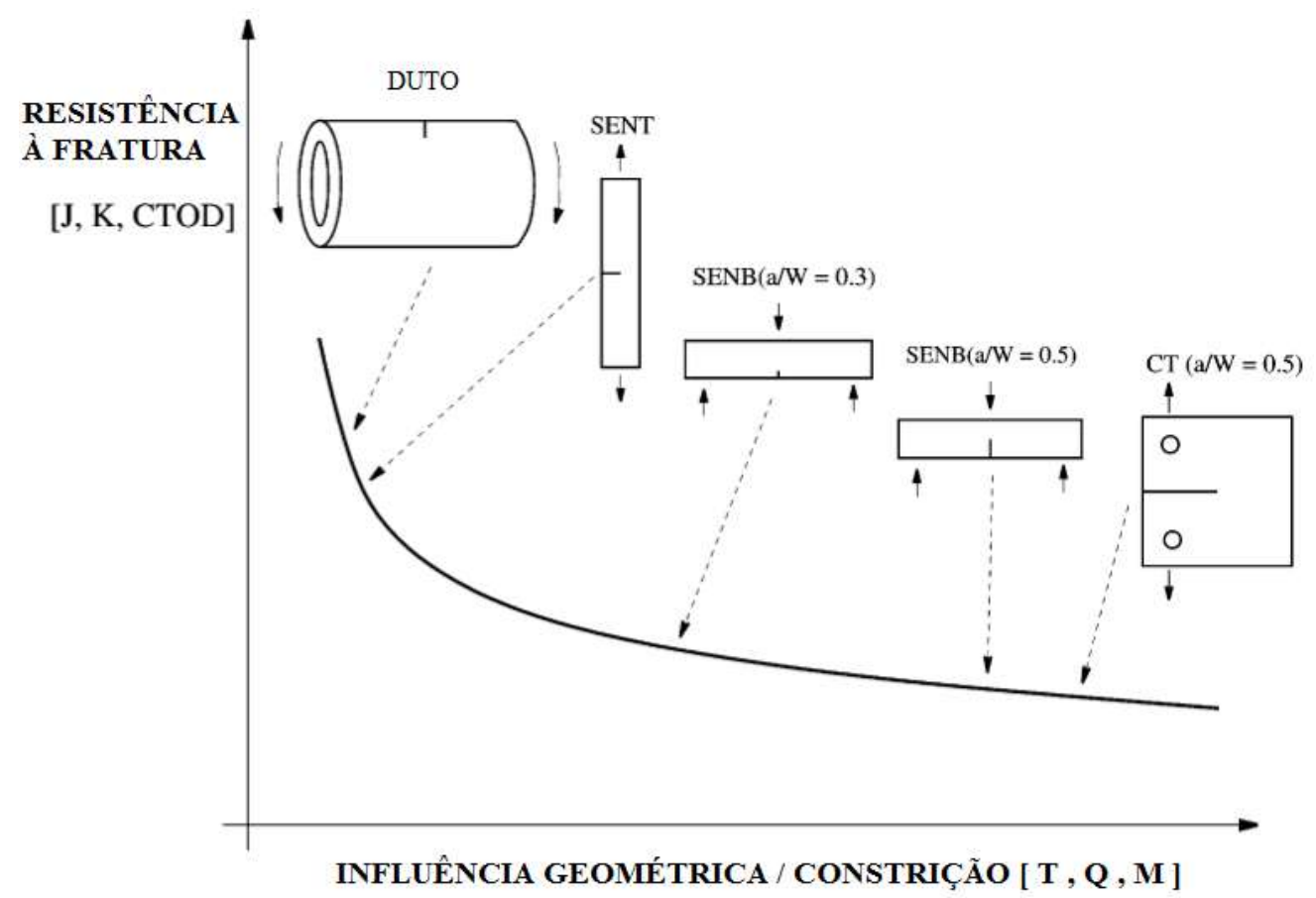

Figura 12 - Ilustração esquemática representando a influência da constrição e geometria do corpo de prova na resistência à fratura. [40]

\subsection{Curva-R}

$\mathrm{O}$ conceito de curva-R é muito atuante na área de engenharia $\mathrm{e}$ detalhadamente descrita em diversas normas de padronização. É objetivamente adotada como um procedimento de análise da propagação de trinca estável em um componente sólido elasto-plástico, relacionando a variação de um parâmetro de tenacidade à fratura do material, integral-J ou CTOD, com a extensão estável de trinca. Na norma ASTM E1820-17 [1] consta que esta curva pode ser adquirida por dois métodos práticos, conhecidos como procedimento básico e procedimento da curva de resistência. O primeiro método mencionado geralmente é aplicado para determinar um parâmetro de tenacidade à fratura no ponto de instabilidade de fratura ou próximo ao início de propagação dúctil de trinca. $\mathrm{O}$ desenvolvimento deste método requer o emprego de múltiplos corpos de prova com as dimensões semelhantes para a plotagem de uma curva-R, diferindo a carga monotônica aplicada, sendo o corpo de prova conduzido até a falha ou até a um deslocamento total previamente determinado, conforme apresentado na Figura 13a, resultando em uma quantidade distinta de extensão de trinca dúctil. Um ponto negativo deste procedimento é o custo e a demanda de tempo requerida para realização do ensaio. 
Ao adotar a segunda técnica descrita na norma ASTM E1820 [1], a qual foi desenvolvida por Clarke [41], conhecida como procedimento da curva de resistência ou método compliance, a quantidade de corpos de prova para o ensaio é minimizada, isto se deve pelo fato de que com apenas um corpo de prova ser possível determinar múltiplos pontos de flexibilidade elástica em cada descarregamento elástico parcial realizado no corpo de prova durante a aplicação incremental de carga e deslocamento, normalmente cerca de 30 descarregamentos são suficientes para realizar um desenvolvimento matemático para obtenção dos valores de tamanho de trinca incrementais, que serão fundamentais para relacionar com o parâmetro de tenacidade à fratura desejado, Figura 13b. Compliance significa o inverso da rigidez do material sendo matematicamente determinado pela eq. (2.3), a qual $\mathrm{V}$ se refere a deslocamento e $\mathrm{P}$ a carga, A medida que a trinca cresce a amostra se torna mais flexível, ou seja, menos rígido, e o compliance aumenta.

$$
\mathrm{C}=\frac{\mathrm{v}}{\mathrm{P}}
$$

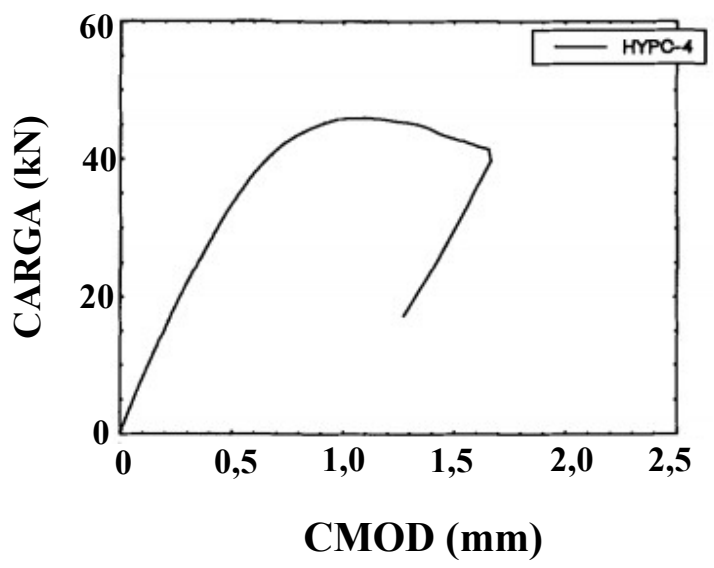

(a)

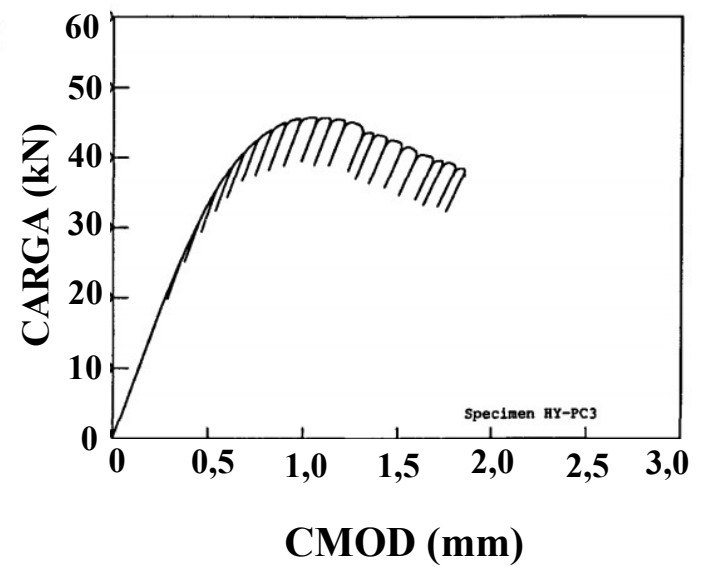

(b)

Figura 13 - Carga versus COD. (a) Método do procedimento básico; (b) Método da curva de resistência. [42]

É requerido que o sistema utilizado neste método permita a avaliação instantânea do comprimento da trinca estimado e o parâmetro de tenacidade à fratura através do monitor de um computador na conclusão de cada descarregamento parcial. Ainda pode ser dito que para ambas técnicas para medição dos deslocamentos, plotado no eixo das ordenadas na curva-R, é necessário a fixação de clip-gages que permitirão o registro do deslocamento, esta medição pode 
ser conduzida sob três formas de controle, através do controle pela abertura da boca da trinca, CMOD, controle do deslocamento da transversina da máquina ou linha de carga, LLD, ou pelo deslocamento do atuador [1]. Há casos em que mais de um controle é efetuado pelo fato da linha de carga e CMOD não serem coincidentes, como no caso das amostras $\mathrm{SE}(\mathrm{B})$.

Em seguida ao procedimento experimental e com os dados definidos, a curva-R é descrita em termos da integral-J ou CTOD, Crack Tip Opening Displacement, e tem o aspecto semelhante à Figura 14. No estágio inicial de deformação do material, a curva de resistência possui uma relação praticamente linear entre o parâmetro de tenacidade à fratura e a extensão da trinca, representando graficamente o embotamento na ponta da trinca antes da propagação. A medida que há uma propagação de trinca estável o valor do parâmetro de tenacidade à fratura aumenta, o que indica um aumento de deformação plástica na ponta da trinca. Sendo capaz de determinar um valor considerado uma propriedade do material, conhecido como J IC. ou $\delta_{\mathrm{i} .}$

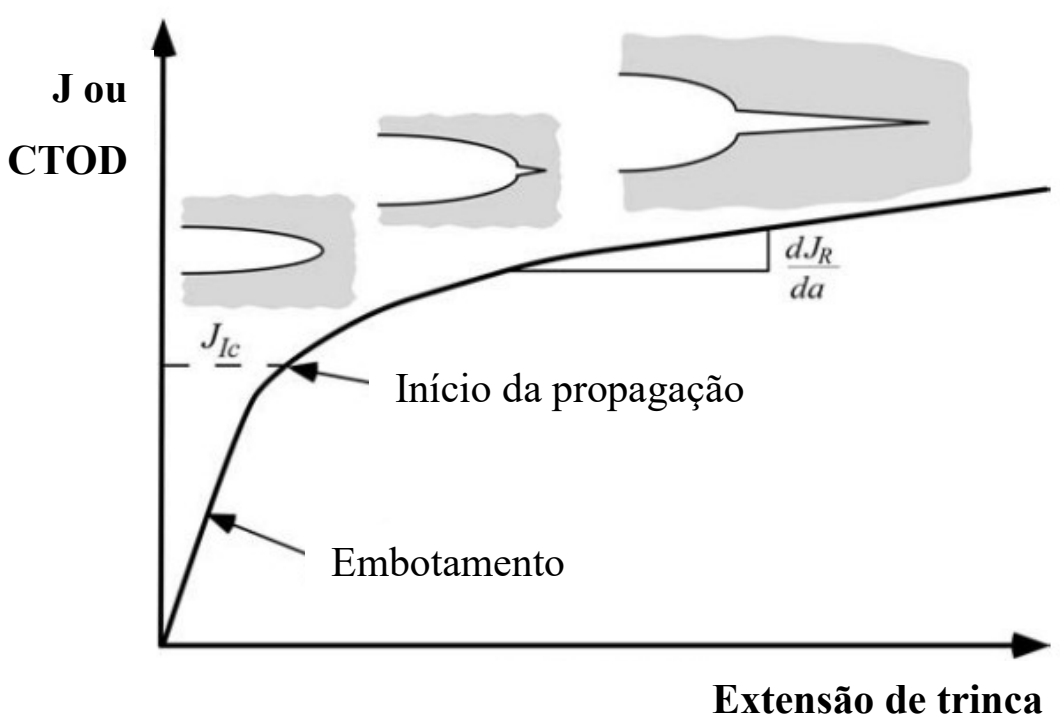

Figura 14 - Esquema da curva de resistência em termos de J mostrando os diferentes estágios do crescimento da trinca. Adaptado de [23]

A determinação desses fatores segundo a norma vigente depende além da plotagem de uma linha de regressão linear, a estimação de uma linha de construção e exclusão para validação dos pontos qualificados, conforme dispostos na Figura 15. A linha de construção é plotada com base na eq. (2.4) conduzindo a determinação de uma linha de exclusão paralela a uma distância de $0,15 \mathrm{~mm}$ 
interceptando a abscissa. Em sequência, uma segunda linha de exclusão é desenhada a $1,5 \mathrm{~mm}$ da linha de construção.

$$
\mathrm{J}=2 \sigma_{\mathrm{y}} \Delta_{\mathrm{a}}
$$

Os valores qualificados de $\mathrm{J}-\Delta \mathrm{a}$ para construção da linha de potência de regressão linear devem estar contidos entre as duas linhas de exclusão e são delimitados pelo valor resultante de $\mathrm{J}_{\text {limite }}$ da eq. (2.5) e o valor de $\Delta$ alimite definido graficamente com a interseção da linha de $1,5 \mathrm{~mm}$ de exclusão com a linha de potência de regressão linear. A linha de potência de regressão linear é definida pela eq. (2.6), na qual o valor de $C_{1}$ e $C_{2}$ são constantes do material, tendo que $C_{2}$ equivaler um valor menor que 1 , e $\mathrm{k}$ assumir valor igual a $1,0 \mathrm{~mm}$ ou 0,0394 polegadas.

$$
\begin{gathered}
\mathrm{J}_{\text {limite }}=\frac{\mathrm{b}_{0} \sigma_{\mathrm{y}}}{7,5} \\
\ln \mathrm{J}=\ln \mathrm{C}_{1}+\mathrm{C}_{2} \ln \left(\frac{\Delta \mathrm{a}}{\mathrm{k}}\right)
\end{gathered}
$$

Outro ponto a ser obtido a partir do levantamento da curva-R é a determinação do valor de $\Delta \mathrm{a}_{\min }$ proveniente da interseção da linha de exclusão a $0,15 \mathrm{~mm}$ com a linha de potência de regressão linear. A plotagem de uma linha de 0,2 mm é aplicada, e o ponto coincidente com a linha de potência da regressão linear define o valor de $\mathrm{J}_{\mathrm{IC}}$ ou $\delta_{\mathrm{i}}$.

A ASTM E1820-17 [1] assegura que a capacidade da amostra ensaiada perante J é determinada pelo menor valor entre o resultado das eq. (2.7a) e eq. (2.7b) e que o máximo valor de extensão de trinca resistiva pelo material, $\Delta \mathrm{a}_{\max }$, é definida pelo valor resultante na eq. (2.8).

$$
\begin{gathered}
\mathrm{J}_{\max }=\frac{\mathrm{b}_{0} \sigma_{\mathrm{y}}}{10} \\
\mathrm{~J}_{\max }=\frac{\mathrm{B} \sigma_{\mathrm{y}}}{10} \\
\Delta \mathrm{a}_{\max }=0,25 \mathrm{~b}_{0}
\end{gathered}
$$




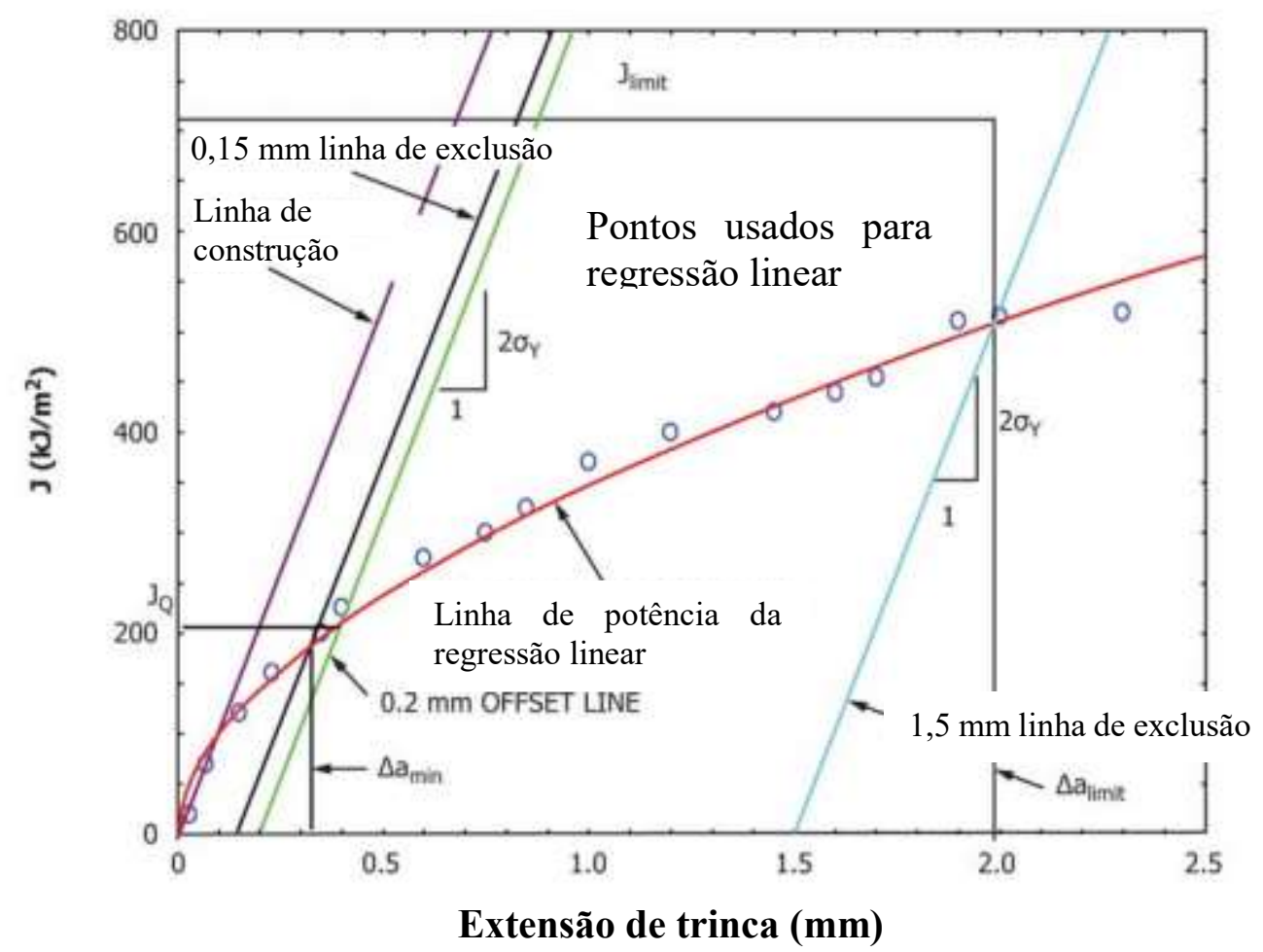

Figura 15 - Definição dos parâmetros para qualificação dos pontos na curva-R Adaptado de [1]

Uma exigência da ASTM E1820-17 [1] para validação do ensaio é que pelo menos um valor de $\mathrm{J}-\Delta \mathrm{a}$ esteja localizado entre a linha de exclusão de $0,15 \mathrm{~mm}$ e a linha de $0,2 \mathrm{~mm}$ e que no mínimo 5 valores de $\mathrm{J}$ - $\Delta$ a se encontrem na área limitada por $\Delta \mathrm{a}_{\min ,} \Delta \mathrm{a}_{\text {limite }} \mathrm{e} \mathrm{J}_{\text {limite. }}$

\subsection{Integral $J$}

Conforme mencionado brevemente no item 2.1.2 deste capítulo, a integral-J é um parâmetro de resistência à fratura aplicada a materiais com ductilidade significante, caracteristicamente acompanhadas por deformação na ponta da trinca no processo de fratura. [23]. O levantamento de tal parâmetro será o objetivo deste trabalho. A integral-J é também definida como uma medida de intensidade de liberação de energia do campo de tensão e deformação ao redor da trinca. Este parâmetro mecânico de integral de linha independente do caminho de integração escolhido é fundamentado na teoria da deformação plástica e foi primeiramente proposto por Rice [36]. Por este parâmetro ser um contorno fechado anti-horário e arbitrário, $\Gamma$, sobre um plano normal ao redor da ponta da trinca, como apresentado na Figura 16, define-se a integral-J pela eq. (2.9). 


$$
J=\int_{\Gamma}\left(w d y-T_{i} \frac{\partial u_{i}}{\partial x} d s\right)
$$

Onde $w$ denota a densidade de energia de deformação elástica, $T_{i}$ e $u_{i}$ são as componentes dos vetores tração e deslocamento, respectivamente; $x$ e $y$ são coordenadas retangulares; $d s$ é o incremento do comprimento ao longo do contorno Г. A densidade de energia de deformação pode ser escrita como:

$$
\mathrm{w}=\int_{0}^{\varepsilon_{\mathrm{ij}}} \sigma_{\mathrm{ij}} \mathrm{d} \varepsilon_{\mathrm{ij}}
$$

Onde o $\sigma_{i j} e \varepsilon_{i j}$ são os tensores tensão e deformação infinitesimal, respectivamente. Rice mostrou que o valor de $\mathrm{J}$ é indepdente do caminho de integração, $\Gamma$, ao redor da ponta da trinca.

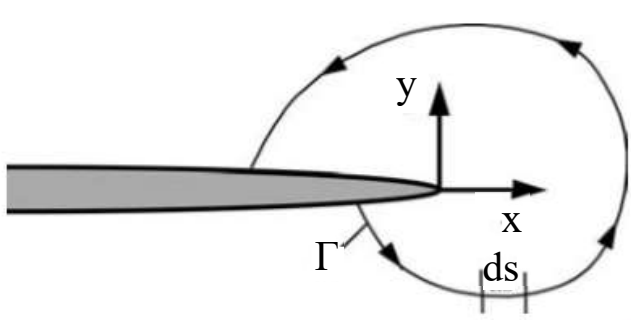

Figura 16 - Contorno arbitrário ao redor da ponta da trinca. [23]

Pelo fato de J ser considerado um parâmetro de caracterização para o campo a frente da ponta da trinca, ele é determina experimentalmente a tenacidade à fratura do material como um valor crítico de J no início de crescimento de trinca, conhecido como $\mathrm{J}_{\mathrm{IC}}$. Em adição, $\mathrm{J}$ pode também ser considerado como uma medida de intensidade mesmo com uma pequena porção de crescimento de trinca, enquanto a condição para então conhecida crescimento o de trinca controlada por $\mathrm{J}$ seja satisfeita. Estas condições limitam a quantidade de crescimento de trinca de tal modo que o descarregamento elástico e o carregamento não proporcional perto da ponta da trinca associados ao crescimento da trinca estejam bem contidos na região em que a plasticidade de deformação sobre a qual J é baseada é ainda aplicável. Baseado nisso, os ensaios são conduzidos para desenvolvimento de $\mathrm{J}$ vs. $\Delta$ a, 
levando construção da curva de resistência, conhecida como curva J-R, mencionada no item 2.2. É a partir desta curva que a interpretação da capacidade de ductilidade do material é analisada já que o valor de J sempre aumenta com pequenas quantidades de avanço de trinca, implicando no levantamento da tolerância de resistir do componente.

A resolução da integral-J é encontrada em diversas normas vigentes que ditam que o cálculo para obtenção da mesma seja dividido em uma componente elástica e uma componente plástica, conforme eq. (2.11) baseadas na área abaixo da curva de carga $\mathrm{x}$ deslocamento registrada durante o ensaio de tenacidade à fratura, Figura 17.

$$
\mathrm{J}=\mathrm{J}_{\mathrm{el}}+\mathrm{J}_{\mathrm{pl}}
$$

O intuito desta separação é melhorar a acuracidade da avaliação da integral J, e obter um valor consistente de J quando a deformação estiver próxima a condições linear-elásticas. Assim sendo, a componente elástica, $\mathrm{J}_{\mathrm{el}}$, conforme eq. (2.12), pode ser diretamente determinada a partir do fator de intensidade $\mathrm{K}$.

$$
\mathrm{J}_{\mathrm{el}}=\frac{\mathrm{K}^{2}}{\mathrm{E}^{\prime}}
$$

Onde: $E^{\prime}=E$ para tensão plana ou $E^{\prime}=\frac{E}{\left(1-v^{2}\right)}$ para deformação plana, assumindo $v$ igual a 0,3 . Como o fator de intensidade de tensão $\mathrm{K}$ é um fator dependente da geometria do corpo de prova, a norma da ASTM possui equações distintas para as geometrias $\mathrm{SE}(\mathrm{B})$ e $\mathrm{C}(\mathrm{T})$, uns dos formatos padrões, adotando-se as eq. (2.13) e a eq. (2.14) respectivamente.

$$
\begin{gathered}
\mathrm{K}=\left[\frac{\mathrm{P}_{\mathrm{i}} S}{\left(\mathrm{BB}_{\mathrm{N}}\right)^{1 / 2} \mathrm{~W}^{3 / 2}}\right] \mathrm{f}\left(\mathrm{a}_{\mathrm{i}} / \mathrm{W}\right) \\
\mathrm{K}=\left[\frac{\mathrm{P}_{\mathrm{i}}}{\left(\mathrm{BB}_{\mathrm{N}} W\right)^{1 / 2}}\right] \mathrm{f}\left(\mathrm{a}_{\mathrm{i}} / \mathrm{W}\right)
\end{gathered}
$$


Sendo a função (ai $/ \mathrm{W})$ da eq. (2.15) aplicável a eq. (2.13) e eq. (2.16) aplicável a eq. (2.14).

$f\left(\frac{a_{i}}{W}\right)=\frac{\left\{3\left(\frac{a_{i}}{W}\right)^{1 / 2}\left[1,99-\left(\frac{a_{i}}{W}\right)\left(1-\frac{a_{i}}{W}\right)\right]\left(2,15-3,93\left(\frac{a_{i}}{W}\right)+2,7\left(\frac{a_{i}}{W}\right)^{2}\right)\right\}}{2\left(1+2 \frac{a_{i}}{W}\right)\left(1-\frac{a_{i}}{W}\right)^{3 / 2}}$

$\mathrm{f}\left(\frac{\mathrm{a}_{\mathrm{i}}}{\mathrm{W}}\right)=\frac{\left\{\left[2+\left(\frac{\mathrm{a}_{\mathrm{i}}}{\mathrm{W}}\right)\right] \times\left[0,886+4,64\left(\frac{\mathrm{a}_{\mathrm{i}}}{\mathrm{W}}\right)\right]-13,32\left(\frac{\mathrm{a}_{\mathrm{i}}}{\mathrm{W}}\right)^{2}+14,72\left(\frac{\mathrm{a}_{\mathrm{i}}}{\mathrm{W}}\right)^{3}-5,6\left(\frac{\mathrm{a}_{\mathrm{i}}}{\mathrm{W}}\right)^{4}\right\}}{\left[1-\left(\frac{\mathrm{a}_{\mathrm{i}}}{\mathrm{W}}\right)\right]^{3 / 2}}$

A parte plástica, $\mathrm{J}_{\mathrm{p}}$, da integral-J, eq. (2.17), é função da energia plástica sob a curva $\mathrm{P}$ vs. $\mathrm{v}$, denotada também como área plástica, proposta por Sumpter e Turner [41]. O valor da $\mathrm{A}_{\mathrm{pl}}$, se adotado procedimento básico de ensaio, pode ser mensurado diretamente do gráfico gerado, conforme apresenta na Figura 17, ilustrando as características essenciais para o procedimento de estimativa de $\mathrm{J}_{\mathrm{p}}$, simplesmente relacionando a contribuição plástica a energia de deformação.

$$
\mathrm{J}_{\mathrm{pl}}=\frac{\eta_{\mathrm{pl}} \mathrm{A}_{\mathrm{pl}}}{\mathrm{Bb}_{0}}
$$

O fator admensional $\eta$ para corpos de prova padronizados são dependentes tanto da geometria como na maneira na qual o controle de desloamento está sendo realizado durante o procedimento experimental para determinação da área plástica. Quando a determinação da área plástica, $A_{\mathrm{pl}}$, for obtida por LLD admite-se $\eta_{\mathrm{pl}}$ igual a 1,9, valor constante durante todo o ensaio. Ao obter $\mathrm{A}_{\mathrm{pl}}$ por controle do CMOD, $\eta_{\mathrm{pl}}$ assume um valor resultante da eq. (2.18) para corpo de prova $\mathrm{SE}(\mathrm{B})$, por exemplo.

$$
\eta_{\mathrm{pl}}=3,667-2,199\left(\frac{\mathrm{a}_{0}}{\mathrm{~W}}\right)+0,437\left(\frac{\mathrm{a}_{0}}{\mathrm{~W}}\right)^{2}
$$


O uso deste fator simplifica consideravelmente a questão da determinação da integral-J e relaciona a contribuição plástica da energia de deformação de um componente trincado com a integral J plástica.

Quando o método compliance é aplicado para determinação da curva-R, a incógnita de $\mathrm{a}_{0}$ da eq. (2.18) é substituída por $\mathrm{a}_{(\mathrm{i}-1)}$, que representa o valor referente ao tamanho de trinca anterior em relação ao que está sendo analisado. Além desta distinção, sabe-se que para o desenvolvimento do método compliance cada ponto i de descarregamento possui um valor instantâneo das variáveis $\mathrm{a}_{\mathrm{i}}, \mathrm{v}_{\mathrm{i}}$ e $\mathrm{P}_{\mathrm{i}}$ que são pertinentes de equações oriundas de $\mathrm{J}_{\mathrm{el}} \mathrm{e} \mathrm{J}_{\mathrm{pl}}$ determinados incrementalmente a partir da eq. (2.14)

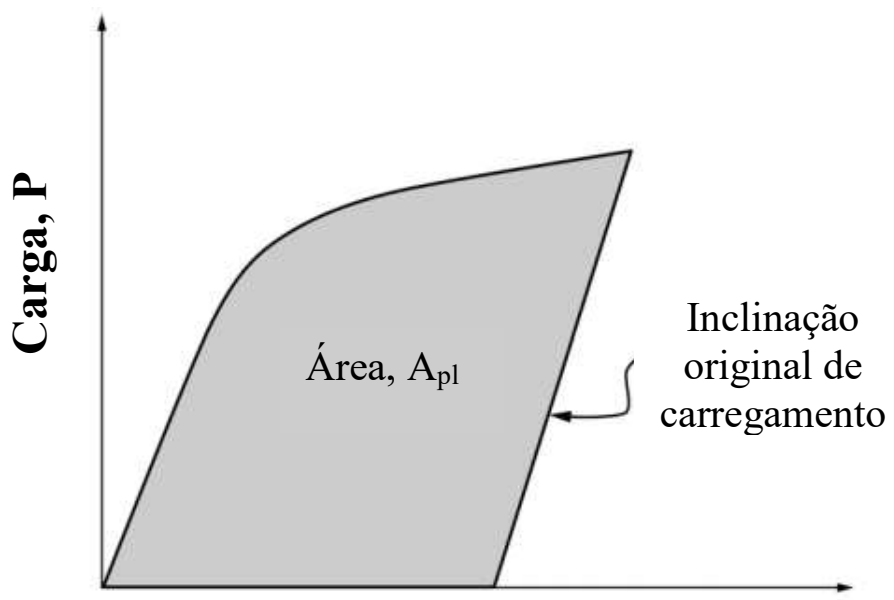

\section{Deslocamento total, $\mathbf{v}$}

Figura 17 - Definição da área para calcular J usando o método básico. Adaptado de [1]

$$
\mathrm{J}_{\text {total(i) }}=\mathrm{J}_{\mathrm{el}(\mathrm{i})}+\mathrm{J}_{\mathrm{pl}(\mathrm{i})}
$$

A determinação do valor de $\mathrm{J}_{\text {el(i) }}$ disposto na eq. (2.19) é calculado conforme eq. (2.12), sendo apenas $\mathrm{K}$ substiruído por $\mathrm{K}_{(\mathrm{i})}$, valor do fator de intensidade de tensão em cada ponto incremental i. Já o termo plástico da integral J, no método compliance é dissimilar quando comparado a eq. (2.17) do procedimento básico, pois representa o $\mathrm{J}$ plástico de crescimento de trinca corrigido total no ponto i. A primeira fração da eq. (2.20) equivale ao incremento do $\mathrm{J}_{\mathrm{pl}(\mathrm{i}-1)}$ da parcela plástica existente, e a segunda envolve a modificação do resultado total acumulado para efetuar a correção do incremento pelo crescimento de trinca. 


$$
\mathrm{J}_{\mathrm{pl}(\mathrm{i})}=\left[\mathrm{J}_{\mathrm{pl}(\mathrm{i}-1)}+\left(\frac{\eta_{\mathrm{pl}(\mathrm{i}-1)}}{\mathrm{b}_{(\mathrm{i}-1)}}\right) \frac{\mathrm{A}_{\mathrm{pl}(\mathrm{i})}-\mathrm{A}_{\mathrm{pl}(\mathrm{i}-1)}}{\mathrm{B}_{\mathrm{N}}}\right]\left[1-\gamma_{(\mathrm{i}-1)}\left(\frac{\mathrm{a}_{(\mathrm{i})}-\mathrm{a}_{(\mathrm{i}-1)}}{\mathrm{b}_{(\mathrm{i}-1)}}\right)\right]
$$

O fator $\gamma$ introduzido na equação anterior define a correção da energia de deformação do componente plástico da integral-J pelo pequeno incremento do tamanho da trinca para uma trinca em propagação. Assim como com $\eta$, a norma ASTM E1820-17 [1] padroniza o fator $\gamma$ para diferentes geometrias e modo de determinação da área plástica, adotando-se para corpos de prova $\mathrm{SE}(\mathrm{B})$ medindo a $\mathrm{A}_{\mathrm{pl}}$ a partir de LLD admite-se $\gamma_{\mathrm{pl}(\mathrm{i}-1)}$ igual a 0,9 e $\gamma_{\mathrm{pl}(\mathrm{i}-1)}$ assumirá valor resultante da eq. (2.21) para ensaios regidos a partir de CMOD para cálculo da área plástica.

$$
\gamma_{\mathrm{pl}(\mathrm{i}-1)}=0,131+2,131\left(\frac{\mathrm{a}_{(\mathrm{i}-1)}}{\mathrm{w}}\right)-1,465\left(\frac{\mathrm{a}_{(\mathrm{i}-1)}}{\mathrm{w}}\right)^{2}
$$

Já para corpo de prova $\mathrm{C}(\mathrm{T}), \gamma_{\mathrm{pl}(\mathrm{i}-1)}$ é obtido a partir da eq. (2.22)

$$
\gamma_{(\mathrm{i}-1)}=1+\frac{0,76 \mathrm{~b}_{(\mathrm{i}-1)}}{\mathrm{W}}
$$

$\mathrm{Na}$ eq. (2.20), a quantidade $\mathrm{A}_{\mathrm{pl} \text { (i) }}-\mathrm{A}_{\mathrm{pl} \text { (i-1) }}$ é o incremento da área plástica sob o registro da curva carga versus deslocamento plástico entre as linhas com deslocamento constante do ponto (i) ao ponto (i-1), Figura 18. A formulação matemática utilizada para cálculo da $A_{p l(i)}$ é definida de acordo com a eq. (2.23)

$$
\mathrm{A}_{\mathrm{pl}(\mathrm{i})}=\mathrm{A}_{\mathrm{pl}(\mathrm{i}-1)}+\left[\mathrm{P}_{(\mathrm{i})}+\mathrm{P}_{(\mathrm{i}-1)}\right]\left(\mathrm{v}_{\mathrm{pl}(\mathrm{i})}-\mathrm{v}_{\mathrm{pl}(\mathrm{i}-1)}\right) / 2
$$




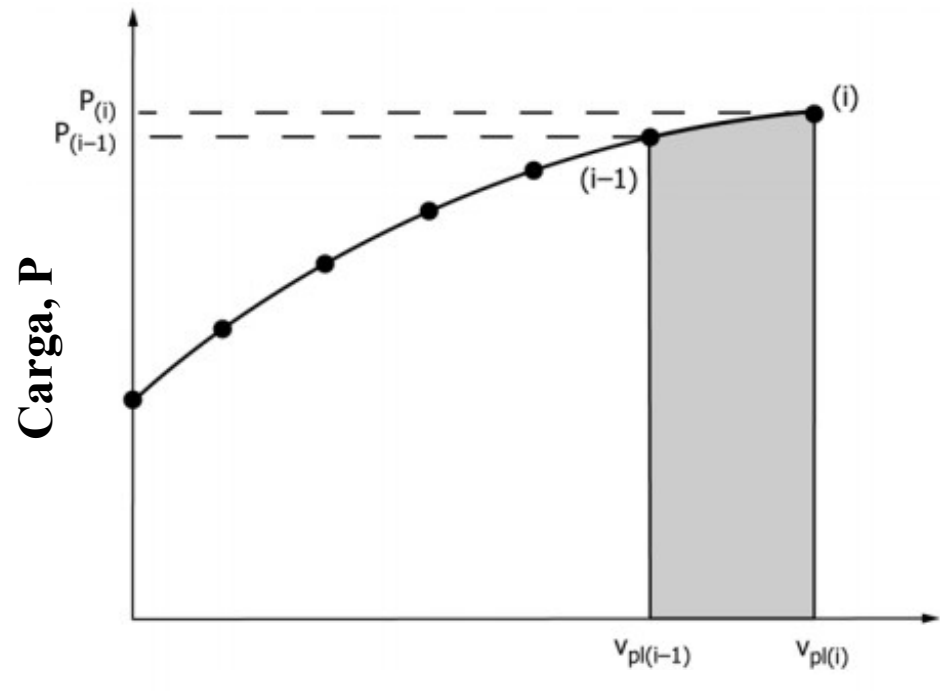

Deslocamento plástico, $\mathrm{v}_{\mathrm{pl}}$

Figura 18 - Definição da área plástica para calcular J usando o método compliance [1]

O termo $V_{p l(i)}$ é a parte plástica do LLD ou CMOD e é encontrado através da eq. (2.24).

$$
\mathrm{v}_{\mathrm{pl}(\mathrm{i})}=\mathrm{v}_{(\mathrm{i})}-\left(\mathrm{P}_{(\mathrm{i})} \mathrm{C}_{(\mathrm{i})}\right)
$$

Sendo $\mathrm{C}_{(\mathrm{i})}$ flexibilidade experimental correspondendo ao tamanho da trinca atualizado $\mathrm{a}_{\mathrm{i}}$ e $\mathrm{P}_{(\mathrm{i})}$ o valor da carga máxima do ponto $\mathrm{a}_{\mathrm{i}}$.

O cálculo para se determinar o tamanho de trinca pelo método compliance é feito para cada valor incremental registrado durante o ensaio em função da perda de rigidez do material, adquirindo-se um valor de tamanho de trinca em cada ciclo de descarregamento e carregamento portanto quanto menor rigidez mais flexível o material. No entanto a medição manual dos tamanhos incrementais é impossível de ser realizada, portando uma equação (2.25) do compliance normalizado, $\mu$, é a abordagem aplicada para determinação desta perda de rigidez a cada incremento do tamanho da trinca.

$$
\mu=\frac{1}{1+\sqrt{\mathrm{E}^{\prime} \mathrm{B}_{\mathrm{ef}} \mathrm{C}_{(\mathrm{i})}}}
$$

Onde:

$$
B_{e f}=B-\frac{\left(B-B_{N}\right)^{2}}{B}
$$


Após resultado da eq. (2.25), uma equação de $\mathrm{a}_{\mathrm{i}} / \mathrm{W}$ em função de $\mu$ é necessária para em seguida encontrar o tamanho de trinca $a_{i}$ em cada ponto de descarregamento parcial. Esta dependência é estimada a partir de uma equação de quinta ordem, na qual os coeficientes $\beta_{\mathrm{n}}$ presente na eq. (2.27) são derivados em concordância com a geometria da amostra aplicada.

$$
\frac{\mathrm{a}}{\mathrm{W}}=\beta_{0}+\beta_{1} \mu+\beta_{2} \mu^{2}+\beta_{3} \mu^{3}+\beta_{4} \mu^{4}+\beta_{5} \mu^{5}
$$

\subsection{Corpo de prova SENT}

Historicamente o corpo de prova SENT foi inicialmente pesquisado por Irwin, Krafft e Sullivan, em 1962, que por meio de uma nota não publicada destinada ao comitê especial da ASTM apresentaram esta geometria com o objetivo de medir a resistência à fratura $\left(\mathrm{K}_{\mathrm{IC}}\right.$ ou $\left.\mathrm{G}_{\mathrm{IC}}\right)$ no plano de deformação elástica. Dois anos seguintes, Sullivan [43] desenvolveu um projeto de corpo de prova SENT em condição de carregamento por pinos, como apresentado na Figura 18a, impulsionando Srawley et al. [44] a desenvolver uma pesquisa sobre a medição da taxa de absorção de energia elástica, G, usando esta geometria. No ano de 1965, Srawley e Brown [45] obtiveram uma expressão para o fator de intensidade de tensão K para a geometria SENT. Em 1973, Tada et al. [46] desenvolveram equações mais acuradas de $\mathrm{K}$ e flexibilidade elástica para SENT.

O corpo de prova SENT são amostras de superfície plana que possui entalhe tipo trinca em apenas uma das bordas laterais e que são carregados em tração na extremidade longitudinal ao plano do entalhe. Como sendo uma amostra de baixa constrição plástica, o corpo de prova SENT vem sendo aplicado a fim de ampliar os estudos do efeito de constrição na curva-R. Existem duas formas geométricas para o corpo de prova SENT, o de fixação por pinos, mencionado anteriormente, o qual exige que fatores de correção sejam aplicados em função da rotação que tende a ocorrer durante o ensaio, e o de fixação por garras, o qual o efeito da rotação é muito menor que para o SENT de fixação por pinos devido a rotação da parte engastada da amostra ficar restrita. Pesquisas apontam que o a geometria SENT de fixação por garras geram curvas-R menos sensíveis ao comprimento de trinca. 


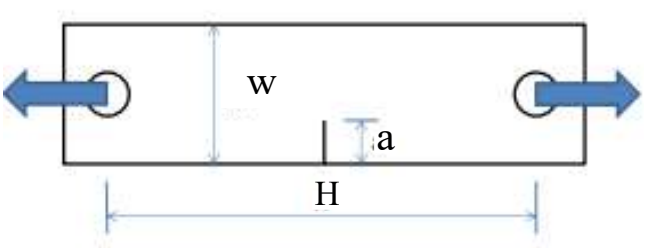

(a)

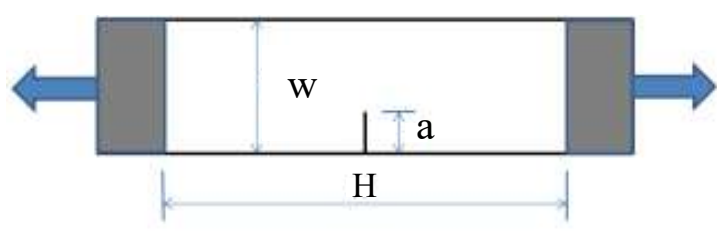

(b)

Figura 19 - Desenho esquemático das amostras SENT. (a) Condição de fixação por pinos; e (b) condição de fixação por garras [47]

\subsubsection{Método DNV-RF-108}

Em 2006, a DNV desenvolveu seu próprio método, DNV-RP-F108 [12], para medir a tenacidade à fratura em materiais de baixa constrição plástica e ampla capacidade de se deformar plasticamente, usando a geometria SENT de fixação por garras, como apresentada na Figura 18b. Este procedimento prático indica a utilização de múltiplas amostras, pelo menos 6 com resultados válidos, para desenvolvimento da curva-R, podendo ser adotada a geometria SENT de fixação por pinos ou por garras. É indicada que a espessura, B, do corpo de prova seja $2 \mathrm{~W}$, o comprimento útil do corpo de prova seja igual a $10 \mathrm{~W}$, e a razão de a/W possua um valor igual ou maior a 0,2 e menor ou igual a 0,5 . Side-grooves ou entalhes laterais não são requeridos. O resultado máximo de extensão de trinca esperado é de $3 \mathrm{~mm}$.

Assim como na ASTM E1820-17 [1], a integral-J sob este procedimento também é dividida em parte elástica e plástica, eq. (2.19), sendo a parte plástica determinada baseando-se no CMOD medido diretamente ou estimada a partir da medição com duplo clip gage.

\subsubsection{Método CanMet}

A CanMet [13] desenvolveu um método efetivo adotando apenas um corpo de prova SENT destinada a geometria de fixação por garras. Quanto a dimensão geométrica deste corpo de prova, CanMet adota a dimensão da largura como sendo igual a espessura, o comprimento útil do corpo de prova possui a mesma recomendação que a $\mathrm{DNV}, \mathrm{H}=10 \mathrm{~W}$ e o tamanho da pré-trinca de fadiga deve ser $0,1 \leq \mathrm{a} / \mathrm{W} \leq 0,7$. De acordo com a CanMet, side-groove com redução de $15 \%$ total da espessura do corpo de prova é recomendado e a técnica do método compliance 
é utilizada para medir o comprimento de trinca utilizando um clip gage montado na abertura da boca da trinca.

\subsection{Integral-J e corpo de prova SENT}

Por este corpo de prova não ser uma geometria padronizada pela ASTM, o desenvolvimento matemático para determinação da integral-J e desenvolvimento da curva-R requer que alguns fatores e equações dispostos no item 2.2 sejam modificados para as condições que esta geometria exige. Sendo assim, pesquisadores como Joyce [48], Zhu [49-50], Cravero [51], Cravero e Ruggieri [52] estudaram esta geometria por diferentes pontos de vista e considerações distintas.

Para o cálculo de Jelástico, Joyce et al [48] desenvolveram uma equação, eq. (2.28), destinada para aplicação em sistemas fixos ou com carregamento monotônico crescente vigente para $0,12 \leq \mathrm{a}_{0} / \mathrm{W} \leq 0,8$. No entanto esta fórmula não considerava a variação H/W nos corpos de prova SENT.

$$
\mathrm{K}_{(\mathrm{i})}=\sqrt{\pi \mathrm{a}} \times \frac{\mathrm{P}}{\mathrm{WB}} \times \mathrm{f}\left(\mathrm{a}_{(\mathrm{i})} / \mathrm{W}\right)
$$

Outras contribuições na literatura [45] [53-55] para levantamento acurado deste fator foi realizado, sendo limitada também sua aplicação devido a faixa a/W e H/W, razão do comprimento útil e largura do corpo de prova, recomendada. Com base nisso, Cravero e Ruggieri [52] determinaram uma equação global para K, eq. (2.29), aplicável tanto em SENT de fixação por pinos quanto para o de fixação por garras na qual é válida para razões de a/W de 0,1 a 0,7 e razões $\mathrm{H} / \mathrm{W}$ iguais a 2, 4, $6,8,10,20$ e 50. O estudo desenvolvido por estes pesquisadores terá domínio nesta dissertação.

$$
K_{I}=\frac{P}{W B} f(a / W)
$$

Seguindo a determinação de variáveis para corpos de prova SENT, Cravero e Ruggieri [52] foram capazes de determinar também por meio do método de elementos finitos os valores da variação do fator de intensidade de tensão adimensional, $\mathrm{f}\left(\mathrm{a}_{\mathrm{i}} / \mathrm{W}\right)$, que variam conforme modo de carregamento, razão a/W e 
H/W. Observando-se a partir da Figura 20, em corpos de prova com trincas rasas, razão de a/W igual a 0,1 e 0,2 , o efeito destas variáveis é discretamente percebida, sendo obtidos valores considerados próximos. No caso de razões a/W de 0,3 a 0,7 , o efeito de $\mathrm{H} / \mathrm{W}$ na configuração geométrica do corpo de prova já não é mais desprezível, sendo observada que para configurações maiores o valor $\mathrm{f}\left(\mathrm{a}_{\mathrm{i}} / \mathrm{W}\right)$ tende a aumentar. Com esta análise, uma variedade de coeficientes, $\xi_{0}$ até $\xi_{5}$, para aplicação em uma equação polinominal de quinta ordem em função de a/W, eq. (2.30), foram definidas e desenvolvidas. Uma tabela com estes coeficientes está disponibilizada na referência do Ruggieri.

$$
f\left(\frac{a_{i}}{W}\right)=\xi_{0}+\xi_{1}\left(\frac{a}{W}\right)+\xi_{2}\left(\frac{a}{W}\right)^{2}+\xi_{3}\left(\frac{a}{W}\right)^{3}+\xi_{4}\left(\frac{a}{W}\right)^{4}+\xi_{5}\left(\frac{a}{W}\right)^{5}
$$

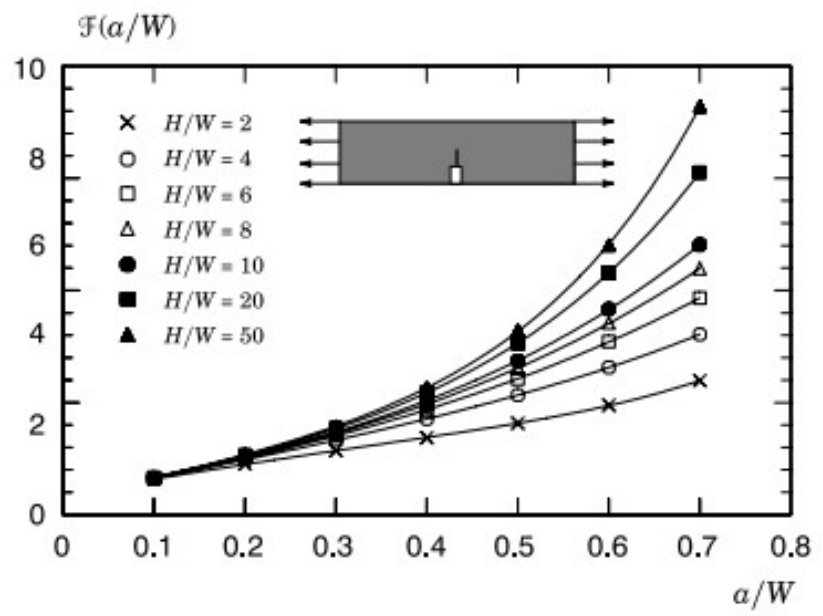

Figura 20 - Diagrama do fator de intensidade de tensão adimensional com razão a/W e variação de H/W. [51]

Outro levantamento realizado por Cravero e Ruggiei [52] mostrou que a dependência de H/W no resultado do compliance normalizado em corpos de prova SENT de fixação por garras, calculado pela eq. (2.21), em trincas mais profundas, $\mathrm{a} / \mathrm{W} \geq 0,4$, porém é independente para trincas mais rasas $\mathrm{a}_{0} / \mathrm{W} \leq 0,2$, conforme disposto na Figura 21b. Enquanto que para os corpos de prova SENT de fixação por pinos esta medida é independente para qualquer razão $\mathrm{H} / \mathrm{W}$, conforme interpretado na Figura 21a.

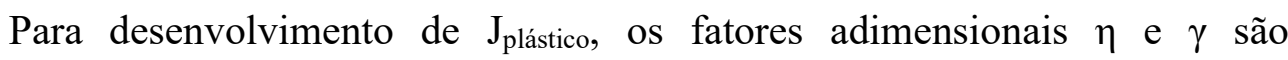
modificados aos apresentados no item 2.2, assumindo os valores do fator $\eta$ derivado de CMOD para amostra SENT, o estudo de Cravero e Ruggieri [52] apresentou que 
este fator diminui minimamente e quase de forma linear para uma faixa de razão a/W entre 0,1 e 0,6 para todos $\mathrm{H} / \mathrm{W}$ estudados. No entanto, o fator $\eta_{\mathrm{CMOD}}$ exibe uma tendência diferente para $\mathrm{a} / \mathrm{W}=0,7$ o qual aumenta ligeiramente para materiais com fator de encruamento moderados a baixo, sendo notório na imagem (a) da Figura 22 , referente a $\mathrm{H} / \mathrm{W}=0,4$. Outra conclusão que pode ser obtida é que quanto maior a razão de a/W menor o valor de $\eta_{\text {CMOD. }}$
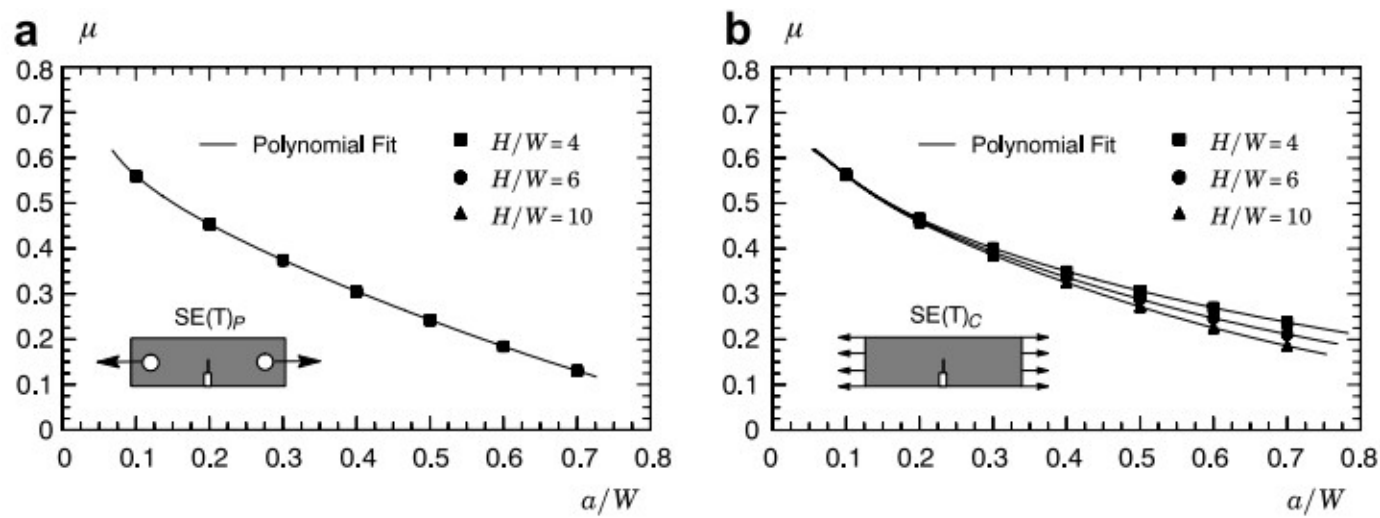

Figura 21 - Variação do compliance normalizado, $\mu$, para diferentes razões de a/W. (a) SENT de fixação por pinos e H/W variados; (b) SENT de fixação por garras e H/W variados. [51]

E a partir deste estudo, foi desenvolvida com base na técnica dos mínimos quadrados perfeitos uma equação de $\eta$, eq. (2.31), para simplificar a aplicabilidade matemática.

$$
\eta_{i}=1,0398-0,6870\left(\frac{\mathrm{a}}{\mathrm{W}}\right)
$$

E o fator de correção $\gamma_{\mathrm{CMOD}}$ da integral-J para crescimento de trinca é então descrita por meio da eq. (2.32).

$$
\gamma_{i}=0,0398-0,6870\left(\frac{a}{W}\right)+\frac{0,6870\left(1-\frac{a}{W}\right)}{1,0398-0,6870\left(\frac{a}{W}\right)}
$$



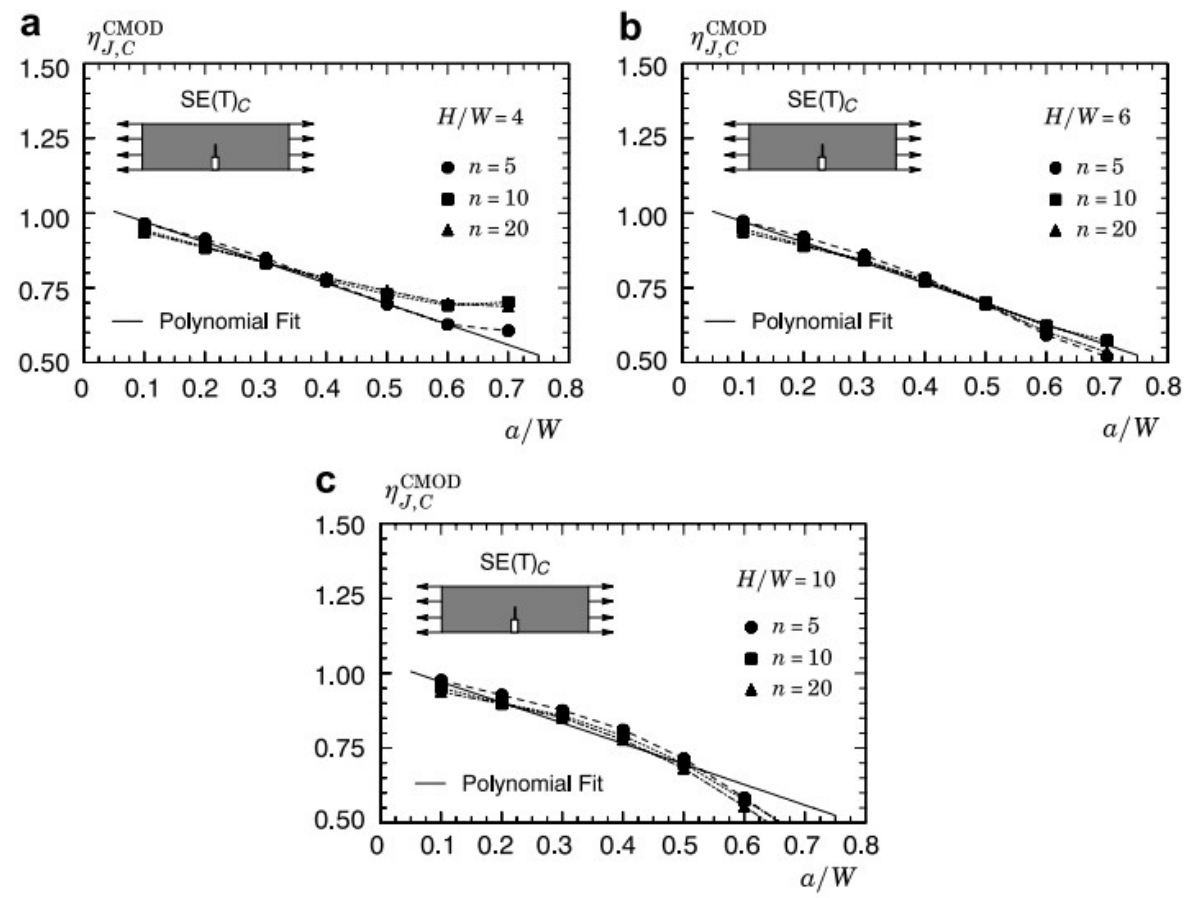

Figura 22 - Variação do fator $\eta$ plástico para diferentes razões a/W derivados de CMOD para corpo de prova SENT. (a) $\mathrm{H} / \mathrm{W}=4$; (b) $\mathrm{H} / \mathrm{W}=6$; e (c) $\mathrm{H} / \mathrm{W}=10$. [51][52] 


\section{MATERIAIS E MÉTODOS}

Neste capítulo é descrito os materiais utilizados para desenvolvimento deste trabalho e os testes de tração para definição das propriedades mecânicas. A metodologia adotada para adquirir resultados no ensaio de tenacidade à fratura também será abordada neste capítulo referindo-se a equações previamente apresentadas no Capítulo 2.

\subsection{Materiais}

Dois materiais metálicos com diferentes razões E/ $\sigma_{Y s}$ para fim de comparação das curvas-R adotando-se corpos de prova do tipo SENT foi aplicada nesta dissertação. Este tipo de geometria, como já mencionado, é geralmente empregada para avaliação da tenacidade à fratura de dutos e tubulações, que são fabricados por materiais da série API com diferentes propriedades mecânicas utilizando como parâmetro de escolha o valor E/бYs que ditam o grau de encruamento do material. No entanto, foi escolhida para esta dissertação os materiais ASTM A36 representando um aço de moderada encruamento $\left(\mathrm{E} / \sigma_{\mathrm{YS}} \approx 615\right.$ e $\left.\mathrm{n}=16\right)$ e o aço DIN 42CrMo4 como baixo encruamento $\left(\mathrm{E} / \sigma_{\mathrm{YS}} \approx 300\right.$ e $\left.\mathrm{n}=30\right)$

O aço ASTM A36, conhecido também como SAE 1020, possui composição química de acordo com a Tabela III [56]. É um aço de baixo carbono classificado como um aço de média resistência mecânica, possuindo boa ductilidade e soldabilidade, características essenciais para aplicação na fabricação de chapas metálicas, eixos, parafusos e na indústria automobilística.

Este material foi obtido através de um fornecedor de materiais metálicos, adquirida uma barra chata com dimensões de 12,5 x 6,35 x $1500 \mathrm{~mm}$ para fabricação das quantidades de amostras requeridas.

Tabela III - Composição química do aço ASTM A 36. [56]

\begin{tabular}{|c|c|c|c|c|c|c|c|c|}
\hline \multicolumn{7}{|c|}{ Composição Química ASTM A 36 } \\
\hline$\% \mathrm{C}$ & $\% \mathrm{Mn}$ & $\% \mathrm{Si}$ & $\% \mathrm{P}$ & $\% \mathrm{~S}$ & $\% \mathrm{Cu}$ & $\% \mathrm{Cr}$ & $\% \mathrm{Ni}$ & $\% \mathrm{Mo}$ \\
\hline 0,15 & 0,55 & 0,12 & 0,011 & 0,023 & 0,10 & 0,06 & 0,04 & 0,01 \\
\hline
\end{tabular}


$\mathrm{O}$ aço 42CrMo4 é um aço normalizado pela DIN e aplicado, geralmente, para beneficiamento do processo e peças industriais como virabrequins, bielas e eixos de automóveis. Suas características principais envolvem a alta temperabilidade. Adequado a aplicações severas de fadiga, abrasão, impacto e tensões a altas temperaturas. Pode ser tratado termicamente após ensaio.

A norma DIN padroniza os materiais de acordo com a propriedade mecânica, assim como a SAE, já a ASTM padroniza conforme composição química.

Tabela IV - Composição química do aço DIN 42CrMo4 [57]

\begin{tabular}{|c|c|c|c|c|c|c|c|c|}
\hline \multicolumn{7}{|c|}{ Composição Química DIN 42CrMo4 } \\
\hline \% C & $\% \mathrm{Mn}$ & $\% \mathrm{Si}$ & $\% \mathrm{P}$ & $\% \mathrm{~S}$ & $\% \mathrm{Cu}$ & $\% \mathrm{Cr}$ & $\% \mathrm{~V}$ & $\% \mathrm{Mo}$ \\
\hline 0,38 & 0,85 & 0,27 & 0,007 & 0,0014 & 0,18 & 0,97 & 0,01 & 0,20 \\
\hline
\end{tabular}

\subsection{Ensaio de Tração}

Para realização do ensaio de tração foi necessário usinar 3 corpos de prova de tração de cada material com geometria cilíndrica, reduzida proporcionalmente a geometria padrão para validação do ensaio. Os corpos de prova foram confeccionados com base na Figura 8 da norma ASTM E8M - 04 (Test Methods for Tension Testing of Metallic Materials) [58] dispondo dimensões conforme representado na Figura 23.

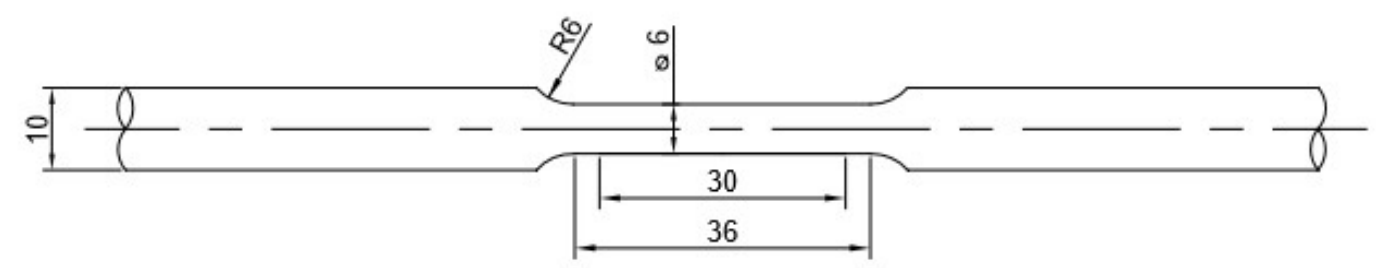

* Dimensões em mm

Figura 23 - Representação esquemática do corpo de prova reduzido para ensaios de tração com seção transversal circular.

As etapas para realização do ensaio de tração foram, primeiramente, realizar a marcação, com o auxílio de um marcador, pontos equidistantes na região útil do corpo de prova, depois prender o corpo de prova pelas extremidades nas garras de fixação da máquina, em seguida acoplar um strain-gage no comprimento útil do 
corpo de prova, como indicado na Figura 24. O strain-gage utilizado tinha capacidade de abertura de $25 \mathrm{~mm}$.

A máquina utilizada neste ensaio foi uma Instron 5500R com capacidade de 10 toneladas que pertence ao laboratório de ensaios mecânicos da Pontifícia Universidade Católica do Rio de Janeiro (PUC-Rio). Dados como comprimento inicial do corpo de prova e diâmetro inicial foram inseridos no software Bluehill e a ajustagem da máquina também foi necessária para que a carga e deformação inicial fossem nulas. Todos os ensaios foram conduzidos a temperatura ambiente, $25^{\circ} \mathrm{C}$, e foram tomadas extrema cautela para que variáveis como velocidade do ensaio não influenciasse no resultado.

Os resultados deste ensaio estão descritos no item 4.1.

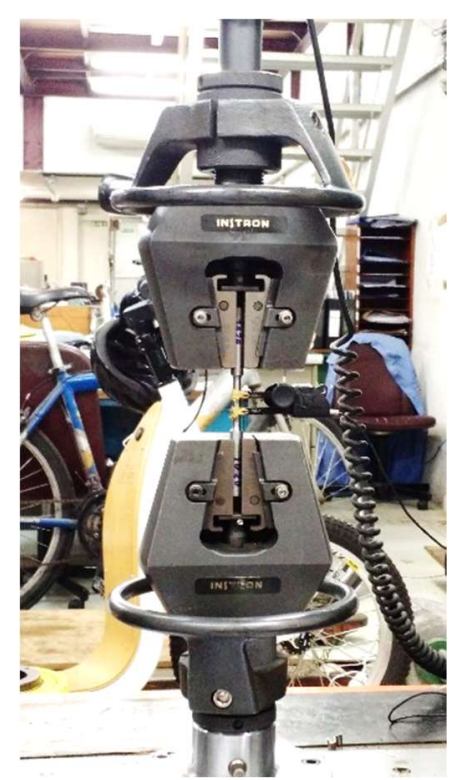

Figura 24 - Modo de fixação do corpo de prova para ensaio de tração

\subsection{Ensaio de Tenacidade à Fratura}

O procedimento utilizado para aquisição dos resultados de tenacidade à fratura foi baseado na obtenção da curva J-R sob aplicação em corpos de prova de geometria SENT de fixação por garras o método compliance.

\subsubsection{Dimensões da geometria SENT}

Como já visto, a grande motivação para o emprego da geometria SENT é pela forte similaridade da tensão na ponta da trinca e campo de deformação que governa 
o processo de fratura em materiais com alta capacidade de deformação plástica. Como o corpo de prova SENT pode ser confeccionado tanto por fixação por pinos como por garras, a dimensão do corpo de prova deverá seguir os requisitos dimensionais pertinentes a geometria escolhida. Sendo assim, a configuração geométrica do corpo de prova SENT adotada nesta pesquisa foi o de fixação por garras com relação de $\mathrm{H} / \mathrm{W}=4 \mathrm{e} \mathrm{W/B}=2,5$, conforme dimensões especificadas no desenho esquemático da Figura 25, para o material DIN 42CrMo4, e para o material ASTM A36 o qual foi inserido o side-groove (item 3.3.3) adotou-se as dimensões apresentadas na Figura 26.

Em adição, foram usinados corpos de prova extras do DIN 42CrMo4 com side-groove, CP_D_0.2C, e do ASTM A36 sem side-groove, CP_A_0.2S, para averiguação da resposta do material na presença do entalhe lateral. Para determinação das dimensões do corpo de prova foi realizado primeiramente um cálculo básico de resistência dos materiais considerando os dados da capacidade máxima da célula da MTS servohidráulica, de $250 \mathrm{kN}$, utilizada inicialmente nos ensaios e que pertence a Universidade Estadual de Ponta Grossa (UEPG), os valores do $\sigma$ Ys e $\sigma_{U}$ material de maior dureza, neste caso o aço DIN 42CrMo4, foram levados em consideração permitindo obter uma área limite máxima dos corpos de prova SENT. Além disso, a região útil do corpo de prova deve possuir um comprimento de 10B e é necessário um acréscimo de 4B em cada extremidade longitudinal do corpo de prova para fixação do corpo de prova na máquina, o comprimento total do corpo de prova equivale a 18B. As dimensões contidas nas Figuras 25 e 26 são representadas na unidade milimétrica.

Um entalhe em uma das extremidades dos corpos de prova SENT também foi confeccionado a fim de representar o defeito nos materiais, a partir deste a trinca tenderá a se propagar. Nesta pesquisa utilizou-se 6 razões a $\mathrm{a}_{0} / \mathrm{W}$ distintas levando a usinagem dos entalhes baseadas nas dimensões dispostas na tabela da Figura 27, as razões $\mathrm{a}_{0} / \mathrm{W}$ aplicadas neste trabalho foram definidas a modo que pudesse ser estudado a influência do tamanho de trinca na resposta do material sendo adotadas razões $\mathrm{a}_{0} / \mathrm{W}$ dispostas nas principais normas de padronização e outras com dimensões fora da norma. 


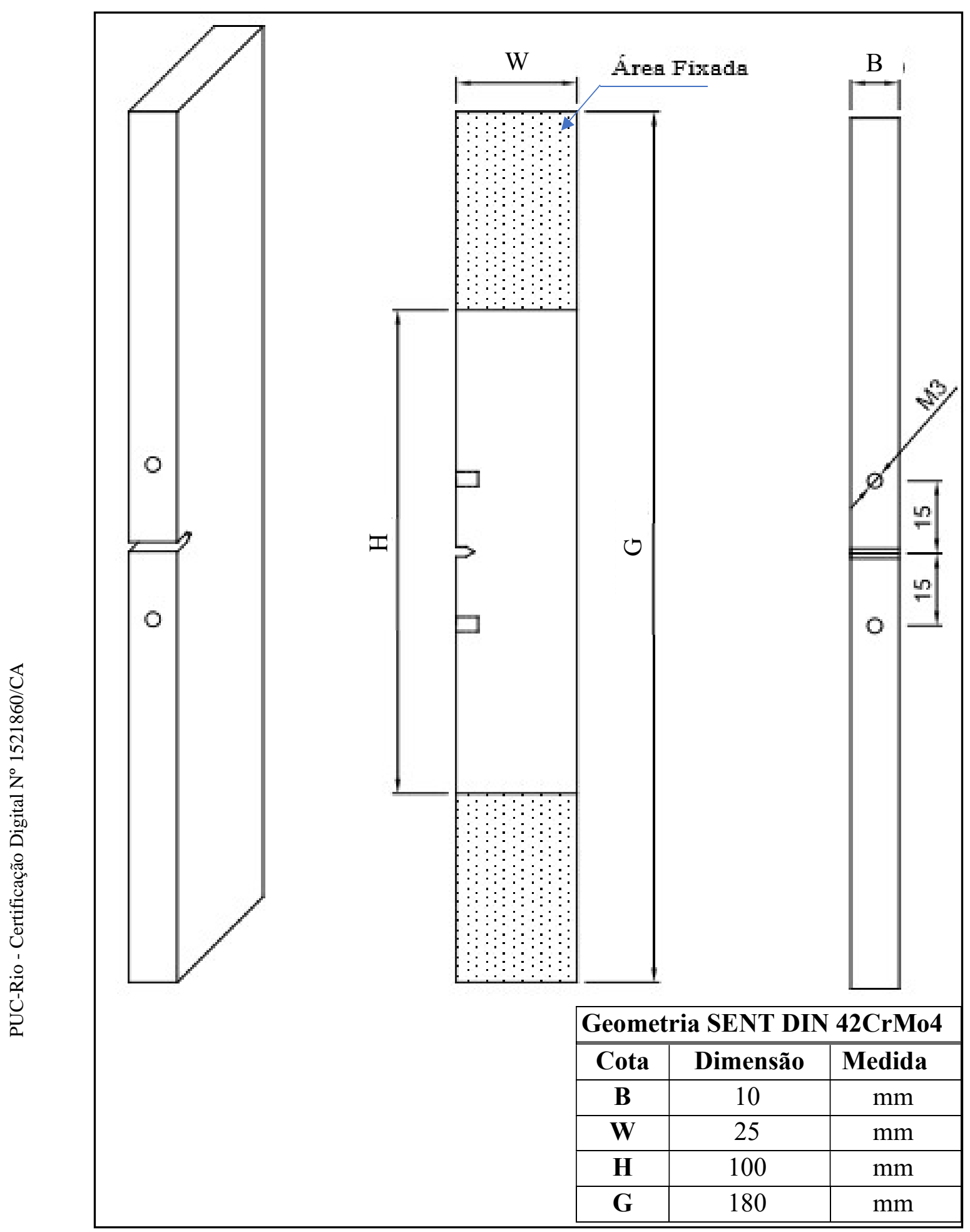

Figura 25 - Representação esquemática dos corpos de prova SENT de fixação por garras para o material DIN 42CrMo4. 


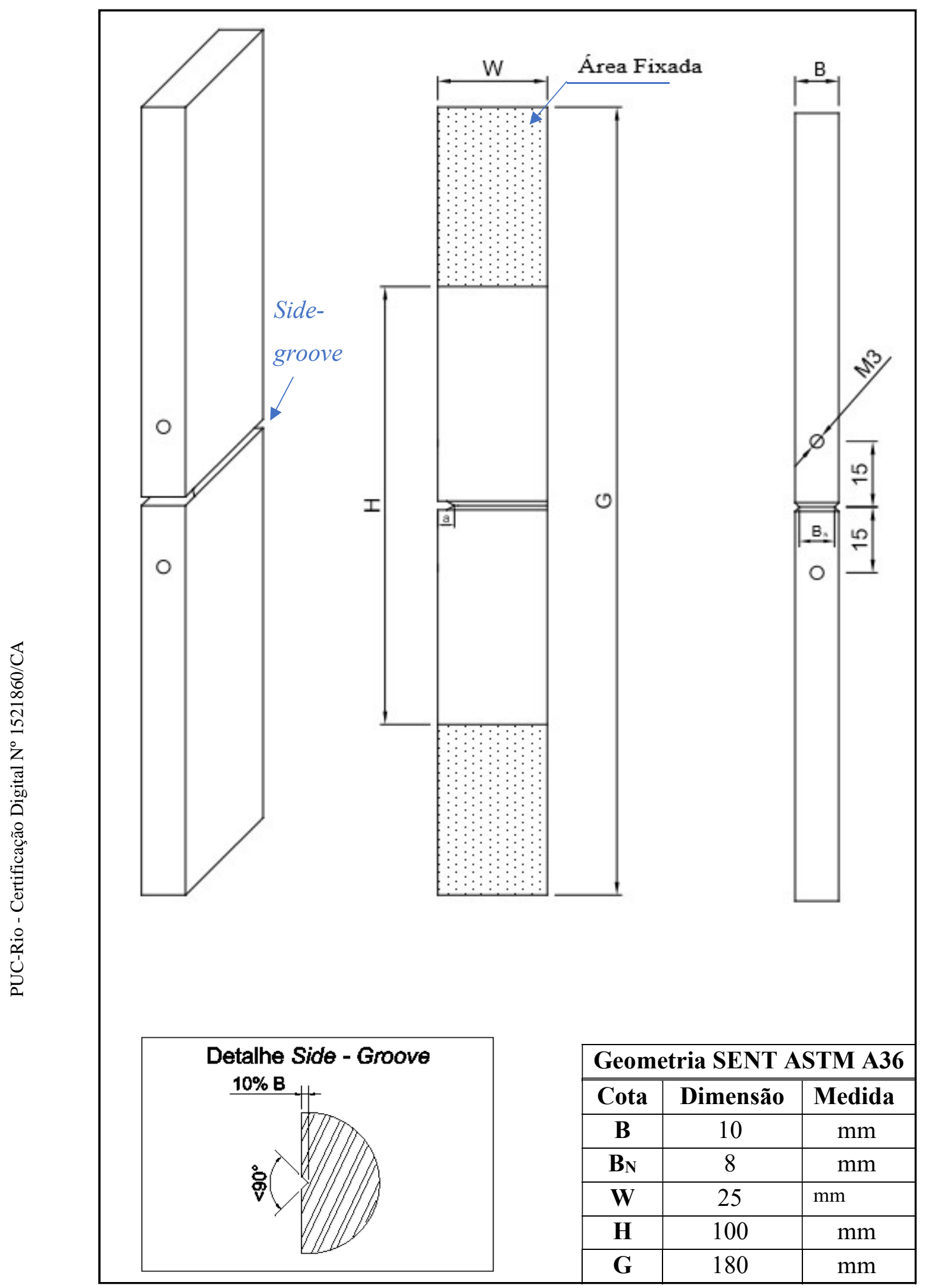

Figura 26 - Representação esquemática dos corpos de prova SENT de fixação por garras para o material ASTM A36 


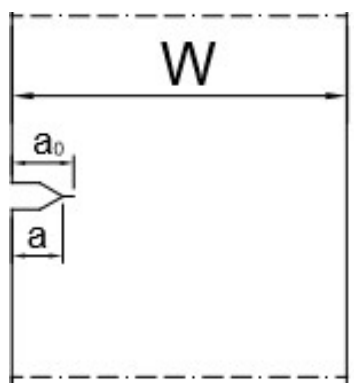

\begin{tabular}{|c|c|c|}
\hline $\mathbf{a}_{\mathbf{0}} / \mathbf{W}$ & $\mathbf{a}(\mathbf{m m})$ & $\mathbf{a}$ (mm) \\
\hline $\mathbf{0 , 2}$ & 3,8 & 5,1 \\
\hline $\mathbf{0 , 3}$ & 6,3 & 7,6 \\
\hline $\mathbf{0 , 4 5}$ & 9,25 & 11,25 \\
\hline $\mathbf{0 , 6}$ & 13 & 15 \\
\hline $\mathbf{0 , 7}$ & 15,5 & 17,5 \\
\hline $\mathbf{0 , 8}$ & 18 & 20 \\
\hline
\end{tabular}

Figura 27 - Esquemático da representação referente ao tamanho da trinca inicial e largura do corpo de prova e suas respectivas dimensões.

Referindo-se ainda a geometria do corpo de prova, é indicado que a altura do entalhe, $\mathrm{N}$, possua uma dimensão menor ou igual a $0,063 \mathrm{~W}$, esquemático apresentado na Figura 28.

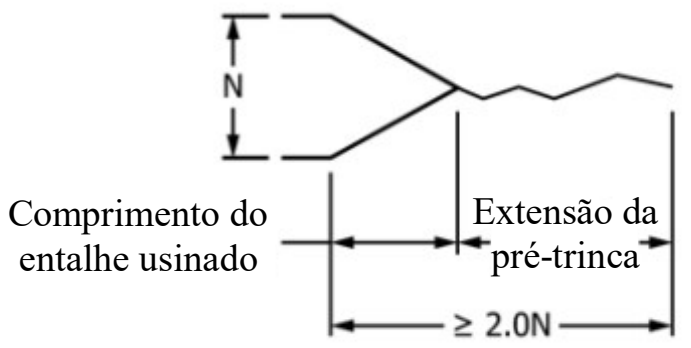

Figura 28 - Detalhe da dimensão do entalhe conforme norma ASTM E1820-17 [1].

\subsubsection{Entalhe de eletroerosão}

Após a etapa de fabricação das amostras SENT e do entalhe pelo processo de usinagem por fresa, realizou-se um entalhe de eletroerosão a fio no final do entalhe usinado para reduzir o raio na ponta do entalhe e facilitar o início da propagação da pré-trinca de fadiga com níveis de fatores de intensidade de tensão baixos. $\mathrm{O}$ princípio deste processo é submeter o material a um desgaste metálico onde a peça e o eletrodo da máquina são colocados submersos em um fluido não condutor de eletricidade, ou seja, dielétrico. O eletrodo geralmente possui polaridade positiva e o material com polaridade negativa. O desgaste ocorre tanto na peça quanto no fio metálico quando ambos desses componentes são aproximados um ao outro e o fluído, antes dielétrico, age como condutor de corrente formando-se uma corrente de íons entre o eletrodo e o material. Sendo assim, partículas metálicas são fundidas pela centelha formada das cargas elétricas. 
O equipamento utilizado para realização do entalhe de eletroerosão, Figura 29a, pertence a PUC-Rio (ITUC).

(a)

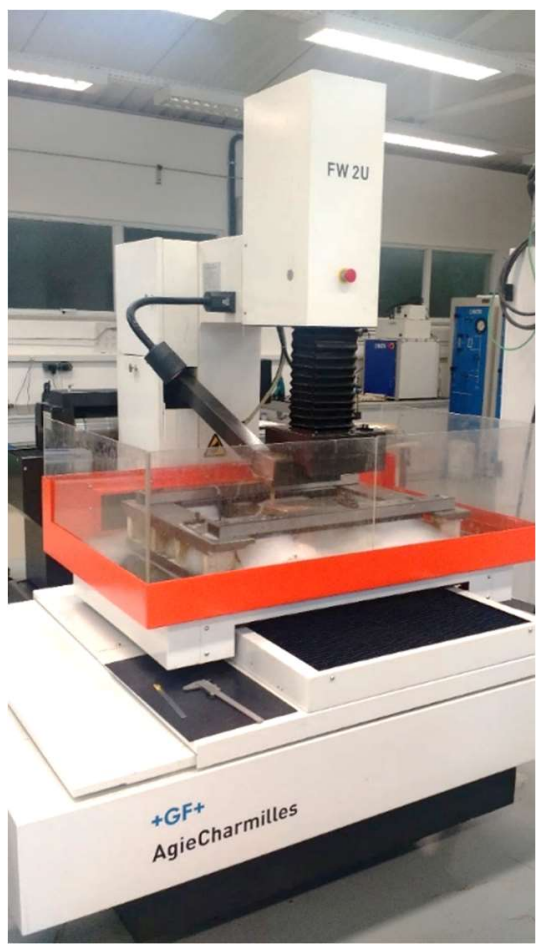

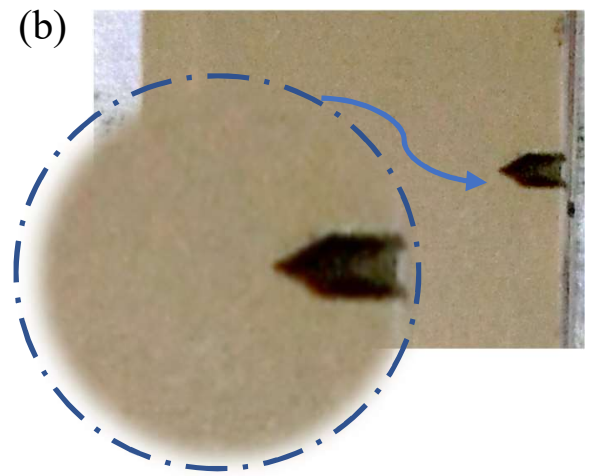

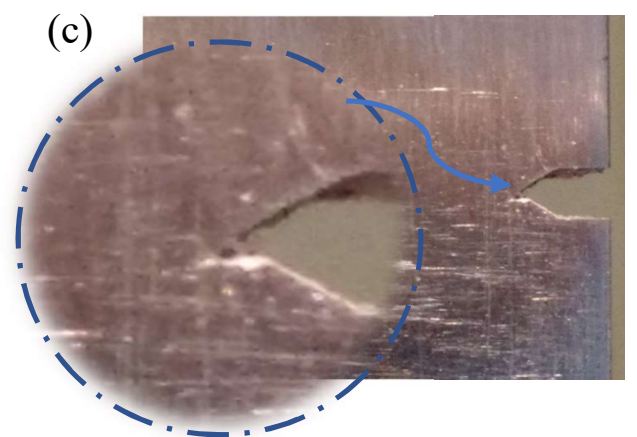

Figura 29 - Equipamento para realização da usinagem por eletroerosão (a); Resolução aproximada da ponta do entalhe usinado sem o entalhe de eletroerosão (b); Resolução aproximada da ponta do entalhe com o entalhe de eletroerosão (c).

\subsubsection{Side-groove ou entalhe lateral}

O side-groove, ou entalhe lateral, mencionado brevemente no item 3.3.1 é recomendado quando o método compliance de determinação indireta do tamanho da trinca incremental é utilizado. O esquemático apresentado na Figura 30 ilustra o efeito desejado com a presença do side-groove no corpo de prova, visualiza-se que o corpo de prova sem o side-groove, Figura 30a, gera uma propagação estável de trinca mais tunelada ou convexa na região central da amostra. Por outro lado, o corpo de prova com side-groove assegura que a propagação homogênea de trinca ocorra, ou seja, sem a presença de tunelamento, minimizando a chance de formação de lábios de cisalhamento nas laterais do corpo de prova, Figura 30b. Além do que, o aparecimento do tunelamento acarretaria a uma possível invalidez na tolerância de $5 \% \mathrm{~B}$ quanto as médias de $\mathrm{a}_{\mathrm{i}} \mathrm{e} \mathrm{a}_{\mathrm{f}}$. Outro requisito da norma é que o ângulo do entalhe lateral seja menor que $90^{\circ}$ e o raio da raiz do entalhe inferior a $0,5 \mathrm{~mm}$. 


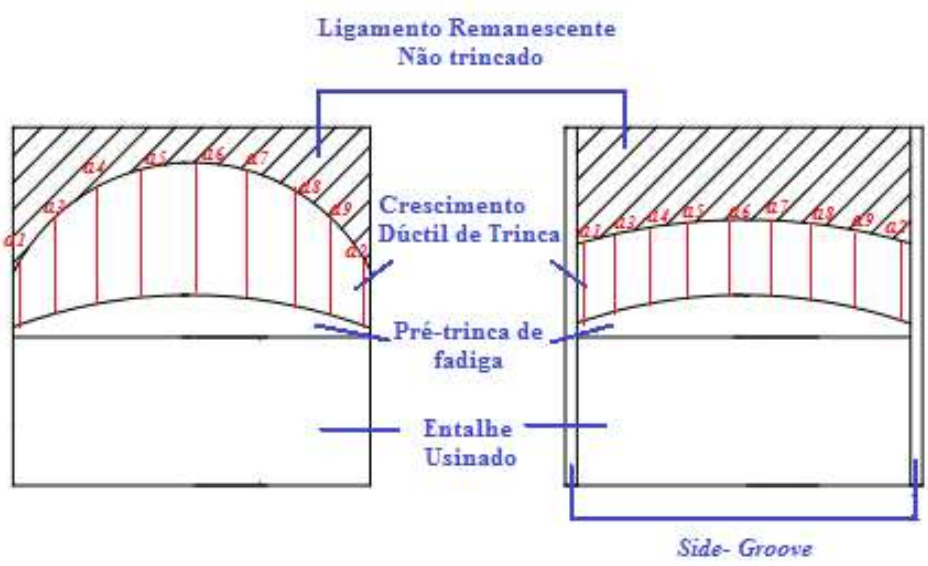

(a)

(b)

Figura 30 - Esquemático ilustrando o efeito do crescimento dúctil de trinca em um corpo de prova sem e com side-groove.

Foi estipulada nesta pesquisa uma redução da espessura total de 0,2B. Apenas os corpos de prova SENT do material ASTM A36 foram submetidos a usinagem dos entalhes laterais. Por ser considerado um material mais dúctil, a expectativa deste material apresentar tunelamento durante a propagação dúctil de trinca era maior em relação ao material DIN 42CrMo4. Como a usinagem dos corpos de prova foram realizadas na PUC-Rio e a pré-trinca de fadiga na UEPG, foi acordado que o side-goove seria confeccionado previamente a pré-trinca de fadiga mesmo não sendo recomendado por norma.

\subsubsection{Classificação dos corpos de prova SENT}

Como foram usados dois materiais com relações de $\mathrm{a}_{0} / \mathrm{W}$ variáveis, os corpos de prova foram identificados sob ambos desses aspectos para facilitar a nomenclatura dos mesmos. A letra "A" é referente a ASTM e "D" referente à DIN. As Tabelas V e VI identificam estas classificações.

Tabela V - Nomenclatura dos corpos de prova SENT do material ASTM A36.

\begin{tabular}{|c|c|c|c|c|}
\hline Identificação & Material & a0/W & H/W & W/B \\
\hline CP_A_0.2 & ASTM A36 & 0,2 & 4 & 2,5 \\
\hline CP_A_0.3 & ASTM A36 & 0,3 & 4 & 2,5 \\
\hline CP_A_0.45 & ASTM A36 & 0,45 & 4 & 2,5 \\
\hline CP_A_0.6 & ASTM A36 & 0,6 & 4 & 2,5 \\
\hline CP_A_0.7 & ASTM A36 & 0,7 & 4 & 2,5 \\
\hline CP_A_0.8 & ASTM A36 & 0,8 & 4 & 2,5 \\
\hline
\end{tabular}


Tabela VI - Nomenclatura dos corpos de prova SENT do material DIN 42CrMo4.

\begin{tabular}{|c|c|c|c|c|}
\hline Identificação & Material & $\mathbf{a 0} / \mathbf{W}$ & $\mathbf{H} / \mathbf{W}$ & W/B \\
\hline CP_D_0.2 & DIN 42CrMo4 & 0,2 & 4 & 2,5 \\
\hline CP_D_0.3 & DIN 42CrMo4 & 0,3 & 4 & 2,5 \\
\hline CP_D_0.45 & DIN 42CrMo4 & 0,45 & 4 & 2,5 \\
\hline CP_D_0.6 & DIN 42CrMo4 & 0,6 & 4 & 2,5 \\
\hline CP_D_0.7 & DIN 42CrMo4 & 0,7 & 4 & 2,5 \\
\hline CP_D_0.8 & DIN 42CrMo4 & 0,8 & 4 & 2,5 \\
\hline
\end{tabular}

\subsubsection{Pré-trinca de fadiga}

Após o procedimento de eletroerosão, todas as amostras SENT foram prétrincadas por fadiga através do ensaio de flexão por três pontos, Figura 31, de acordo como indicado pela norma ASTM E 1820-17 [1]. Neste ensaio o corpo de prova foi apoiado transversalmente a dois apoios fixos e o terceiro apoio provém do atuador que aplica cargas cíclicas na região da linha de centro da amostra.

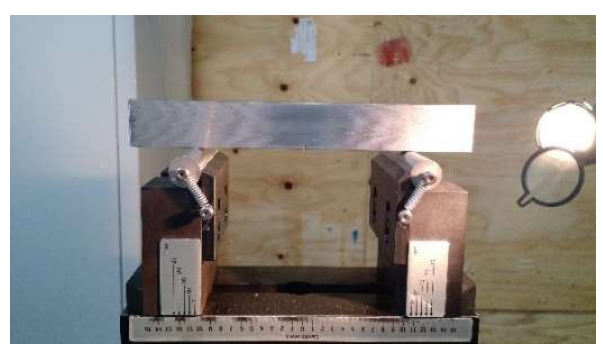

Figura 31 - Disposição do corpo de prova para realização da pré-trinca de fadiga em modo de flexão em três apoios

O ensaio de flexão em três pontos foi realizado na Universidade Estadual de Ponta Grossa (UEPG) no Departamento de Engenharia de Materiais. O sistema utilizado neste procedimento contava com uma máquina da MTS LandMark Servohydraulic Test System de capacidade de $333 \mathrm{kN}$ para carregamentos monotônicos, $250 \mathrm{kN}$ para carregamentos cíclicos e pressão máxima equivalente a $69 \mathrm{MPa}$ (10000 psi), uma bomba hidráulica MTS SilentFlo HPU para manter a frequência ideal para realização do ensaio e um Chiller de refrigeração da MECALOR/UMAG que tem a finalidade de manter o equilíbrio térmico no sistema. Esses equipamentos se encontram apresentados na Figura 32 (a) a (c). 


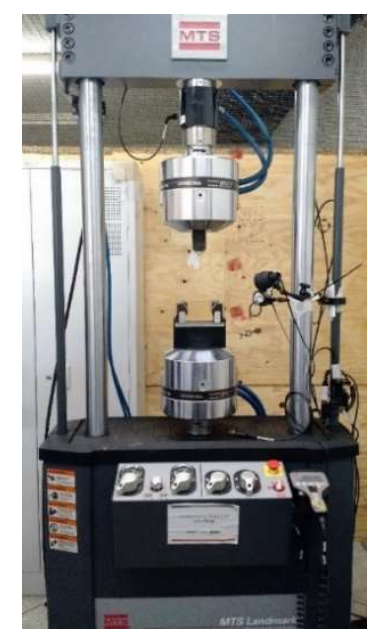

(a)

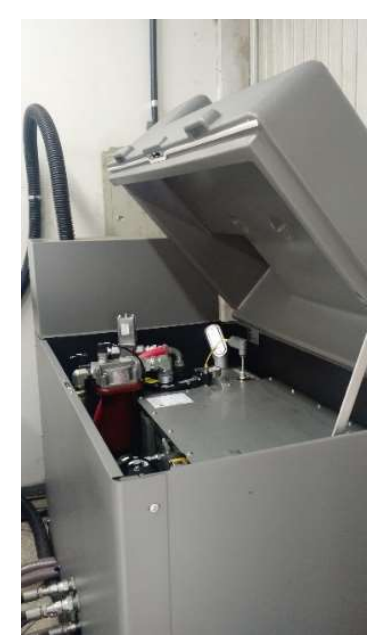

(b)

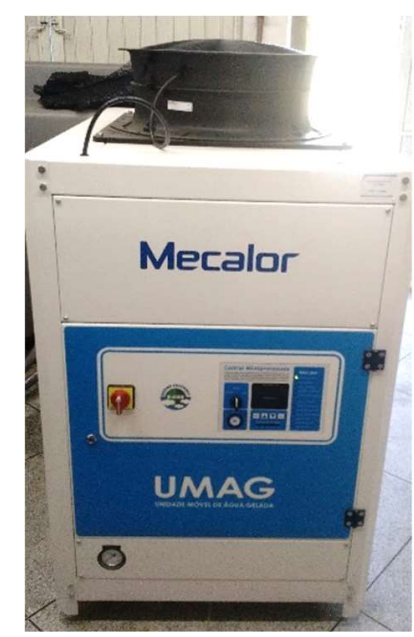

(c)

Figura 31 - Equipamentos do sistema: (a) Máquina MTS servohidráulica; (b) Bomba hidráulica MTS SilentFlo HPU e (c) Chiller de refrigeração Mecalor.

A equação para determinação da carga máxima de fadiga, $\mathrm{P}_{\mathrm{m}}$, varia conforme característica geométrica do corpo de prova, sendo a eq. $(3,1)$ direcionada a corpo de prova de geometria SENT, adotando $\mathrm{R}=0,1$, razão da carga máxima e mínima aplicada em um ciclo, para determinação da carga recomendada mínima de fadiga. O desenho esquemático do entalhe foi apresentado anteriormente no item 3.3.1 na Figura 28.

$$
\mathrm{P}_{\mathrm{m}}=\frac{0,5 \times \mathrm{B} \times \mathrm{b}_{0}^{2} \times \sigma_{\mathrm{y}}}{\mathrm{S}}
$$

Sendo:

$$
\sigma_{\mathrm{y}}=\frac{\sigma_{\mathrm{YS}}+\sigma_{\mathrm{TS}}}{2}
$$

Com base na norma ASTM E1820-17 [1], a extensão da pré-trinca de fadiga deve ser o maior valor resultante entre $0,5 \mathrm{~N}$ ou $0,25 \mathrm{~mm}$, e a soma do entalhe usinado com a extensão da pré-trinca de fadiga deve ser um valor superior ou igual a $2 \mathrm{~N}$. Sob estas exigências, estipulou-se uma dimensão de $1,2 \mathrm{~mm}$ de extensão de pré-trinca para os corpos de prova com razão de $\mathrm{a}_{0} / \mathrm{W}=0,2$ e 0,3 , para as demais razões a pré-trinca foi projetada para ter uma dimensão igual a 2,0 $\mathrm{mm}$. A Tabela 7 indica estas informações e os valores iniciais desejados dos entalhes, a $a_{0}$ O acompanhamento da propagação da pré-trinca foi realizado com o auxílio de uma lupa e holofotes telescópicos iluminando a região a frente da ponta da trinca. Como 
a usinagem do side-groove nos corpos de prova ASTM A36 foi feita antes da prétrinca de fadiga foi preciso colocar líquido penetrante no entalhe lateral para tentar facilitar a visualização da extensão da pré-trinca, por este motivo erros na identificação da extensão da pré-trinca pode vir a ser encontrado.

Tabela VII - Tamanho da pré-trinca estimada para diferentes tamanhos de entalhes

\begin{tabular}{|c|c|c|c|}
\hline $\mathrm{a}_{0} / \mathrm{W}$ & Entalhe usinado $(\mathrm{mm})$ & Extensão da pré-trinca $(\mathrm{mm})$ & $\mathrm{a}_{0}(\mathrm{~mm})$ \\
\hline $\mathbf{0 , 2}$ & 3,8 & 1,2 & 5 \\
\hline $\mathbf{0 , 3}$ & 6,3 & 1,2 & 7,5 \\
\hline $\mathbf{0 , 4 5}$ & 9,25 & 2,0 & 11,25 \\
\hline $\mathbf{0 , 6}$ & 13 & 2,0 & 15 \\
\hline $\mathbf{0 , 7}$ & 15,5 & 2,0 & 17,5 \\
\hline $\mathbf{0 , 8}$ & 18 & 2,0 & 20 \\
\hline
\end{tabular}

\subsubsection{Procedimento do ensaio}

Uma parte da metodologia adotada para o ensaio e processamento de dados foi desenvolvida com base no trabalho orientado por Waldeck [26] em 2009, que desenvolveu uma pesquisa sobre Avaliação da tenacidade à fratura de aço API $5 \mathrm{~L}$ X70 utilizado na fabricação de dutos transportadores de gás e petróleo realizada na Universidade de São Paulo em São Carlos, SP. [57]. Em vista da disponibilidade e imprevistos ocorridos durante a realização deste trabalho, uma parte dos ensaios de tenacidade à fratura foi realizado na UEPG e outra na PUC-Rio. As máquinas de ambos os laboratórios são distintas, sendo a da UEPG já descrita previamente no item 3.3.5, e a máquina do laboratório de ensaios mecânicos da PUC-Rio utilizada foi uma Instron servohidráulica com capacidade de $100 \mathrm{kN}$, Figura 33, taxa de $0,5 \mathrm{kN} / \mathrm{s}$ com um software limitado que não permite a inserção de dados em apenas um arquivo, sendo necessário a separação dos descarregamentos parciais em blocos com 5 incrementos distintos no valor desejada da carga aplicada, além disso, para determinação do CMOD foi requerido uma equivalência entre deformação $(\mathrm{mm} / \mathrm{mm})$ e CMOD em cada ensaio. Tal equivalência foi determinada por intermédio de medidas de 0,25, 0,5,1 e 1,5 mm colocadas no instrumento de medição e averiguando quanto esta medida equivalia na coluna de deformação do software para ser anotada a relação. Este procedimento pode influenciar negativamente nos resultados já que a técnica compliance exige equipamentos 
muito bem aferidos e com excelente precisão para aquisição e processamento de dados.

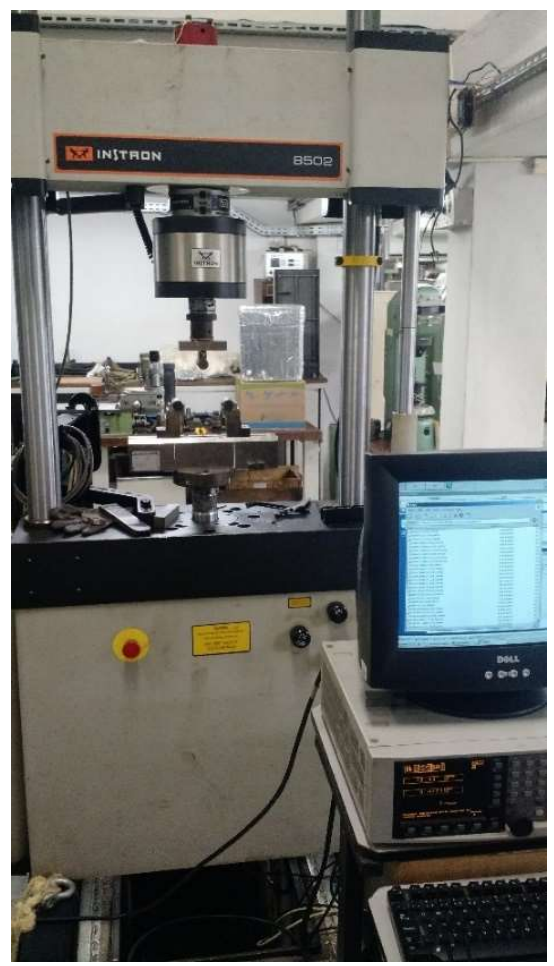

Figura 33 - Segunda máquina utilizada para desenvolvimento do ensaio de tenacidade à fratura.

Inicialmente foi preciso realizar o ajuste das condições elásticas da máquina em relação a rigidez de cada material através do sistema analógico PID que realiza a leitura dos sinais do material quanto a rigidez da máquina. Em seguida o corpo de prova foi fixado a máquina e foram inseridos os dados de carga previamente calculadas. Uma parte do ensaio foi conduzido com base na norma ASTM E182017 [1] no entanto como a geometria do corpo de prova não é padronizada, é compreensível e necessário adotar medidas para tentar alcançar resultados mais satisfatório. A princípio foi planejado que os corpos de prova fossem carregados em uma faixa de carga tal qual o tempo que o ensaio leva para alcançar a força $\mathrm{Pm}$ esteja entre 0,3 e 3 minutos e o tempo para realizar as sequencias de descarregamentos e carregamentos para determinação acurada do tamanho de trinca não ultrapasse 10 minutos. A faixa de carga mencionada anteriormente deve possuir um valor de 0,5 a 1,0 vezes a carga máxima adotada para pré-trinca de fadiga, Pm, para que o compliance seja mensurado e o tamanho da trinca original, a determinado. O desenvolvimento dos ensaios foi conduzido exclusivamente por controle de carga. Sendo assim, foi estipulado para o primeiro descarregamento 
ocorreria quando a carga atingisse um valor equivalente a 55\% Pm e para os demais incrementos seriam acrescidos $2 \%$ da carga máxima absoluta até ser alcançado o valor de $100 \%$ Pm. Depois desta etapa, os incrementos de cargas foram ampliados para $25 \%$ permitindo atingir uma quantidade média de 20 incrementos por corpo de prova.

Complementando esta informação, foi determinado também que para cada ponto de incremento, mais de uma rampa de descarregamento e carregamento seria realizada para desenvolvimento do método, e uma média dos registros dos valores de CMOD e da carga deve ser efetuada para encontrar o valor do compliance no incremento analisado.

\subsubsection{Processamento de dados}

Os pontos levados em consideração para determinação dos dados iniciais para desenvolvimento dos cálculos estão detalhados na Figura 34 e são aplicadas as eq. (3.3) e eq. (3.4) para resolução da média de cada incremento. Os valores registrados com sub índices 0 caracteriza o máximo valor de carga e CMOD antes de ocorrer a primeira rampa de descarregamento parcial, prosseguindo para um valor mínimo de descarregamento igual a $15 \%$ do valor de carga no ponto 0 , correspondendo ao registro com sub índice 1. Esta faixa de descarregamento foi aplicada para o ensaio de todos os corpos de prova. Após atingir o menor valor de carga, o ensaio segue para o ponto 2, que constitui um valor próximo ao valor máximo inicial, descarregando novamente até ao ponto 3, referindo-se a mais um valor mínimo, sendo conduzido em seguida até o ponto 4, significando o fim das rampas e do ciclo do ponto incremental analisado. Posteriormente, um próximo valor de carga máxima é efetuado, indicando o valor máximo do incremento seguinte e então a interpretação dos dados registrados é realizado conforme citado anteriormente. No final do último descarregamento a carga deve ser levada até zero garantindo nenhum aumento adicional no deslocamento.

$$
\begin{gathered}
\Delta_{\mathrm{CMOD}}=\frac{\left(\mathrm{CMOD}_{2}-\mathrm{CMOD}_{1}\right)+\left(\mathrm{CMOD}_{4}-\mathrm{CMOD}_{3}\right)}{2} \\
\Delta_{\mathrm{P}}=\frac{\left(\mathrm{P}_{2}-\mathrm{P}_{1}\right)+\left(\mathrm{P}_{4}-\mathrm{P}_{3}\right)}{2}
\end{gathered}
$$




$$
\mathrm{C}_{(\mathrm{i})}=\frac{\Delta_{\mathrm{CMOD}}}{\Delta_{\mathrm{P}}}
$$

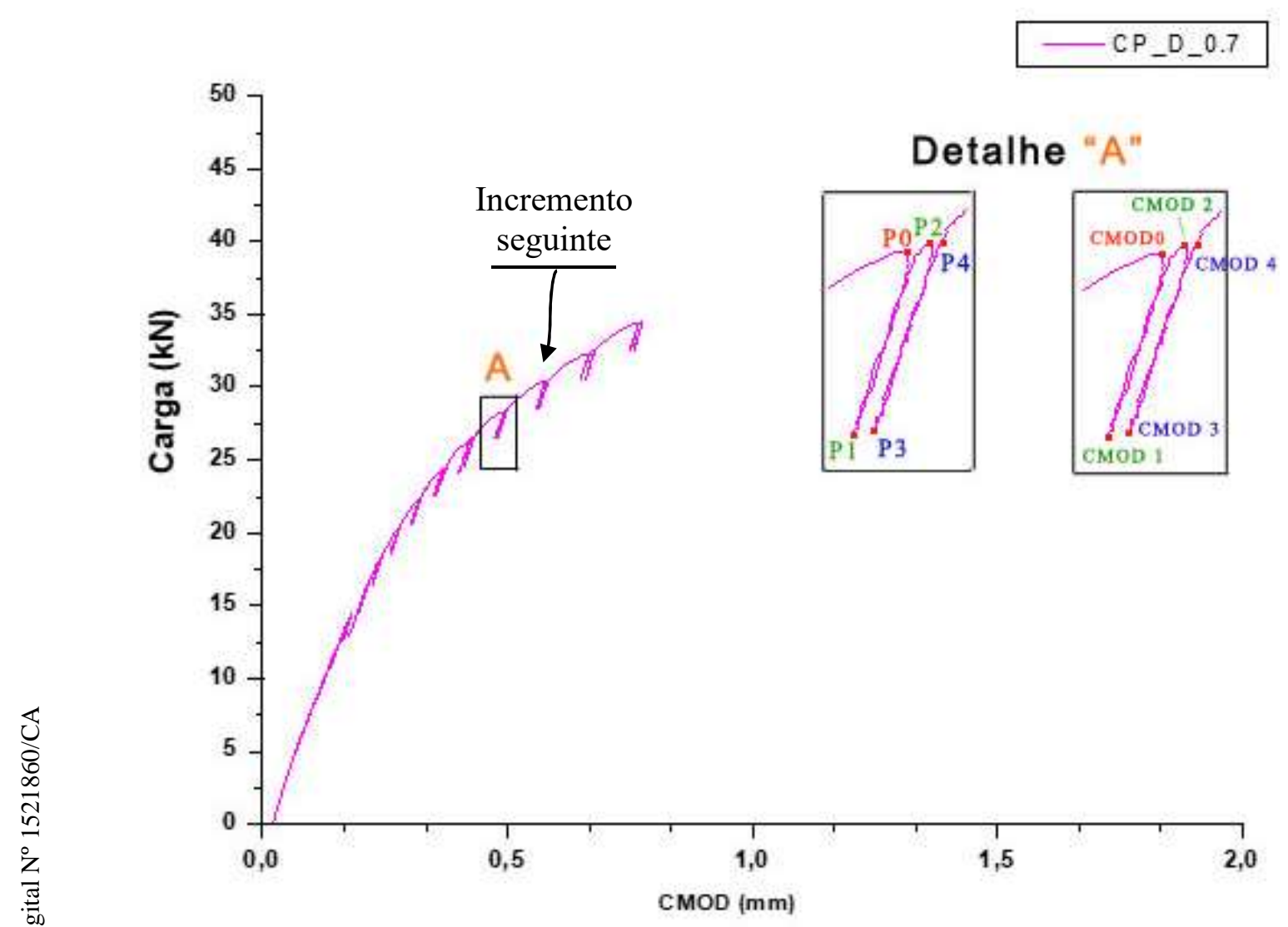

Figura 34 - Detalhamento dos pontos adotados para início do desenvolvimento matemático do método compliance

Após encontrado o valor do compliance mensurado em cada ponto, a aquisição de dados segue para determinação tamanho de trinca em cada incremento. Dessa forma, a primeira equação aplicada é a eq. (3.4) e subsequentemente o resultado das eq. (2.25) e eq. (2.27) são encontrados. Os fatores $\beta_{\mathrm{n}}$ da eq. (2.27) adotados nesta pesquisa estão dispostos na Tabela VIII definidos por Cravero e Ruggieri [48] para corpos de prova SENT de fixação por garras e H/W igual a 4.

Tabela VIII - Coeficientes $\beta_{\mathrm{n}}$ para SENT de fixação por garras [51]

\begin{tabular}{|c|c|c|c|c|c|}
\hline $\boldsymbol{\beta}_{\mathbf{0}}$ & $\boldsymbol{\beta}_{\mathbf{1}}$ & $\boldsymbol{\beta}_{\mathbf{2}}$ & $\boldsymbol{\beta}_{\mathbf{3}}$ & $\boldsymbol{\beta}_{\mathbf{4}}$ & $\boldsymbol{\beta}_{\mathbf{5}}$ \\
\hline 1,6485 & $-9,1005$ & 33,0250 & $-78,4670$ & 97,3440 & $-47,2270$ \\
\hline
\end{tabular}

Após a determinação de $\mathrm{a}_{\mathrm{i}} / \mathrm{W}$ é possível estipular o tamanho de trinca para cada instante i a partir da multiplicação deste valor por W. O resultado dos três primeiros tamanhos de trincas incrementais apurado pela técnica do compliance é 
utilizado para realização de uma média desses valores para encontrar o tamanho de trinca previsto inicial por intermédio do método, $\mathrm{a}_{0 \mathrm{q}}$. Com os valores de $\mathrm{a}_{(\mathrm{i})}$ definidos, é possível determinar a medida do ligamento remanescente em cada instante, $\mathrm{b}_{(\mathrm{i})}$. Assim como o valor de $\mathrm{a}_{(\mathrm{i}-1)} / \mathrm{W}$ é utilizado para determinar os fatores $\eta$ e $\gamma$, das eq. (2.31) e (2.32).

Determinar o $\mathrm{V}_{\mathrm{pl}(\mathrm{i})}$ é o próximo passo do desenvolvimento matemático do método compliance, e então a utilização da eq. (2.24) é requerida, sendo inseridos como $\mathrm{P}_{(\mathrm{i})}$ e $\mathrm{v}_{(\mathrm{i})}$ o valor da carga e de CMOD no ponto 4, respectivamente. Subsequente ao cálculo de $\mathrm{vpl(i)}$, o cálculo da área plástica incremental é realizado adotando a eq. (2.23).

A apuração de $\mathrm{J}_{\text {el(i) }}$ é efetuado adotando a eq. (2.12) na qual o fator $\mathrm{K}_{(\mathrm{i})}$ é desenvolvido a partir da eq. (2.29) adotando a eq. (3.5) na substituição em $\mathrm{f}\left(\mathrm{a}_{(\mathrm{i})} / \mathrm{W}\right)$.

$$
\begin{aligned}
& \mathrm{f}\left(\frac{\mathrm{a}_{\mathrm{i}}}{\mathrm{W}}\right)=0,2565+4,4604\left(\frac{\mathrm{a}}{\mathrm{W}}\right)-7,0538\left(\frac{\mathrm{a}}{\mathrm{W}}\right)^{2}+18,6928\left(\frac{\mathrm{a}}{\mathrm{W}}\right)^{3}-19,4703\left(\frac{\mathrm{a}}{\mathrm{W}}\right)^{4} \\
& +9,2523\left(\frac{\mathrm{a}}{\mathrm{W}}\right)^{5}
\end{aligned}
$$

Com todas as variáveis necessárias para se determinar $\mathrm{J}_{\mathrm{pl}(\mathrm{i})}$ já encontradas, a eq. (2.20) é usada. Permitindo a seguir que o somatório de $\mathrm{J}_{\mathrm{el}(\mathrm{i})}$ e $\mathrm{J}_{\mathrm{pl}(\mathrm{i})}$ para se encontrar $\mathrm{J}_{\text {total(i) }}$ seja feito conforme disposto na eq. (2.11). Obtendo-se o valor total de $\mathrm{J}$ e determinando o incremento de trinca em cada ponto de descarregamento, aplicando a eq. (3.6), traça-se a curva de resistência J-R.

$$
\Delta \mathrm{a}_{(\mathrm{i})}=\left(\mathrm{a}_{\mathrm{i}}-\mathrm{a}_{(\mathrm{i}-1)}\right)+\Delta \mathrm{a}_{(\mathrm{i}-1)}
$$

Finalizado o desenvolvimento do método indireto para determinação do tamanho de trinca incremental e levantamento da curva J-R, uma medição visual da propagação dúctil de trinca é indicada para que possa ser comparado o valor medido com o valor previsto calculado. Sendo assim, é proposto que o corpo de prova após ter sido ensaiado seja levado ao forno a uma temperatura equivalente a $300^{\circ} \mathrm{C}$ por cerca de 30 minutos com o objetivo de evidenciar as regiões formadas no decorrer do ensaio, permitindo a identificação do início e fim da propagação de trinca dúctil. Em seguida, o corpo de prova é submetido ao nitrogênio líquido o que o torna frágil 
favorecendo a ruptura total do corpo de prova. Através da metodologia de cálculo dos 9 pontos equidistantes, eq. (3.7), é possível, com auxílio de um microscópio ou programas computacionais, como o ImageJ, realizar a medição a frente da prétrinca de fadiga e a frente da região que demarca a extensão estável de trinca.

$$
\mathrm{a}_{\mathrm{M}(\mathrm{i}) \text { ou } \mathrm{p}}=\frac{1}{8}\left[\frac{\left(\mathrm{a}_{1}+\mathrm{a}_{9}\right)}{2}+\sum_{\mathrm{i}=2}^{8} \mathrm{a}_{\mathrm{i}}\right]
$$

E o cálculo da extensão de trinca física é realizado pela seguinte eq. (3.8).

$$
\Delta \mathrm{a}_{\mathrm{p}}=\mathrm{a}_{\mathrm{p}}-\mathrm{a}_{\mathrm{M}(\mathrm{i})}
$$

A diferença da extensão de trinca inicial prevista com a extensão de trinca inicial medida não deve ultrapassar $0,15 \Delta \mathrm{a}_{\mathrm{p}}$ para extensões dúcteis de trinca menores que $0,2 b_{0}$ e não deve ultrapassar $0,03 b_{0}$ para extensões maiores.

Para determinação de $\mathrm{J}_{\mathrm{IC}}$ foi adotada a interseção da curva com a linha de construção, pois a linha de construção refere-se ao início do embotamento do material, enquanto que se adotasse a linha $0,2 \mathrm{~mm}$ offset entraria em uma orientação da norma e não uma resposta física do corpo de prova. 


\section{RESULTADOS E DISCUSSÃO}

Neste capítulo serão apresentados os resultados das propriedades mecânicas adquiridas através do ensaio de tração e os dos corpos de prova SENT adotados no o ensaio de tenacidade à fratura que possibilitaram aquisição de dados e registros experimentais.

\subsection{Ensaio de Tração}

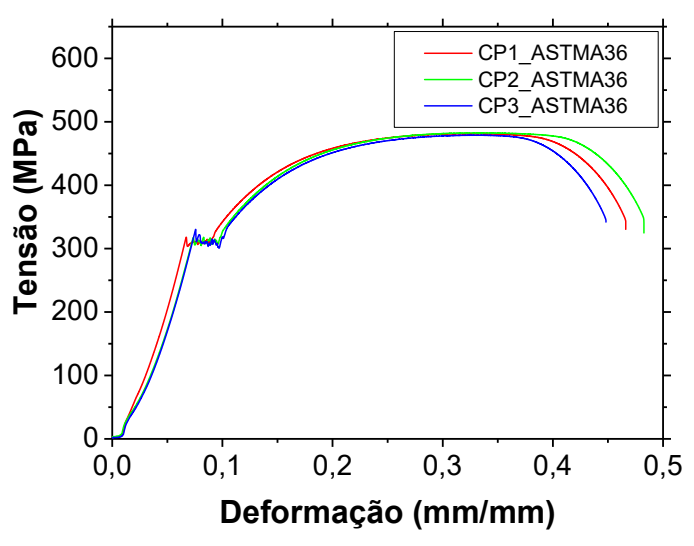

(a)

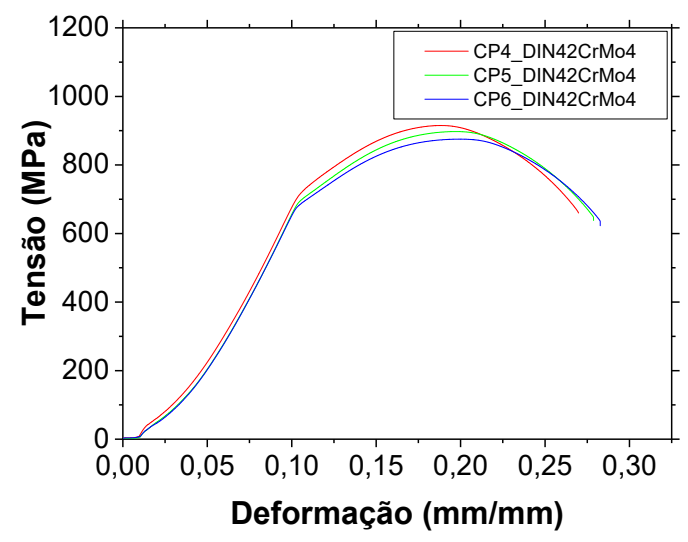

(b)

Gráfico 1 - Tensão x deformação dos materiais. (a) Aço ASTM A36 e (b) DIN 42CrMo4

Tabela IX - Resultado do ensaio de tração para os aços ASTM A36 e DIN 42CrMo4

\begin{tabular}{|l|c|c|c|c|c|c|}
\hline \multicolumn{1}{|c|}{ Material } & \multicolumn{3}{c|}{ ASTM A36 } & \multicolumn{3}{c|}{ DIN 42CrMo4 } \\
\hline Dados Amostra & CP1 & CP2 & CP3 & CP4 & CP5 & CP6 \\
\hline$\varnothing_{\mathrm{f}}(\mathrm{mm})$ & 3,4 & 3,5 & 3,65 & 3,1 & 3,9 & 4,05 \\
\hline $\mathrm{L}_{\mathrm{f}}(\mathrm{mm})$ & 40,6 & 40,6 & 39,7 & 34,75 & 34,25 & 34,45 \\
\hline $\boldsymbol{\sigma}_{\mathbf{Y S}}(\mathrm{MPa})$ & 315 & 316 & 316 & 740 & 720 & 724 \\
\hline $\boldsymbol{\sigma}_{\mathbf{T S}}(\mathrm{MPa})$ & 481,2 & 482,6 & 478,9 & 915,16 & 900 & 875,38 \\
\hline Alongamento (\%) & 35,33 & 35,33 & 32,33 & 15,83 & 14,17 & 14,83 \\
\hline Redução de área (\%) & 67,89 & 65,97 & 62,99 & 57,75 & 54,44 & 55,56 \\
\hline
\end{tabular}

Os resultados dos ensaios de tração estão ilustrados nos Gráficos 1a e 1b, observa-se que a curva tensão deformação dos aços ASTM A36 e DIN 42CrMo4 quase não apresentaram dispersão, resultados dispostos na Tabela IX. A média dos 
valores de limite de escoamento e limite de resistência mecânica foi realizada para aplica-los em ensaios subsequentes, sendo definido para o aço ASTM A36 o valor de $\sigma_{\mathrm{YS}}=316 \mathrm{MPa}$ e de $\sigma_{\mathrm{TS}}=481 \mathrm{MPa}$ e para o DIN $42 \mathrm{CrMo} 4 \sigma_{\mathrm{YS}}=728 \mathrm{MPa} \mathrm{e}$ $\sigma_{\mathrm{TS}}=897 \mathrm{MPa}$. O valor adotado para o módulo de elasticidade, E, é de $207 \mathrm{GPa}$.

\subsection{Pré-trinca de fadiga}

As cargas máximas aplicadas para nucleação da pré-trinca de fadiga estão detalhadas na Tabela X. Admitindo-se $\mathrm{R}=0,1$.

Tabela X - Valores de cargas máximas aplicadas para realização da pré-trinca de fadiga

\begin{tabular}{|c|c|c|}
\hline & ASTM A36 & DIN 42CrMo4 \\
\hline Razão ao/W & $\mathbf{P}_{\mathbf{m}} \mathbf{( N )}$ & $\mathbf{P}_{\mathbf{m}} \mathbf{( N )}$ \\
\hline 0,2 & 7970 & 16250 \\
\hline 0,3 & 6102,03 & 12441,4 \\
\hline 0,45 & 3767,07 & 7680,66 \\
\hline 0,6 & 1992,5 & 4062,5 \\
\hline 0,7 & 1120,78 & 2285,2 \\
\hline 0,8 & 498,25 & 1015,6 \\
\hline
\end{tabular}

No final de todos os ensaios de tenacidade a fratura foi permissível mensurar pelo método dos nove pontos o valor alcançado da pré-trinca de fadiga, este procedimento se faz necessário a fim de garantir que nenhuma das nove medições físicas do tamanho inicial difiram mais que 0,05B da média de $\mathrm{a}_{0}$. Nas Figuras 3540 são comprovadas as medidas encontradas, sendo as mesmas dispostos na Tabela X. Verificou-se então que as dimensões da pré-trinca de fadiga ultrapassaram os tamanhos pré-estimados prescrito anteriormente na Tabela 7 no item 3.3.5. Isto acarretou a tamanhos de entalhes iniciais maiores, em média 7\%, consequentemente modificando as razões $\mathrm{a}_{0} / \mathrm{W}$ para a $\mathrm{M(i)} / \mathrm{W}$. Novas razões apresentadas na Tabela XI. 


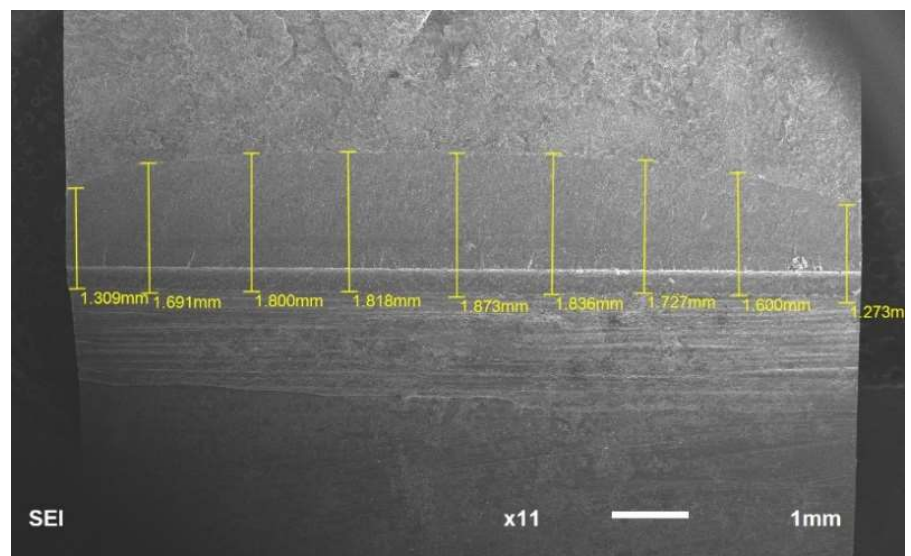

Figura 35 - Medição do tamanho médio real de trinca inicial do CP_D_0.2.

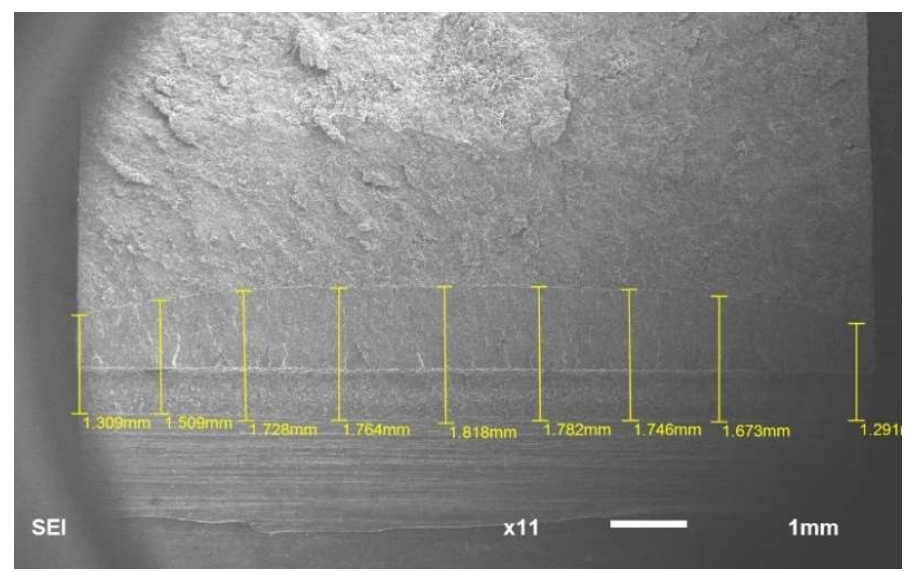

Figura 36- Medição do tamanho médio real de trinca inicial do CP_D_0.3.

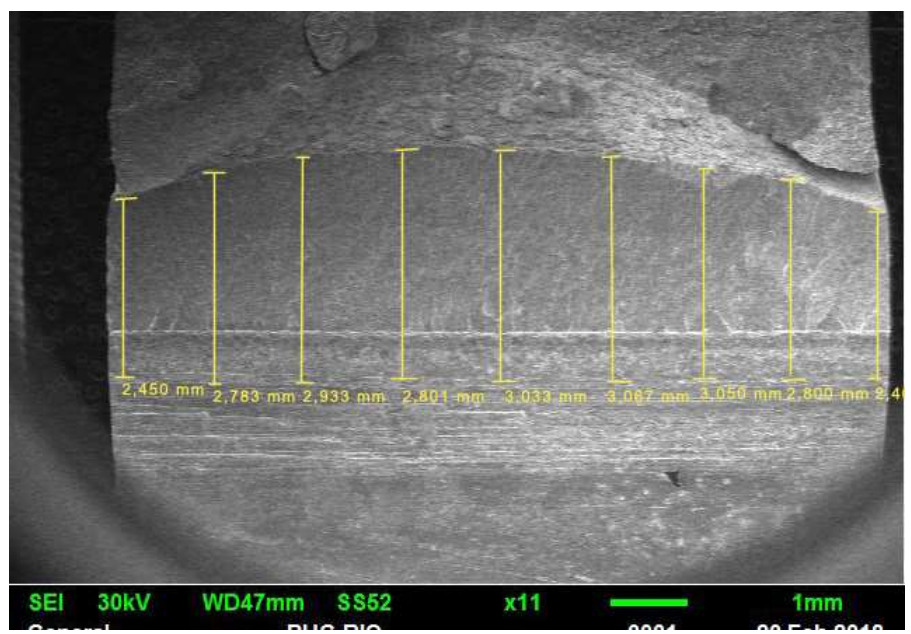

Figura 37 - Medição do tamanho médio real de trinca inicial do CP_D_0.45. 


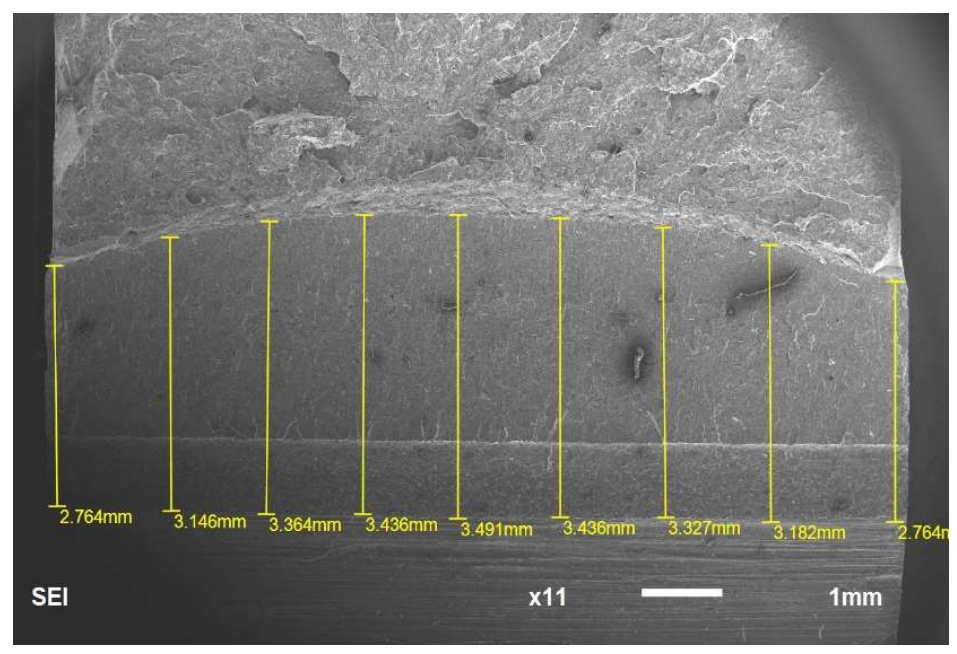

Figura 38 - Medição do tamanho médio real de trinca inicial do CP_D_0.6.11x

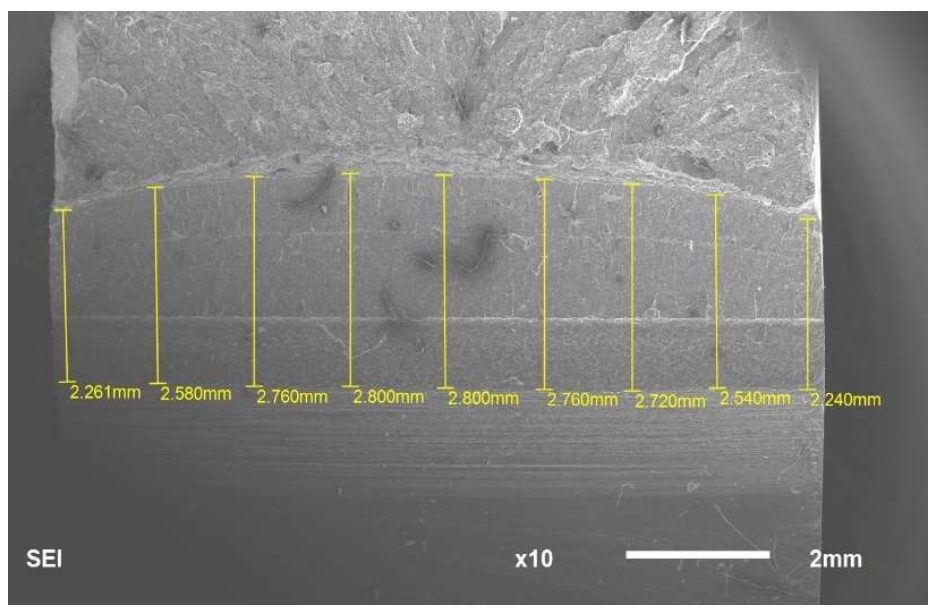

Figura 39 - Medição do tamanho médio de trinca do CP_D_0.7.

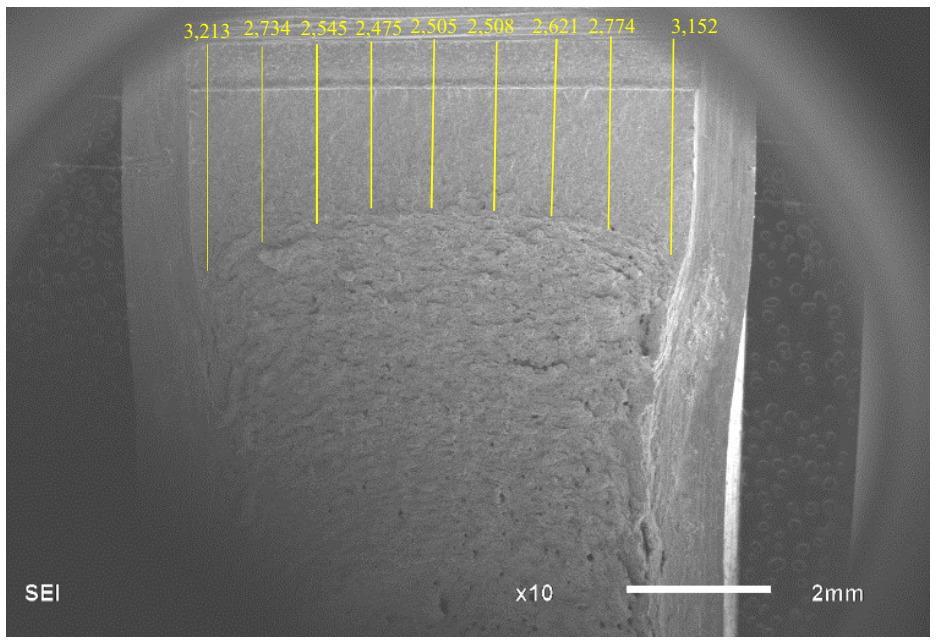

Figura 40 - Medição do tamanho médio de trinca do CP_A_0.6. 
Tabela XI - Dados das dimensões físicas das pré-trincas de fadiga e do entalhe total nos nove pontos equidistantes mensurados

\begin{tabular}{|c|c|c|c|c|c|c|}
\hline & \multicolumn{2}{|c|}{ CP_D_0.2 } & \multicolumn{2}{|c|}{ CP_D_0.3 } & \multicolumn{2}{|c|}{ CP_D_0.45 } \\
\hline $\mathbf{a}_{\mathbf{n}}$ & $\mathrm{M}^{*}$ & $\begin{array}{c}\text { Entalhe } \\
\text { total }\end{array}$ & $\mathrm{M}^{*}$ & $\begin{array}{c}\text { Entalhe } \\
\text { total }\end{array}$ & $\mathrm{M}^{*}$ & $\begin{array}{c}\text { Entalhe } \\
\text { total }\end{array}$ \\
\hline $\mathbf{a}_{1}$ & 1,309 & 5,109 & 1,308 & 7,608 & 2,450 & 11,700 \\
\hline $\mathbf{a}_{2}$ & 1,691 & 5,491 & 1,509 & 7,09 & 2,783 & 12,033 \\
\hline a3 & 1,800 & 5,600 & 1,728 & 8,028 & 2,933 & 12,183 \\
\hline $\mathbf{a 4}$ & 1,818 & 5,618 & 1,764 & 8,064 & 3,033 & 12,283 \\
\hline a5 & 1,873 & 5,673 & 1,818 & 8,118 & 3,067 & 12,317 \\
\hline a6 & 1,836 & 5,636 & 1,782 & 8,082 & 3,050 & 12,300 \\
\hline a7 & 1,727 & 5,527 & 1,746 & 8,046 & 3,000 & 12,250 \\
\hline $\mathbf{a 8}$ & 1,600 & 5,400 & 1,673 & 7,973 & 2,800 & 12,050 \\
\hline \multirow[t]{2}{*}{ a9 } & 1,273 & 5,073 & 1,291 & 7,591 & 2,400 & 11,650 \\
\hline & \multicolumn{2}{|c|}{ CP_D_0.6 } & \multicolumn{2}{|c|}{ CP_D_0.7 } & \multicolumn{2}{|c|}{ CP_A_0.6 } \\
\hline $\mathbf{a n}_{\mathbf{n}}$ & $\mathrm{M}^{*}$ & $\begin{array}{c}\text { Entalhe } \\
\text { total }\end{array}$ & $\mathrm{M}^{*}$ & $\begin{array}{c}\text { Entalhe } \\
\text { total }\end{array}$ & $\mathrm{M}^{*}$ & $\begin{array}{c}\text { Entalhe } \\
\text { Total }\end{array}$ \\
\hline $\mathbf{a}_{1}$ & 2,770 & 15,77 & 2,621 & 17,761 & 3,213 & 16,21 \\
\hline $\mathbf{a 2}$ & 3,146 & 16,146 & 2,580 & 18,080 & 2,734 & 15,73 \\
\hline $\mathbf{a 3}$ & 3,364 & 16,364 & 2,760 & 18,260 & 2,545 & 15,54 \\
\hline $\mathbf{a 4}$ & 3,436 & 16,436 & 2,800 & 18,300 & 2,475 & 15,47 \\
\hline a5 & 3,491 & 16,491 & 2,800 & 18,300 & 2,505 & 15,5 \\
\hline $\mathrm{ab}_{6}$ & 3,436 & 16,436 & 2,760 & 18,260 & 2,508 & 15,5 \\
\hline a7 & 3,327 & 16,327 & 2,720 & 18,220 & 2,621 & 15,62 \\
\hline $\mathbf{a 8}$ & 3,182 & 16,182 & 2,540 & 18,040 & 2,774 & 15,77 \\
\hline a9 & 2,764 & 15,764 & 2,240 & 17,740 & 3,152 & 16,15 \\
\hline
\end{tabular}

*Todas as medidas em mm

Tabela XII - Dimensão média do entalhe inicial mensurado, $\mathrm{a}_{\mathrm{M}(\mathrm{i})}$

\begin{tabular}{|l|c|c|c|c|c|c|}
\hline & CP_D_0.2 & CP_D_0.3 & CP_D_0.45 & CP_D_0.6 & CP_D_0.7 & CP_A_0,6 \\
\hline a0 & 5 & 7,5 & 11,25 & 15 & 17,5 & 15 \\
\hline aM(i) & 5,505 & 7,965 & 12,10 & 16,3 & 18,17 & 15,66 \\
\hline Diferença & 0,505 & 0,465 & 0,9 & 1,3 & 0,67 & 0,66 \\
\hline Variação & $9,17 \%$ & $5,84 \%$ & $7,30 \%$ & $7,80 \%$ & $3,59 \%$ & $4,24 \%$ \\
\hline
\end{tabular}

Tabela XIII - Valor encontrado de $\mathrm{a}_{\mathrm{M}(\mathrm{i})} / \mathrm{W}$

\begin{tabular}{|l|c|c|c|c|c|c|}
\hline & CP_D_0.2 & CP_D_0.3 & CP_D_0.45 & CP_D_0.6 & CP_D_0.7 & CP_A_0,6 \\
\hline aM(i)/W & 0,220 & 0,318 & 0,486 & 0,651 & 0,726 & 0,626 \\
\hline
\end{tabular}


No entanto, mesmo que o corpo de prova utilizado não seja padronizado pela ASTM e que a necessidade de seguir os padrões de qualificação sejam desprezíveis, todas as medidas adquiridas tanto da pré-trinca de fadiga quanto do tamanho inicial dos entalhes, não excederam o valor de qualificação exigido para que o ensaio se mantivesse válido.

\subsection{Tenacidade à fratura}

No ensaio de tenacidade à fratura de controle de deslocamento de carga pelo método compliance, para o CP_D_0,2 foram efetuados 48 pontos de descarregamentos parciais durante o ensaio, adotando-se o valor estimado de carga para ocorrer o primeiro descarregamento equivalente a $8,94 \mathrm{kN}$ conduzindo até a um incremento que equivalesse a $97,4 \mathrm{kN}$ de carga. Devido a capacidade da célula da máquina Instron utilizada ser de $100 \mathrm{kN}$, a aplicação de maiores cargas neste corpo de prova ficou limitada, assim como a abertura da boca da trinca. A curva plotada no Gráfico 2 foi gerada sob/ o registro de dados de carga vs. CMOD deste ensaio.

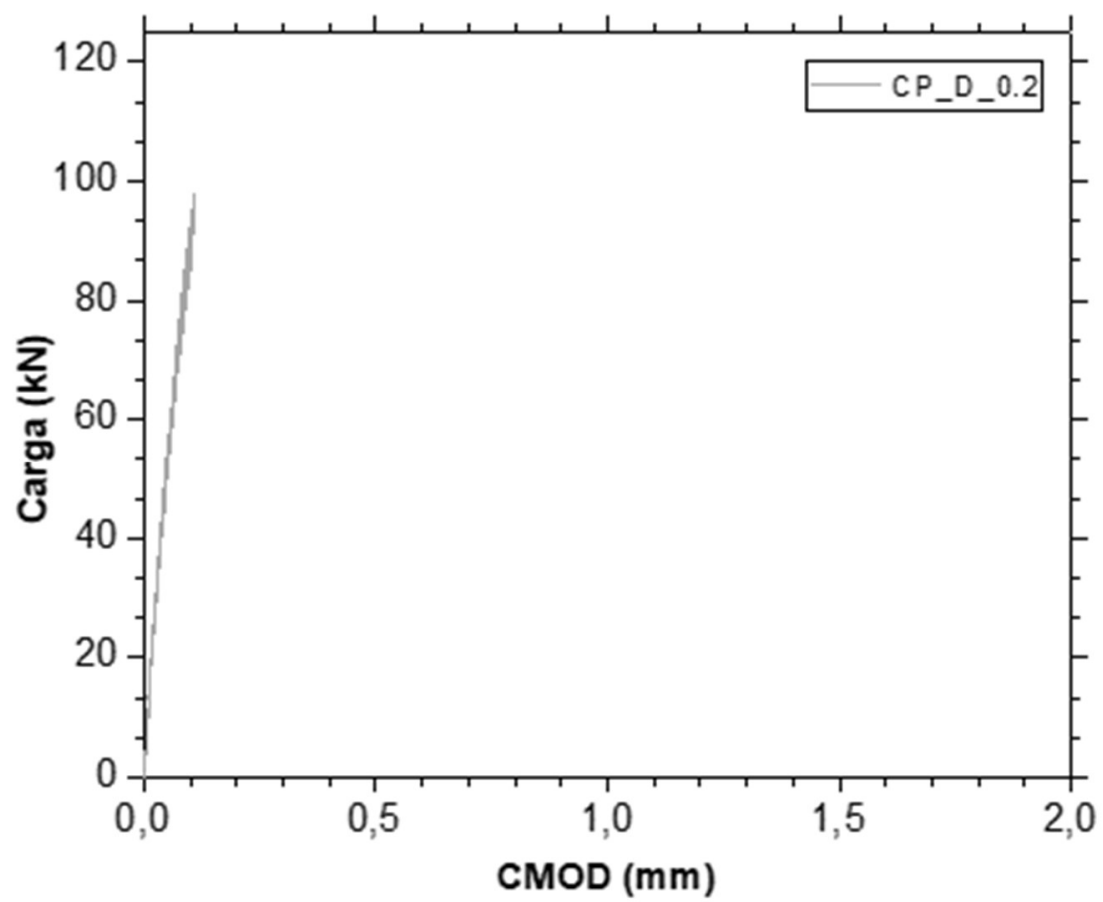

Gráfico 2 - Curva P vs. CMOD referente ao CP_D_0.2

Observa-se que a escala do eixo das abscissas no gráfico anterior está com um valor máximo correspondente a $2,0 \mathrm{~mm}$ de $\mathrm{CMOD}$, muito superior a região 
relevante plotada, esta medida foi adotada com o intuito de fazê-lo comparável aos demais gráficos que serão apresentados a seguir. No entanto, amplificando a região contida até CMOD máximo equivalente a 0,1106 $\mathrm{mm}$, tem-se uma imagem conforme plotada no Gráfico 3 e pode-se visualizar com maior nitidez a resposta do corpo de prova a aplicação dos incrementos dos descarregamentos parciais. Os registros do ensaio com valores de carga até $12,8 \mathrm{kN}$ foram desconsiderados, como mostra no "Detalha A" do gráfico em questão, pois registros mal efetivados ocorreram no princípio do ensaio, o que não permitiu determinar os valores de carga e CMOD com eficácia, restando apenas 23 incrementos a partir deste ponto, detectando um primeiro descarregamento cerca de $12,4 \mathrm{kN}$. Valores maiores de CMOD a partir da posição incremental 19 até CMOD na posição incremental 23 foi observada, mas não implica no aparecimento de propagação dúctil de trinca.

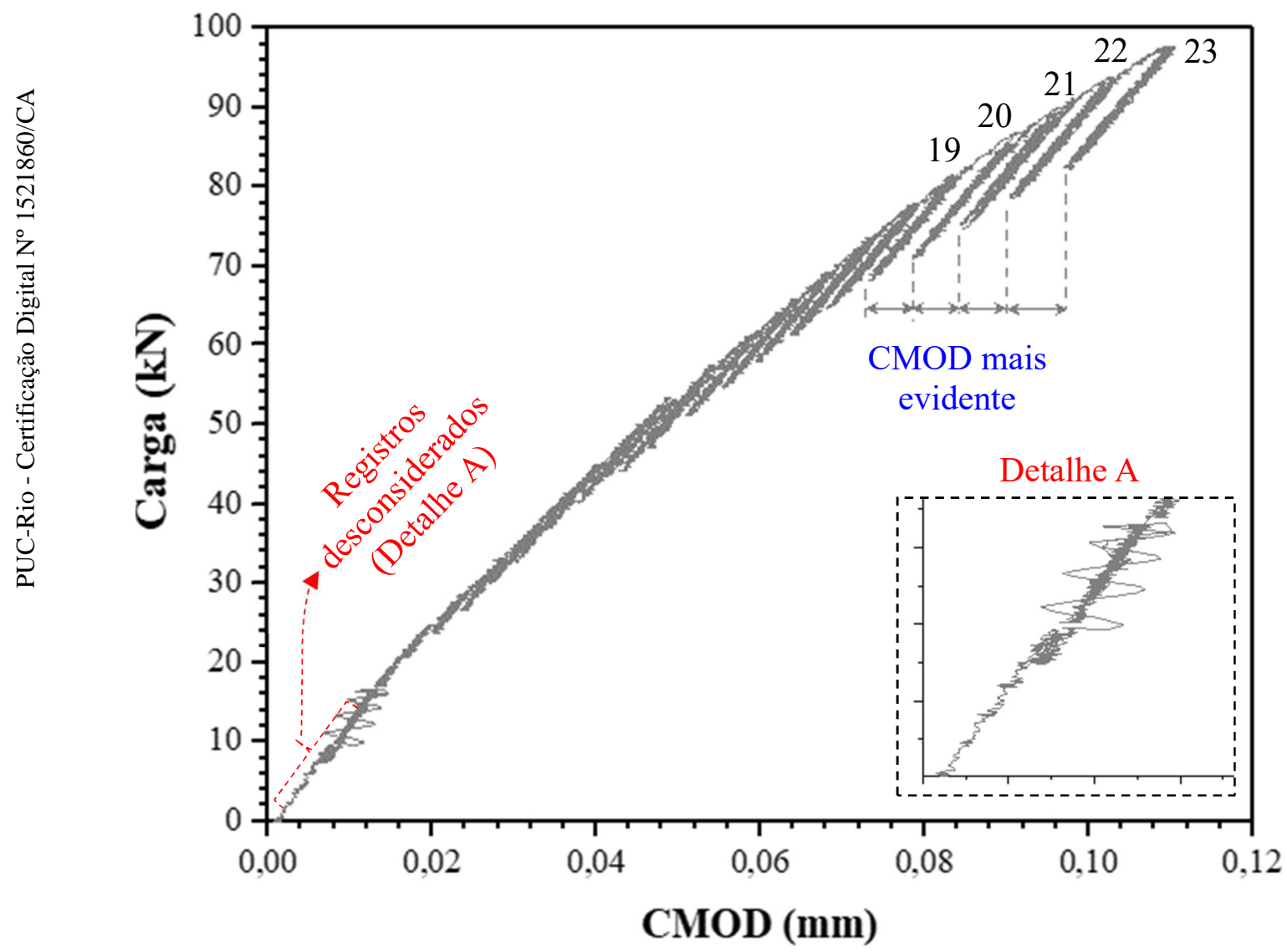

Gráfico 3 - Ampliação da região mais relevante do registro ensaio de tenacidade à fratura do CP_D_0.2.

Após a identificação de todos os pontos incrementais, o desenvolvimento matemático do método compliance pertinente a este ensaio foi realizado, resultando 
nos valores dispostos na terceira coluna da Tabela XIV. Permitindo assim o cálculo de $\mu$, daí encontra-se $a_{(i)} / W$ e consequentemente $a_{(i)}$. Seus respectivos valores constam na Tabela XV.

Tabela XIV - Parâmetros do ensaio do CP D 0.2

\begin{tabular}{|c|c|c|c|c|}
\hline Posição & $\begin{array}{l}\Delta \mathrm{CMOD}_{(\mathrm{i})} \\
\quad(\mathrm{mm})\end{array}$ & $\begin{array}{l}\Delta \mathbf{P}_{(\mathbf{i})} \\
(\mathbf{N})\end{array}$ & $\begin{array}{c}\text { Compliance } \\
\text { medido }(\mathrm{mm} / \mathrm{N})\end{array}$ & $\mu$ \\
\hline 1 & 0,00160 & 2305,31 & $6,928 \mathrm{E}-07$ & $4,43 \mathrm{E}-01$ \\
\hline 2 & 0,00159 & 2634,40 & 6,019E-07 & $4,61 \mathrm{E}-01$ \\
\hline 3 & 0,00169 & 2402,48 & 7,034E-07 & $4,42 \mathrm{E}-01$ \\
\hline 4 & 0,00247 & 3538,05 & 6,968E-07 & $4,43 \mathrm{E}-01$ \\
\hline 5 & 0,00318 & 3915,85 & $8,128 \mathrm{E}-07$ & $4,24 \mathrm{E}-01$ \\
\hline 6 & 0,0038 & 4706,4 & 7,967E-07 & $4,26 \mathrm{E}-01$ \\
\hline 7 & 0,0042 & 6098,8 & $6,850 \mathrm{E}-07$ & $4,45 \mathrm{E}-01$ \\
\hline 8 & 0,0057 & 7129,8 & 7,954E-07 & $4,26 \mathrm{E}-01$ \\
\hline 9 & 0,0059 & 7354,8 & $8,041 \mathrm{E}-07$ & $4,25 \mathrm{E}-01$ \\
\hline 10 & 0,0060 & 7176,9 & $8,369 \mathrm{E}-07$ & $4,20 \mathrm{E}-01$ \\
\hline 11 & 0,0073 & 8985,7 & $8,101 \mathrm{E}-07$ & $4,24 \mathrm{E}-01$ \\
\hline 12 & 0,0075 & 9177,7 & $8,121 \mathrm{E}-07$ & $4,24 \mathrm{E}-01$ \\
\hline 13 & 0,0078 & 9714,0 & $8,066 \mathrm{E}-07$ & $4,25 \mathrm{E}-01$ \\
\hline 14 & 0,0082 & 10547,0 & 7,802E-07 & $4,29 \mathrm{E}-01$ \\
\hline 15 & 0,0075 & 9365,9 & 7,970E-07 & $4,26 \mathrm{E}-01$ \\
\hline 16 & 0,0088 & 11198,44 & 7,906E-07 & $4,27 \mathrm{E}-01$ \\
\hline 17 & 0,0104 & 12667,43 & $8,186 \mathrm{E}-07$ & $4,23 \mathrm{E}-01$ \\
\hline 18 & 0,0105 & 13053,18 & $8,104 \mathrm{E}-07$ & $4,24 \mathrm{E}-01$ \\
\hline 19 & 0,0103 & 12271,91 & $8,403 \mathrm{E}-07$ & $4,20 \mathrm{E}-01$ \\
\hline 20 & 0,0116 & 14375 & $8,059 \mathrm{E}-07$ & $4,25 \mathrm{E}-01$ \\
\hline 21 & 0,0136 & 16070 & $8,440 \mathrm{E}-07$ & $4,19 \mathrm{E}-01$ \\
\hline 22 & 0,0119 & 14401 & $8,246 \mathrm{E}-07$ & $4,22 \mathrm{E}-01$ \\
\hline 23 & 0,0117 & 13647 & $8,557 \mathrm{E}-07$ & $4,43 \mathrm{E}-01$ \\
\hline
\end{tabular}

Tabela XV-Parâmetros da curva J- $\Delta$ a do CP D 0.2

\begin{tabular}{|r|c|c|c|c|c|}
\hline Posição & $\begin{array}{c}\mathbf{J} \\
\left(\mathbf{k J} / \mathbf{m}^{\mathbf{2}}\right)\end{array}$ & $\mathbf{a}(\mathbf{i}) / \mathbf{W}$ & $\begin{array}{c}\mathbf{a}(\mathbf{i}) \\
(\mathbf{m m})\end{array}$ & $\begin{array}{c}\Delta \mathbf{a} \\
(\mathbf{m m})\end{array}$ & $\begin{array}{c}\Delta \mathbf{a} \text { TOTAL } \\
(\mathbf{m m})\end{array}$ \\
\hline $\mathbf{1}$ & 0,3269022 & 0,219135776 & 5,47839 & $-0,02611$ & $-0,02611$ \\
\hline $\mathbf{2}$ & 0,471293171 & 0,197562854 & 4,93907 & $-0,53932$ & $-0,56543$ \\
\hline $\mathbf{3}$ & 0,526456179 & 0,221519513 & 5,53799 & 0,59892 & 0,03349 \\
\hline $\mathbf{4}$ & 0,827271069 & 0,220032435 & 5,50081 & $-0,03718$ & $-0,00369$ \\
\hline $\mathbf{5}$ & 1,20173107 & 0,245080854 & 6,12702 & 0,62621 & 0,62252 \\
\hline $\mathbf{6}$ & 1,831824332 & 0,241765326 & 6,04413 & $-0,08289$ & 0,53963 \\
\hline $\mathbf{7}$ & 2,783488644 & 0,217365636 & 5,43414 & $-0,60999$ & $-0,07036$ \\
\hline $\mathbf{8}$ & 2,617088909 & 0,241484822 & 6,03712 & 0,60298 & 0,53262 \\
\hline
\end{tabular}




\begin{tabular}{|r|c|c|c|c|c|}
\hline $\mathbf{9}$ & 4,240988988 & 0,2432936 & 6,08234 & 0,04522 & 0,57784 \\
\hline $\mathbf{1 0}$ & 6,146113613 & 0,249995019 & 6,24988 & 0,16754 & 0,74538 \\
\hline $\mathbf{1 1}$ & 7,662658953 & 0,244539737 & 6,11349 & $-0,13638$ & 0,60899 \\
\hline $\mathbf{1 2}$ & 8,843368365 & 0,244944926 & 6,12362 & 0,01013 & 0,61912 \\
\hline $\mathbf{1 3}$ & 10,54649475 & 0,243808006 & 6,09520 & $-0,02842$ & 0,59070 \\
\hline $\mathbf{1 4}$ & 11,63737868 & 0,238295428 & 5,95739 & $-0,13781$ & 0,45289 \\
\hline $\mathbf{1 5}$ & 13,72248591 & 0,241825995 & 6,04565 & 0,08826 & 0,54115 \\
\hline $\mathbf{1 6}$ & 15,84606294 & 0,240487661 & 6,01219 & $-0,03346$ & 0,50769 \\
\hline $\mathbf{1 7}$ & 17,58160939 & 0,246278893 & 6,15697 & 0,14478 & 0,65247 \\
\hline $\mathbf{1 8}$ & 19,2540928 & 0,244590411 & 6,11476 & $-0,04221$ & 0,61026 \\
\hline $\mathbf{1 9}$ & 22,04027928 & 0,250668105 & 6,26670 & 0,15194 & 0,76220 \\
\hline $\mathbf{2 0}$ & 26,35414156 & 0,243668328 & 6,09171 & $-0,17499$ & 0,58721 \\
\hline $\mathbf{2 1}$ & 27,50367452 & 0,251420971 & 6,28552 & 0,19382 & 0,78102 \\
\hline $\mathbf{2 2}$ & 30,9091891 & 0,247489901 & 6,18725 & $-0,09828$ & 0,68275 \\
\hline $\mathbf{2 3}$ & 21,81860145 & 0,253741273 & 6,34353 & 0,15628 & 0,83903 \\
\hline & & & & & \\
\hline
\end{tabular}

Com base nesses valores, foi analisado que o compliance medido, o qual diversifica de acordo com $\triangle \mathrm{CMOD}_{(\mathrm{i})}$ e $\triangle \mathrm{CARGA}_{(\mathrm{i})}$, resultou em números variantes. Em alguns pontos, o valor do incremento (i-1) atingiu um valor maior do que no incremento (i), como por exemplo nos incrementos 2 e 3 , os quais idealmente deveriam ser sucedidos por valores crescentes. Isto acarretou em aquisições de $\mathrm{a}_{(\mathrm{i})} / \mathrm{W}$ também inferiores, o que fisicamente não é condizente, já que a medida que o corpo de prova está sendo carregado a incrementos de carga maiores o ligamento remanescente passa a ser afetado de duas maneiras: permanecendo do mesmo tamanho, indicando que não houve propagação dúctil de trinca e o valor de $\mathrm{a}_{(\mathrm{i})} / \mathrm{W}$ é conservado, ou então será reduzido, indicando propagação dúctil de trinca e aumentando o valor de $\mathrm{a}_{(\mathrm{i})} / \mathrm{W}$. Uma vez o ligamento remanescente reduzido, a sua dimensão referente ao incremento $\mathrm{a}_{(\mathrm{i})} / \mathrm{W}$ anterior é irreversível inviabilizando a ideia de se ter um $\mathrm{a}_{(\mathrm{i})} / \mathrm{W}$ menor que $\mathrm{a}_{(\mathrm{i}-1)} / \mathrm{W}$.

Tabela XVI-Comparação entre a dimensão da trinca mensurada com a calculada do CP_D_0.2

\begin{tabular}{|l|c|c|c|c|}
\hline \multicolumn{5}{|c|}{ Resultados para o CP_D_0.2 } \\
\hline & Mensurado $(\mathrm{mm})$ & & Compliance $(\mathrm{mm})$ & $\boldsymbol{\Delta}$ \\
\hline $\mathbf{a} \mathbf{M}(\mathbf{i})=$ & 5,505 & $\mathbf{a 0 q}=$ & 5,32 & 0,186 \\
\hline $\mathbf{a}_{\mathbf{p}}=$ & 5,505 & $\mathbf{a p ~ e s t i m a d o ~}_{\mathbf{n}}=$ & 6,34 & $-0,839$ \\
\hline $\mathbf{\Delta a}_{\mathbf{p}}=$ & 0 & $\mathbf{\Delta}$ aprevisto $=$ & 1,02 & \\
\hline
\end{tabular}


A aplicação do modelo matemático para o procedimento de curva de resistência gerou um resultado de $\Delta$ a igual a $0,83 \mathrm{~mm}$ com uma $A_{p l(23)}$ de 1,70N.m. No entanto, imagens fractográficas adquiridas no MEV, com ampliação de 11x e $800 x$, não assinalam com os resultados obtidos numericamente. Isto porque nenhuma região com extensão dúctil de trinca é visualizada, pelo contrário, há identificação clara da interface entre a pré-trinca de fadiga e a fratura frágil do ligamento remanescente do corpo de prova, visto na Figura 41, sem ao menos ter uma stretching zone perceptível caracterizando o embotamento do material.

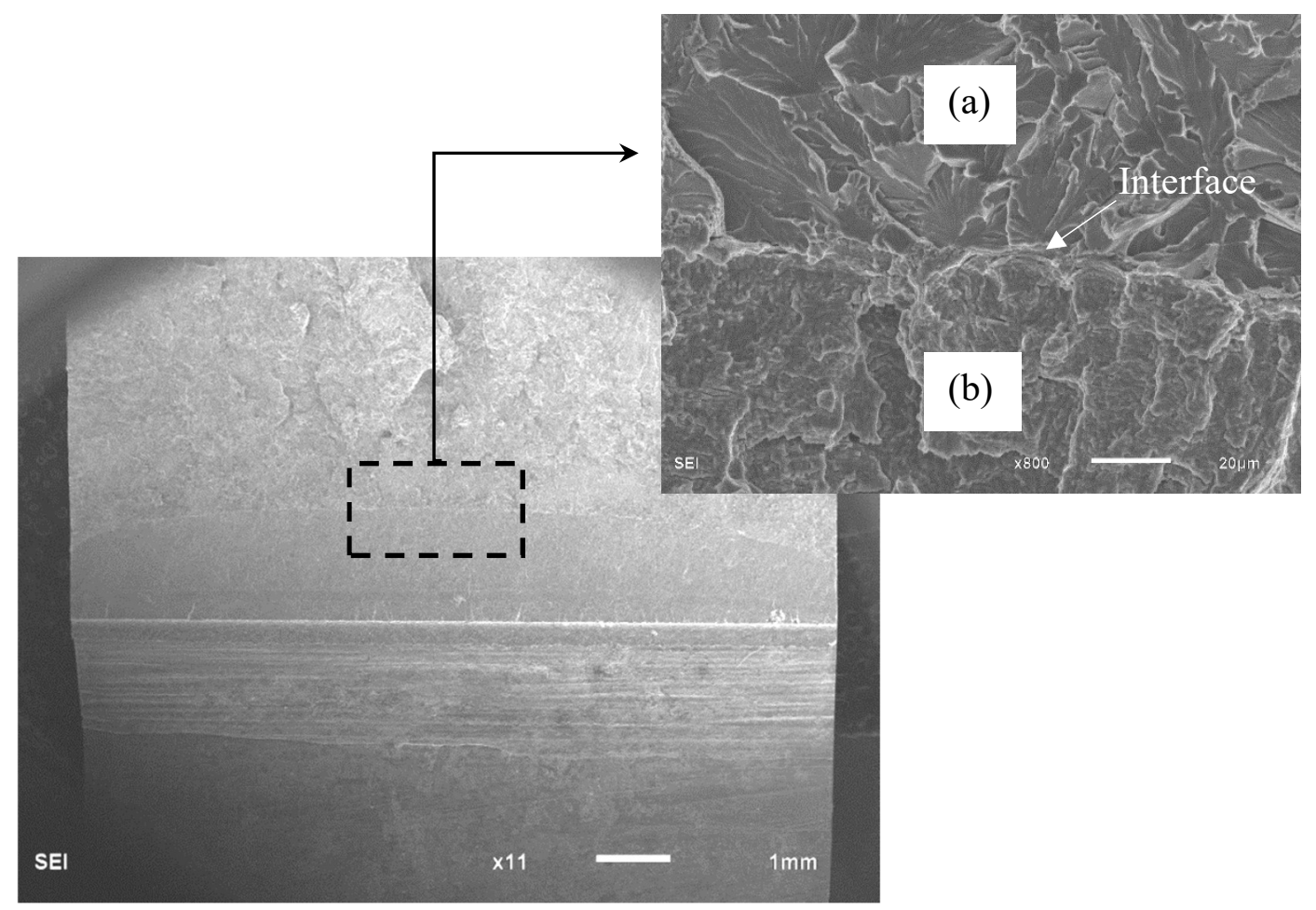

Figura 41 - Análise fractográfica do CP_D_0.2

Outro ponto relevante, é de ter encontrado valores de $\Delta \mathrm{a}$ TOTAL negativos em alguns pontos iniciais do ensaio, equivalente ao total de 4 dentre 23. No escopo desse contexto, foi determinado então que os valores negativos não seriam adotados no desenvolvimento do gráfico $\mathrm{J}-\Delta \mathrm{a}$ do CP_D_0.2, gerando assim o Gráfico 4 . Como os resultados obtidos apresentaram grandes dispersões e encontram-se distante do eixo das ordenadas, decidiu-se traçar uma curva de ajuste a fim de evidenciar o comportamento do corpo de prova, e realizar o deslocamento do eixo $\Delta \mathrm{a}$ até o valor do primeiro ponto qualificado, proporcionando a definição do valor de $\mathrm{J}_{\mathrm{IC}}$ e $\Delta \mathrm{a}_{\mathrm{min}}$, Tabela XVII. 


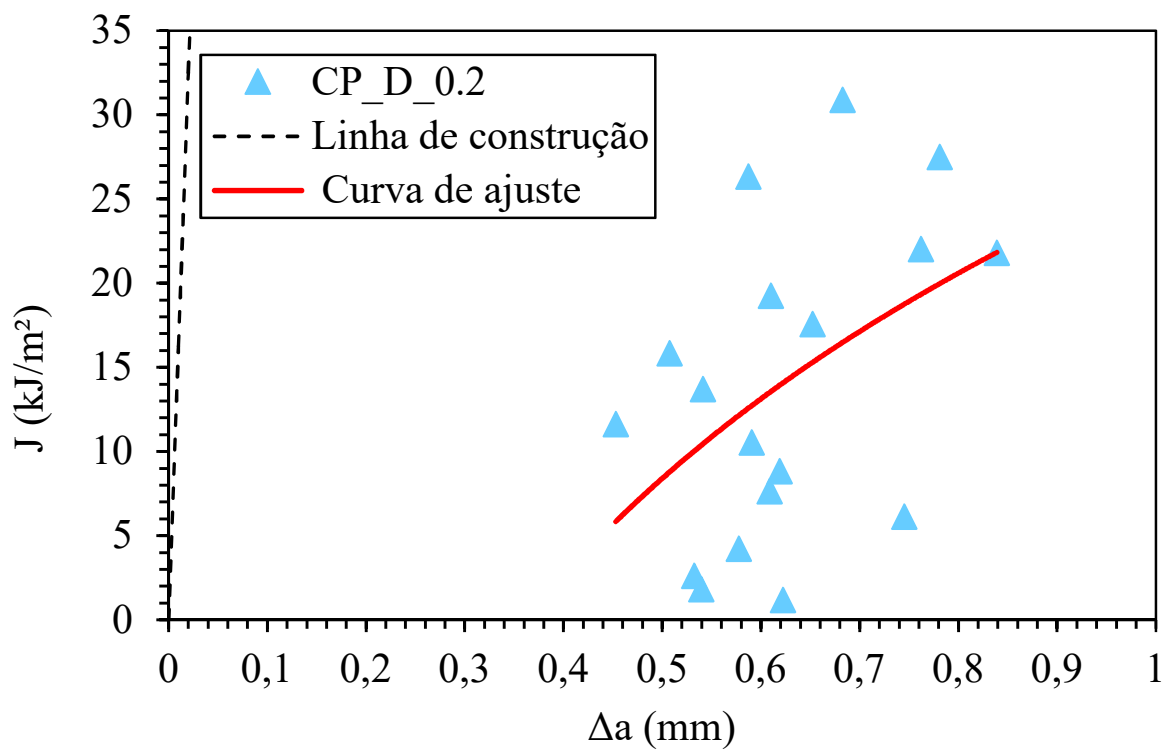

Gráfico 4 - Curva J-R do CP_D_0.2.

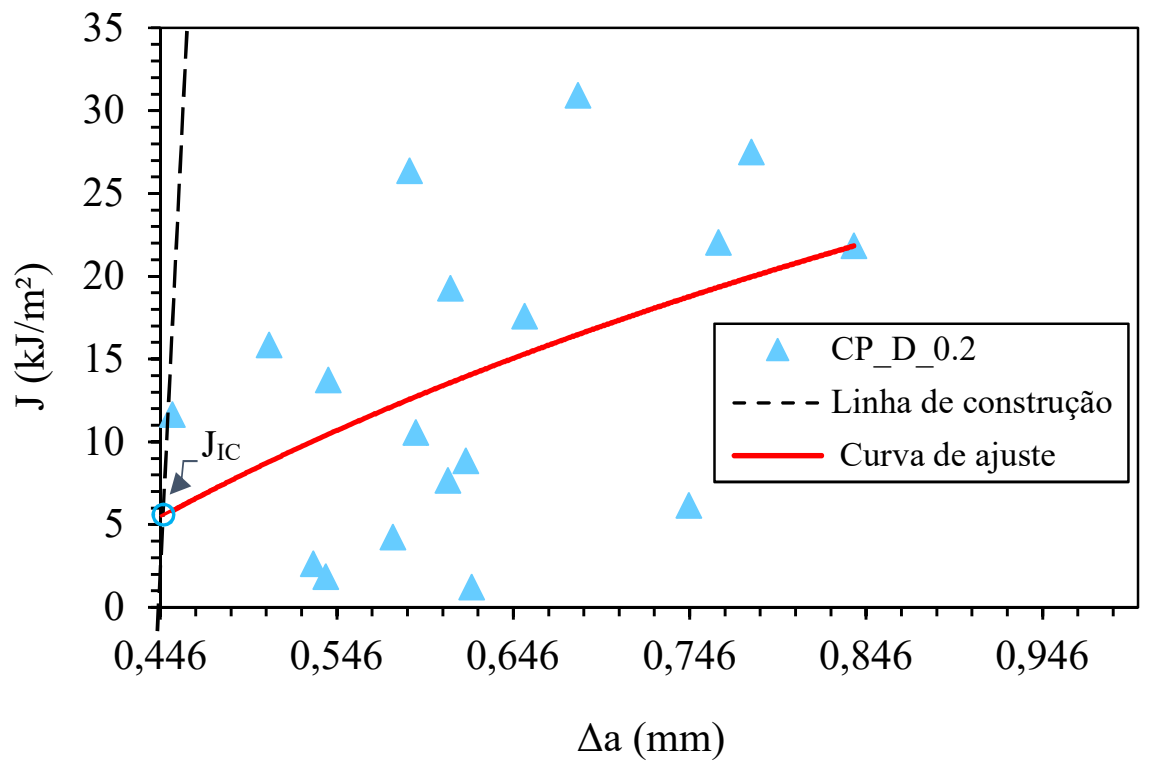

Gráfico 5 - Mesmo conjunto de dados apresentado no Gráfico 4 analisado após o deslocamento do zero até próximo ao primeiro valor de $\Delta$ a qualificado.

Tabela XVII - Determinação do valor de J J do CP_D 0.2

\begin{tabular}{|c|c|}
\hline \multicolumn{2}{|c|}{ CP_D_0.2 } \\
\hline $\mathrm{J}_{\mathrm{IC}}\left(\mathrm{kJ} / \mathrm{m}^{2}\right)$ & $\Delta \mathrm{a}_{\min }(\mathrm{mm})$ \\
\hline 5,5 & 0,4486 \\
\hline
\end{tabular}

Em seguida ao CP_D_0.2, a mesma análise foi efetuada para os demais corpos de prova ensaiados. A partir dos registros de ensaio do CP_D_0.3 gerou-se a plotagem contida no Gráfico 5. A princípio, este corpo de prova foi dimensionado 
para se ter um tamanho de entalhe usinado equivalente a $6,3 \mathrm{~mm}$ e pré-trinca de 1,2 $\mathrm{mm}$, conforme apresentado na Tabela VII do item 3.3.5. A dimensão do entalhe usinado é um valor constante certificado após a usinagem, sendo a dimensão da prétrinca a única variável que pode influenciar no valor da razão a 0 /W. A mesma alcançou, neste caso, uma dimensão de $1,665 \mathrm{~mm}$, totalizando um $\mathrm{a}_{\mathrm{M}(\mathrm{i})}$ de dimensão $7,965 \mathrm{~mm}$, Tabela XII, que gera um $\mathrm{a}_{\mathrm{M}(\mathrm{i})} / \mathrm{W}$ igual 0,3186. No entanto, observa-se a partir dos dados da Tabela XVIII e Tabela XIX que o valor de $\mathrm{a}_{\mathrm{M}(\mathrm{i})} / \mathrm{W}$ é de aproximadamente 0,1574 , equivalendo cerca de $50 \%$ do valor de $\mathrm{a}_{0} / \mathrm{W}$. Como $\mathrm{a}_{\text {(i) }} / \mathrm{W}$ é função de $\mu$ e este função do compliance, ao menos que o compliance obtivesse um valor mínimo de 1,232E-06 mm/N, ao invés de 4,51E-07 como calculado por intermédio dos registros de ensaio, poderia ter sido adquirido um valor igual ou superior de a $0 / \mathrm{W}$ para o CP_D_0.3. A diferença entre compliance calculado e o esperado foi de $0,00000117 \mathrm{~mm} / \mathrm{N}$ o que representa um valor de $36,16 \%$ a menos. Apenas o incremento 13 resultou em um compliance na ordem de $10^{-6}$ permanecendo insuficiente a quantidade de pontos necessários para plotagem do gráfico J- $\Delta \mathrm{a}$, a passo de que os valores encontrados de $\Delta \mathrm{a}$ foram grande parte negativos.

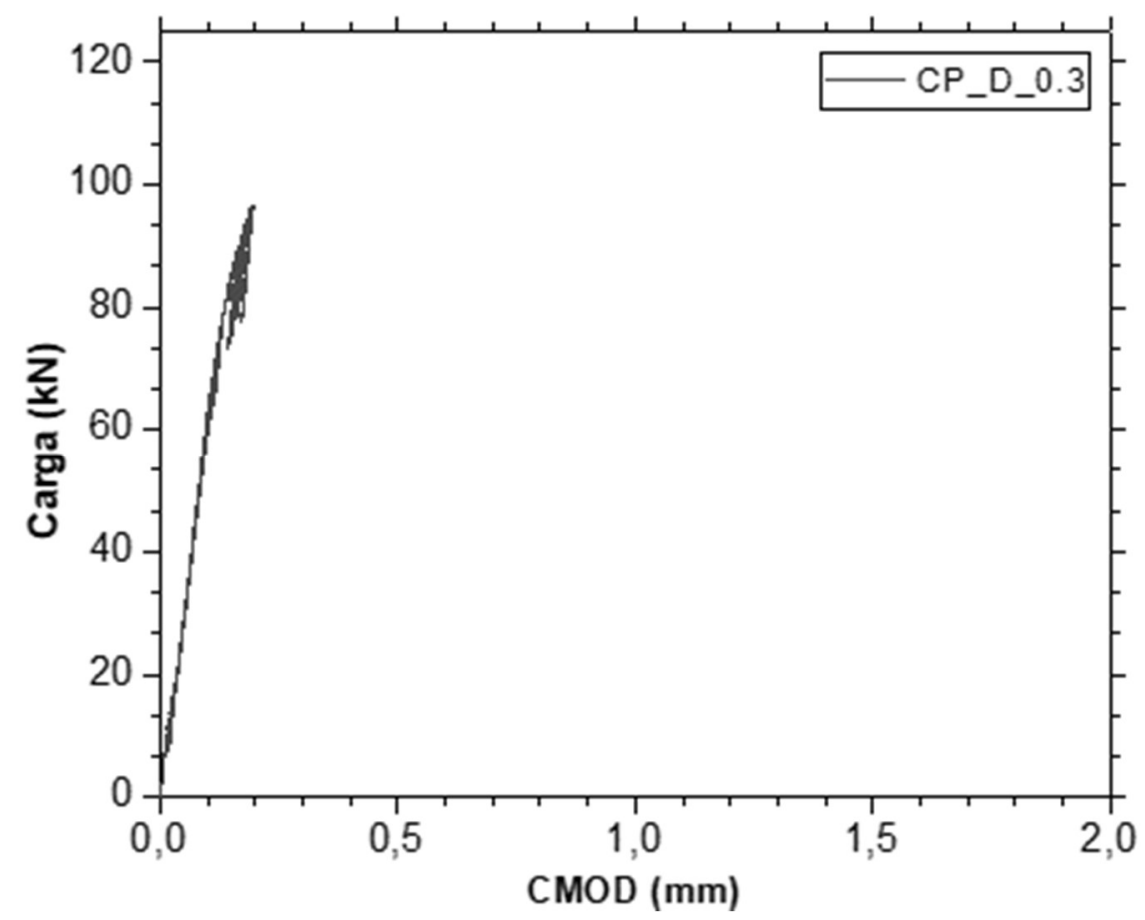

Gráfico 6 - Curva P vs. CMOD referente ao CP_D_0.3 
Tabela XVIII - Parâmetros do ensaio do CP_D_0.3

\begin{tabular}{|c|c|c|c|c|}
\hline Posição & $\begin{array}{c}\triangle C^{\Delta M O D}(\mathbf{i}) \\
(\mathrm{mm})\end{array}$ & $\begin{array}{l}\Delta \mathbf{P}_{(\mathbf{i})} \\
(\mathbf{N})\end{array}$ & $\begin{array}{c}\text { Compliance } \\
\text { medido }(\mathrm{mm} / \mathrm{N})\end{array}$ & $\mu$ \\
\hline 1 & 0,0007 & 1642,5 & $4,51 \mathrm{E}-07$ & $4,97 \mathrm{E}-01$ \\
\hline 2 & 0,001 & 2043,5 & 4,89E-07 & $4,87 \mathrm{E}-01$ \\
\hline 3 & 0,0012 & 2459,8 & 4,74E-07 & 4,91E-01 \\
\hline 4 & 0,0015 & 2622,2 & 5,83E-07 & $4,65 \mathrm{E}-01$ \\
\hline 5 & 0,0019 & 3357,3 & $5,76 \mathrm{E}-07$ & $4,66 \mathrm{E}-01$ \\
\hline 6 & 0,002 & 3511,9 & $5,72 \mathrm{E}-07$ & $4,67 \mathrm{E}-01$ \\
\hline 7 & 0,0023 & 4005,9 & 5,79E-07 & $4,66 \mathrm{E}-01$ \\
\hline 8 & 0,0028 & 4639,6 & $5,95 \mathrm{E}-07$ & $4,62 \mathrm{E}-01$ \\
\hline 9 & 0,0029 & 5210,9 & $5,63 \mathrm{E}-07$ & $4,69 \mathrm{E}-01$ \\
\hline 10 & 0,0030 & 5587,3 & $5,33 \mathrm{E}-07$ & $4,76 \mathrm{E}-01$ \\
\hline 11 & 0,0017 & 2741,8 & $6,15 \mathrm{E}-07$ & $4,58 \mathrm{E}-01$ \\
\hline 12 & 0,0015 & 2198,9 & $6,66 \mathrm{E}-07$ & $4,48 \mathrm{E}-01$ \\
\hline 13 & 0,0001 & 41,24 & $3,15 \mathrm{E}-06$ & $2,72 \mathrm{E}-01$ \\
\hline 14 & 0,0045 & 8199,6 & $5,53 \mathrm{E}-07$ & $4,71 \mathrm{E}-01$ \\
\hline 15 & 0,0023 & 4422,4 & $5,17 \mathrm{E}-07$ & $4,80 \mathrm{E}-01$ \\
\hline 16 & 0,0051 & 9162,3 & $5,57 \mathrm{E}-07$ & $4,71 \mathrm{E}-01$ \\
\hline 17 & 0,0054 & 9440,7 & $5,70 \mathrm{E}-07$ & $4,67 \mathrm{E}-01$ \\
\hline 18 & 0,0057 & 10254 & $5,55 \mathrm{E}-07$ & 4,71E-01 \\
\hline 19 & 0,0058 & 10664 & $5,47 \mathrm{E}-07$ & $4,73 \mathrm{E}-01$ \\
\hline 20 & 0,006 & 10631 & $5,65 \mathrm{E}-07$ & $4,69 \mathrm{E}-01$ \\
\hline 21 & 0,0066 & 11333 & $5,86 \mathrm{E}-07$ & $4,64 \mathrm{E}-01$ \\
\hline 22 & 0,0066 & 11734 & $5,62 \mathrm{E}-07$ & $4,69 \mathrm{E}-01$ \\
\hline 23 & 0,0064 & 11100 & 5,79E-07 & $4,66 \mathrm{E}-01$ \\
\hline 24 & 0,0069 & 12262 & $5,64 \mathrm{E}-07$ & $4,69 \mathrm{E}-01$ \\
\hline 25 & 0,008 & 14232 & $5,59 \mathrm{E}-07$ & $4,70 \mathrm{E}-01$ \\
\hline 26 & 0,0085 & 15581 & $5,47 \mathrm{E}-07$ & $4,73 \mathrm{E}-01$ \\
\hline 27 & 0,0091 & 15440 & $5,86 \mathrm{E}-07$ & 4,64E-01 \\
\hline 28 & 0,0087 & 15333 & $5,68 \mathrm{E}-07$ & $4,68 \mathrm{E}-01$ \\
\hline
\end{tabular}

Tabela XIX - Parâmetros da curva J- $\Delta$ a do CP D 0.3

\begin{tabular}{|r|c|c|c|c|c|}
\hline Posição & $\begin{array}{c}\mathbf{J} \\
\left(\mathbf{k J} / \mathbf{m}^{\mathbf{2}}\right)\end{array}$ & $\mathbf{a}(\mathbf{i}) / \mathbf{W}$ & $\begin{array}{c}\mathbf{a}(\mathbf{i}) \\
(\mathbf{m m})\end{array}$ & $\begin{array}{c}\Delta \mathbf{a} \\
(\mathbf{m m})\end{array}$ & $\begin{array}{c}\Delta \mathbf{a} \text { TOTAL } \\
(\mathbf{m m})\end{array}$ \\
\hline $\mathbf{1}$ & 0,111836893 & 0,157404742 & 3,9 & $-4,02988$ & $-4,02988$ \\
\hline $\mathbf{2}$ & 0,133138676 & 0,168257852 & 4,2 & 0,27133 & $-3,75855$ \\
\hline $\mathbf{3}$ & 0,263315422 & 0,163905928 & 4,1 & $-0,10880$ & $-3,86735$ \\
\hline $\mathbf{4}$ & 0,380481571 & 0,192975495 & 4,8 & 0,72674 & $-3,14061$ \\
\hline $\mathbf{5}$ & 0,418272802 & 0,191177378 & 4,8 & $-0,04495$ & $-3,18557$ \\
\hline $\mathbf{6}$ & 0,462942994 & 0,190159319 & 4,8 & $-0,02545$ & $-3,21102$ \\
\hline $\mathbf{7}$ & 0,506164983 & 0,19190642 & 4,8 & 0,04368 & $-3,16734$ \\
\hline $\mathbf{8}$ & 0,602447604 & 0,195822735 & 4,9 & 0,09791 & $-3,06943$ \\
\hline
\end{tabular}




\begin{tabular}{|r|c|c|c|c|c|}
\hline $\mathbf{9}$ & 0,833207694 & 0,187841485 & 4,7 & $-0,19953$ & $-3,26896$ \\
\hline $\mathbf{1 0}$ & 1,082690335 & 0,180080145 & 4,5 & $-0,19403$ & $-3,46300$ \\
\hline $\mathbf{1 1}$ & 1,416177674 & 0,200675433 & 5,0 & 0,51488 & $-2,94811$ \\
\hline $\mathbf{1 2}$ & 1,921237921 & 0,213008418 & 5,3 & 0,30832 & $-2,63979$ \\
\hline $\mathbf{1 3}$ & $-1,14511029$ & 0,500149715 & 12,5 & 7,17853 & 4,53874 \\
\hline $\mathbf{1 4}$ & 18,85591127 & 0,185225393 & 4,6 & $-7,87311$ & $-3,33437$ \\
\hline $\mathbf{1 5}$ & 19,60665043 & 0,175660475 & 4,4 & $-0,23912$ & $-3,57349$ \\
\hline $\mathbf{1 6}$ & 19,89878173 & 0,18614238 & 4,7 & 0,26205 & $-3,31144$ \\
\hline $\mathbf{1 7}$ & 20,38705957 & 0,18966804 & 4,7 & 0,08814 & $-3,22330$ \\
\hline $\mathbf{1 8}$ & 22,04053783 & 0,185703728 & 4,6 & $-0,09911$ & $-3,32241$ \\
\hline $\mathbf{1 9}$ & 22,1965087 & 0,183695801 & 4,6 & $-0,05020$ & $-3,37260$ \\
\hline $\mathbf{2 0}$ & 23,47838478 & 0,188257286 & 4,7 & 0,11404 & $-3,25857$ \\
\hline $\mathbf{2 1}$ & 22,93707247 & 0,193585557 & 4,8 & 0,13321 & $-3,12536$ \\
\hline $\mathbf{2 2}$ & 24,00170876 & 0,187645425 & 4,7 & $-0,14850$ & $-3,27386$ \\
\hline $\mathbf{2 3}$ & 24,55495051 & 0,191797913 & 4,8 & 0,10381 & $-3,17005$ \\
\hline $\mathbf{2 4}$ & 25,44674084 & 0,18811879 & 4,7 & $-0,09198$ & $-3,26203$ \\
\hline $\mathbf{2 5}$ & 26,97960205 & 0,18664784 & 4,7 & $-0,03677$ & $-3,29880$ \\
\hline $\mathbf{2 6}$ & 28,24213411 & 0,183773159 & 4,6 & $-0,07187$ & $-3,37067$ \\
\hline $\mathbf{2 7}$ & 28,19170036 & 0,193640796 & 4,8 & 0,24669 & $-3,12398$ \\
\hline $\mathbf{2 8}$ & 30,09398242 & 0,189150231 & 4,7 & $-0,11226$ & $-3,23624$ \\
\hline & & & & & \\
\hline
\end{tabular}

Embora que o valor de $\Delta \mathrm{a}$ TотAL negativo sejam reconhecidos nas literaturas quando se aplica a técnica compliance para medição de extensão dúctil de trinca, e diz-se ocorrer por conta dos fatores de fricção, desalinhamento do corpo de prova com a célula de carga, pelo balanceamento do equipamento eletrônico, ou talvez pelo efeito físico do comportamento do material diante ao embotamento na ponta da trinca, não é comum se encontra-lo grande parte dos incrementos, tanto que não foi achado em nenhuma dissertação ou tese relatando este fato. Como se sabe que o valor do compliance é independente do valor da carga e do deslocamento, as variáveis que podem ter guiado a ocorrência deste fato é o tamanho da trinca, geometria do corpo de prova diante do material confeccionado ou influência na aquisição do controle de dados.

Tabela XX - Comparação entre a dimensão da trinca mensurada com a calculada do CP_D_0.3

\begin{tabular}{|c|c|c|c|c|}
\hline \multicolumn{5}{|c|}{ Resultados para o CP_D_0.3 } \\
\hline & Mensurado (mm) & & Compliance $(\mathrm{mm})$ & $\Delta$ \\
\hline $\mathbf{a}_{\mathbf{M}(\mathbf{i})}=$ & 7,965 & $\mathbf{a}_{0 \mathrm{q}}=$ & 4,08 & $-3,885$ \\
\hline $\mathbf{a}_{\mathbf{p}}=$ & 7,965 & $a_{p}$ estimado $=$ & 4,7 & $-3,265$ \\
\hline$\Delta \mathbf{a}_{\mathbf{p}}=$ & 0 & $\Delta$ aprevisto $=$ & 0,62 & \\
\hline
\end{tabular}


A imagem micrográfica deste corpo de prova apresentou a mesma característica da encontrada no CP_D_0.2, fratura 100\% frágil após a pré-trinca de fadiga, visto na Figura 42.

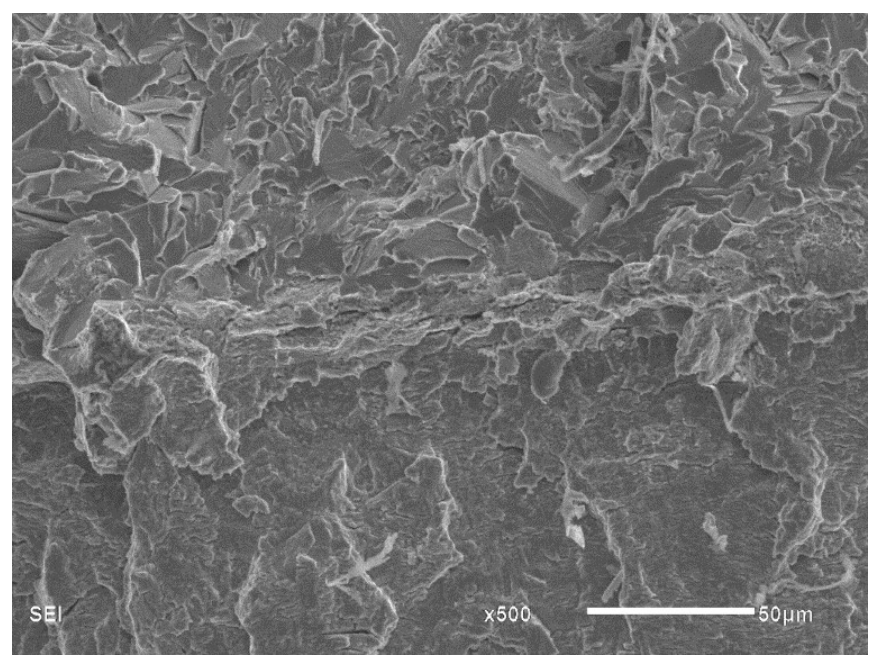

Figura 42 - Ampliação da região entre a pré-trinca de fadiga e a frente da trinca do CP_D_0.3.

Agora, analisando o desenvolvimento do CP_D_0.45, mesmo que o registro do ensaio do CP_D_0.45 tenha apresentado um gráfico mais próximo ao encontrado nas literaturas, ver Gráfico 7 , e as razões de $\mathrm{a}_{\mathrm{i}} / \mathrm{W}$ tenham resultado em valores equiparados ao $\mathrm{a}_{\mathrm{M}(\mathrm{i})} / \mathrm{W}$ deste corpo de prova que equivale aproximadamente 0,485 e a $\mathrm{M}$ (i) igual a $16,3 \mathrm{~mm}$, ainda assim foi encontrado valores negativos de $\Delta \mathrm{a}$ em $92,45 \%$ dos pontos incrementais consequentes, como mostra na Tabela XX.

Tabela XXI - Parâmetros do ensaio do CP D 0.45

\begin{tabular}{|r|c|c|c|c|}
\hline \multicolumn{1}{|c|}{ Posição } & $\begin{array}{c}\mathbf{\Delta C M O D} \\
(\mathbf{m m})\end{array}$ & $\begin{array}{c}\mathbf{\Delta} \mathbf{P}_{(\mathbf{i})} \\
\mathbf{( N )}\end{array}$ & $\begin{array}{c}\text { Compliance } \\
\text { medido }(\mathbf{m m} / \mathbf{N})\end{array}$ & $\boldsymbol{\mu}$ \\
\hline $\mathbf{1}$ & 0,0029 & 1379,9 & $2,11 \mathrm{E}-06$ & $3,13 \mathrm{E}-01$ \\
\hline $\mathbf{2}$ & 0,0032 & 1302,9 & $2,49 \mathrm{E}-06$ & $2,96 \mathrm{E}-01$ \\
\hline $\mathbf{3}$ & 0,0026 & 1383,3 & $1,89 \mathrm{E}-06$ & $3,25 \mathrm{E}-01$ \\
\hline $\mathbf{4}$ & 0,0034 & 1428,2 & $2,35 \mathrm{E}-06$ & $3,02 \mathrm{E}-01$ \\
\hline $\mathbf{5}$ & 0,0038 & 1710,2 & $2,20 \mathrm{E}-06$ & $3,09 \mathrm{E}-01$ \\
\hline $\mathbf{6}$ & 0,0039 & 1534 & $2,53 \mathrm{E}-06$ & $2,94 \mathrm{E}-01$ \\
\hline $\mathbf{7}$ & 0,0038 & 1592,1 & $2,36 \mathrm{E}-06$ & $3,01 \mathrm{E}-01$ \\
\hline $\mathbf{8}$ & 0,0037 & 1532,4 & $2,32 \mathrm{E}-06$ & $3,03 \mathrm{E}-01$ \\
\hline $\mathbf{9}$ & 0,0029 & 1314,5 & $2,18 \mathrm{E}-06$ & $3,10 \mathrm{E}-01$ \\
\hline $\mathbf{1 0}$ & 0,0032 & 1558,9 & $2,07 \mathrm{E}-06$ & $3,15 \mathrm{E}-01$ \\
\hline $\mathbf{1 1}$ & 0,0027 & 1574,5 & $1,71 \mathrm{E}-06$ & $3,36 \mathrm{E}-01$ \\
\hline $\mathbf{1 2}$ & 0,004 & 1648,3 & $2,42 \mathrm{E}-06$ & $2,99 \mathrm{E}-01$ \\
\hline
\end{tabular}




\begin{tabular}{|c|c|c|c|c|}
\hline 13 & 0,0075 & 3075,3 & $2,45 \mathrm{E}-06$ & $2,98 \mathrm{E}-01$ \\
\hline 14 & 0,0097 & 3639,7 & $2,66 \mathrm{E}-06$ & $2,89 \mathrm{E}-01$ \\
\hline 15 & 0,01 & 3701,5 & 2,71E-06 & $2,87 \mathrm{E}-01$ \\
\hline 16 & 0,109 & 3971,5 & $2,75 \mathrm{E}-06$ & $2,86 \mathrm{E}-01$ \\
\hline 17 & 0,0140 & 3714,4 & $2,79 \mathrm{E}-06$ & $2,84 \mathrm{E}-01$ \\
\hline 18 & 0,009 & 3351,9 & $2,68 \mathrm{E}-06$ & $2,88 \mathrm{E}-01$ \\
\hline 19 & 0,109 & 4167,5 & $2,63 \mathrm{E}-06$ & $2,90 \mathrm{E}-01$ \\
\hline 20 & 0,013 & 4569,6 & $2,85 \mathrm{E}-06$ & $2,82 \mathrm{E}-01$ \\
\hline 21 & 0,0131 & 4758,4 & $2,75 \mathrm{E}-06$ & $2,86 \mathrm{E}-01$ \\
\hline 22 & 0,0135 & 4560,3 & $2,96 \mathrm{E}-06$ & $2,78 \mathrm{E}-01$ \\
\hline 23 & 0,0142 & 5032,7 & $2,82 \mathrm{E}-06$ & $2,83 \mathrm{E}-01$ \\
\hline 24 & 0,0166 & 6264,5 & $2,65 \mathrm{E}-06$ & $2,89 \mathrm{E}-01$ \\
\hline 25 & 0,0173 & 6969,2 & $2,48 \mathrm{E}-06$ & $2,96 \mathrm{E}-01$ \\
\hline 26 & 0,0178 & 6808,6 & $2,62 \mathrm{E}-06$ & 2,91E-01 \\
\hline 27 & 0,0199 & 6997,4 & $2,84 \mathrm{E}-06$ & $2,82 \mathrm{E}-01$ \\
\hline 28 & 0,0191 & 6811,5 & $2,80 \mathrm{E}-06$ & $2,84 \mathrm{E}-01$ \\
\hline 29 & 0,0212 & 7404,2 & $2,47 \mathrm{E}-06$ & $2,97 \mathrm{E}-01$ \\
\hline 30 & 0,0217 & 7720,4 & $2,82 \mathrm{E}-06$ & $2,83 \mathrm{E}-01$ \\
\hline 31 & 0,0215 & 7574,2 & $2,84 \mathrm{E}-06$ & $2,82 \mathrm{E}-01$ \\
\hline 32 & 0,0274 & 9603,5 & $2,85 \mathrm{E}-06$ & $2,82 \mathrm{E}-01$ \\
\hline 33 & 0,0258 & 9222,5 & $2,79 \mathrm{E}-06$ & $2,84 \mathrm{E}-01$ \\
\hline 34 & 0,0286 & 10389 & $2,75 \mathrm{E}-06$ & $2,86 \mathrm{E}-01$ \\
\hline 35 & 0,0274 & 9925,4 & $2,76 \mathrm{E}-06$ & $2,85 \mathrm{E}-01$ \\
\hline 36 & 0,0267 & 9611,2 & $2,78 \mathrm{E}-06$ & $2,85 \mathrm{E}-01$ \\
\hline 37 & 0,0325 & 11252 & 2,89E-06 & $2,81 \mathrm{E}-01$ \\
\hline 38 & 0,030 & 10947 & 2,74E-06 & $2,86 \mathrm{E}-01$ \\
\hline 39 & 0,0302 & 11006 & $2,74 \mathrm{E}-06$ & $2,86 \mathrm{E}-01$ \\
\hline 40 & 0,0293 & 10614 & $2,76 \mathrm{E}-06$ & $2,85 \mathrm{E}-01$ \\
\hline 41 & 0,0322 & 11597 & $2,78 \mathrm{E}-06$ & $2,85 \mathrm{E}-01$ \\
\hline 42 & 0,0319 & 11549 & $2,76 \mathrm{E}-06$ & $2,85 \mathrm{E}-01$ \\
\hline 43 & 0,0337 & 12117 & $2,78 \mathrm{E}-06$ & $2,84 \mathrm{E}-01$ \\
\hline 44 & 0,0353 & 12843 & $2,75 \mathrm{E}-06$ & $2,86 \mathrm{E}-01$ \\
\hline 45 & 0,0384 & 13430 & $2,86 \mathrm{E}-06$ & $2,82 \mathrm{E}-01$ \\
\hline 46 & 0,0356 & 12557 & $2,84 \mathrm{E}-06$ & $2,82 \mathrm{E}-01$ \\
\hline 47 & 0,0389 & 13192 & $2,95 \mathrm{E}-06$ & $2,78 \mathrm{E}-01$ \\
\hline 48 & 0,0383 & 13127 & $2,91 \mathrm{E}-06$ & $2,80 \mathrm{E}-01$ \\
\hline 49 & 0,0392 & 14016 & $2,80 \mathrm{E}-06$ & $2,84 \mathrm{E}-01$ \\
\hline 50 & 0,0398 & 13719 & $2,90 \mathrm{E}-06$ & $2,80 \mathrm{E}-01$ \\
\hline 51 & 0,0417 & 13984 & 2,98E-06 & $2,78 \mathrm{E}-01$ \\
\hline 52 & 0,0544 & 14737 & $3,69 \mathrm{E}-06$ & $2,57 \mathrm{E}-01$ \\
\hline 53 & 0,054 & 15220 & $3,55 \mathrm{E}-06$ & $2,60 \mathrm{E}-01$ \\
\hline
\end{tabular}




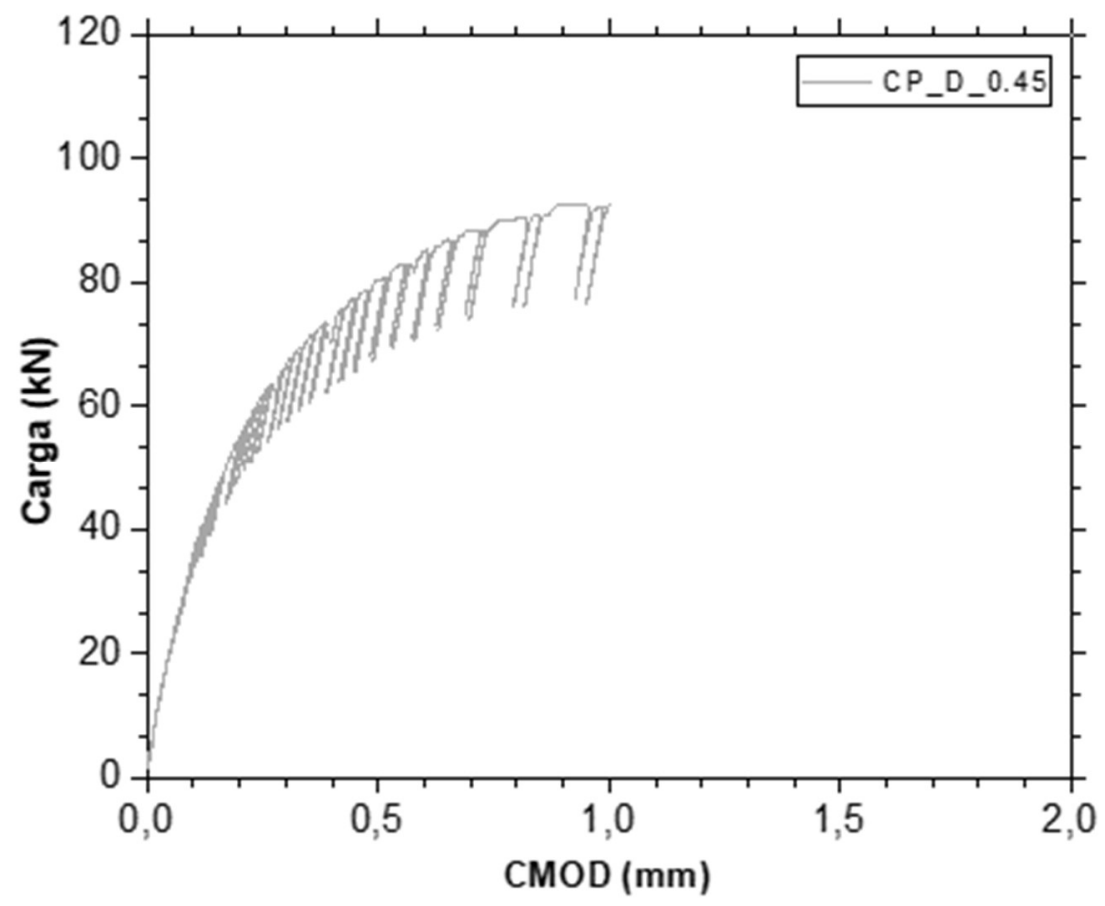

Gráfico 7 - Curva P vs. CMOD referente ao CP_D_0.45

Tabela XXII - Parâmetros da curva J- $\Delta \mathrm{a}$ do CP_D_0.45

\begin{tabular}{|r|c|c|c|c|c|}
\hline \multicolumn{1}{|c|}{ Posição } & $\begin{array}{c}\mathbf{J} \\
\left(\mathbf{k J} / \mathbf{m}^{\mathbf{2}}\right)\end{array}$ & $\mathbf{a}(\mathbf{i}) / \mathbf{W}$ & $\begin{array}{c}\mathbf{a}(\mathbf{i}) \\
(\mathbf{m m})\end{array}$ & $\begin{array}{c}\mathbf{\Delta a} \\
(\mathbf{m m})\end{array}$ & $\begin{array}{c}\Delta \mathbf{a} \text { TOTAL } \\
(\mathbf{m m})\end{array}$ \\
\hline $\mathbf{1}$ & 0,162767333 & 0,421373434 & 10,5 & $-1,600039$ & $-1,600039$ \\
\hline $\mathbf{2}$ & 0,114023121 & 0,453283086 & 11,3 & 0,797741 & $-0,802298$ \\
\hline $\mathbf{3}$ & 0,169672182 & 0,399717652 & 10,0 & $-1,339136$ & $-2,141434$ \\
\hline $\mathbf{4}$ & 0,164036526 & 0,442129607 & 11,1 & 1,060299 & $-1,081135$ \\
\hline $\mathbf{5}$ & 0,226971008 & 0,429144776 & 10,7 & $-0,324621$ & $-1,405756$ \\
\hline $\mathbf{6}$ & 0,209382406 & 0,456892179 & 11,4 & 0,693685 & $-0,712071$ \\
\hline $\mathbf{7}$ & 0,244997709 & 0,443169613 & 11,1 & $-0,343064$ & $-1,055135$ \\
\hline $\mathbf{8}$ & 0,262014065 & 0,439716619 & 11,0 & $-0,086325$ & $-1,141460$ \\
\hline $\mathbf{9}$ & 0,249852232 & 0,427736748 & 10,7 & $-0,299497$ & $-1,440956$ \\
\hline $\mathbf{1 0}$ & 0,273231117 & 0,417434224 & 10,4 & $-0,257563$ & $-1,698519$ \\
\hline $\mathbf{1 1}$ & 0,411001267 & 0,380618437 & 9,5 & $-0,920395$ & $-2,618914$ \\
\hline $\mathbf{1 2}$ & 0,365183124 & 0,448094599 & 11,2 & 1,686904 & $-0,932010$ \\
\hline $\mathbf{1 3}$ & 0,78310393 & 0,450011887 & 11,3 & 0,047932 & $-0,884078$ \\
\hline $\mathbf{1 4}$ & 1,181861428 & 0,466398491 & 11,7 &, 409665 & $-0,474413$ \\
\hline $\mathbf{1 5}$ & 1,513487452 & 0,470032845 & 11,8 & 0,090859 & $-0,383554$ \\
\hline $\mathbf{1 6}$ & 1,999649088 & 0,472742903 & 11,8 & 0,067751 & $-0,315802$ \\
\hline $\mathbf{1 7}$ & 2,466016888 & 0,47607696 & 11,9 & 0,083351 & $-0,232451$ \\
\hline $\mathbf{1 8}$ & 3,039918214 & 0,467956446 & 11,7 & $-0,203013$ & $-0,435464$ \\
\hline $\mathbf{1 9}$ & 4,008773762 & 0,46406521 & 11,6 & $-0,097281$ & $-0,532745$ \\
\hline $\mathbf{2 0}$ & 4,38539609 & 0,480288187 & 12,0 & 0,405574 & $-0,127170$ \\
\hline $\mathbf{2 1}$ & 5,492021158 & 0,472807371 & 11,8 & $-0,187020$ & $-0,314191$ \\
\hline
\end{tabular}




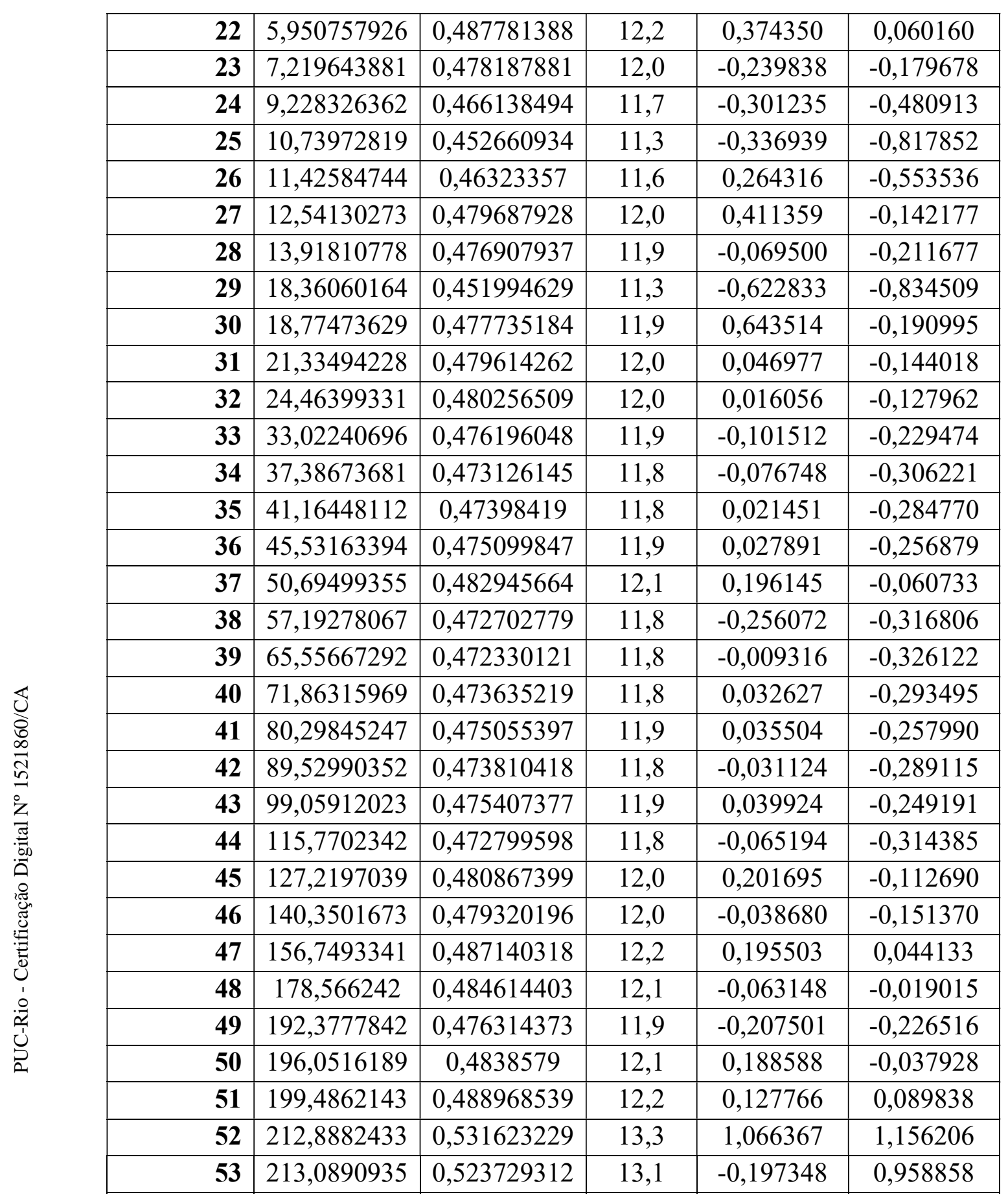

Um ponto relevante por ter atingido esta condição está vinculado a diferença de cerca de 1,515 $\mathrm{mm}$ obtido entre $\mathrm{a}_{\mathrm{M}(\mathrm{i})}$ e a0q. A soma de tal diferença com as variações de $\mathrm{a}_{(\mathrm{i})} / \mathrm{W}$ se tornam fatores imprescindíveis para geração $\Delta \mathrm{a}$ TOTAL negativos, fazendo com que o valor de $\Delta \mathrm{a}_{(\mathrm{i})}$ não supra o valor negativo de $\Delta$ aTOTAL(i-1), persistindo na obtenção de $\Delta$ aTOTAL negativo em quase todos os pontos. Para que se tivesse obtido valores mais condizentes ao esperado, idealizou-se a resultante do compliance conforme valor mostrado na Tabela XXII. 
Tabela XXIII - Comparação entre a dimensão da trinca mensurada do CP_D_0.45 com a calculada

\begin{tabular}{|l|c|c|c|c|}
\hline \multicolumn{5}{|c|}{ Resultados para o CP_D_0.45 } \\
\hline & Mensurado (mm) & & Compliance $(\mathrm{mm})$ & $\boldsymbol{\Delta}$ \\
\hline $\mathbf{a} \mathbf{M}(\mathbf{i})=$ & 12,1340 & $\mathbf{a 0 q}=$ & 10,62 & $-1,515$ \\
\hline $\mathbf{a}_{\mathbf{p}}=$ & 13,6270 & $\mathbf{a p}_{\mathbf{p}}$ estimado $=$ & 13,1 & $-0,53$ \\
\hline $\mathbf{\Delta a}=$ & 1,49 & $\boldsymbol{\Delta} \mathbf{a}$ previsto $=$ & 2,48 & \\
\hline
\end{tabular}

Tabela XXIV - Valor ideal dos parâmetros de ensaio para CP_D_0.45

\begin{tabular}{|c|c|c|c|}
\hline $\begin{array}{c}\text { Compliance } \\
(\mathbf{m m} / \mathbf{N})\end{array}$ & $\boldsymbol{\mu}$ & $\mathbf{a}(\mathbf{1}) / \mathbf{W}$ & $\begin{array}{c}\mathbf{a}_{(\mathbf{1})} \\
(\mathbf{m m})\end{array}$ \\
\hline $2,11 \mathrm{E}-06$ & $2,8 \mathrm{E}-01$ & 0,485 & 12,1 \\
\hline
\end{tabular}

Diante desses resultados apresentados, não foi viável plotar um gráfico J- $\Delta \mathrm{a}$ para o CP_D_0.45.

Para obtenção do tamanho físico da extensão dúctil de trinca foi levada em consideração apenas a região central do corpo de prova já que na região adjacente a extremidade, os valores de $\mathrm{a}_{\mathrm{p}}-\mathrm{a} \mathrm{M}(\mathrm{i})$ seriam muito inferiores ao da região central o que afetaria bastante no resultado de apuração do $\Delta \mathrm{a}$. A característica microscópica da região de extensão dúctil de trinca do CP_D_0.45 se encontra apresentada na Figura 44, onde pode ser visualizado uma região mista com dimples rasos e clivagem.

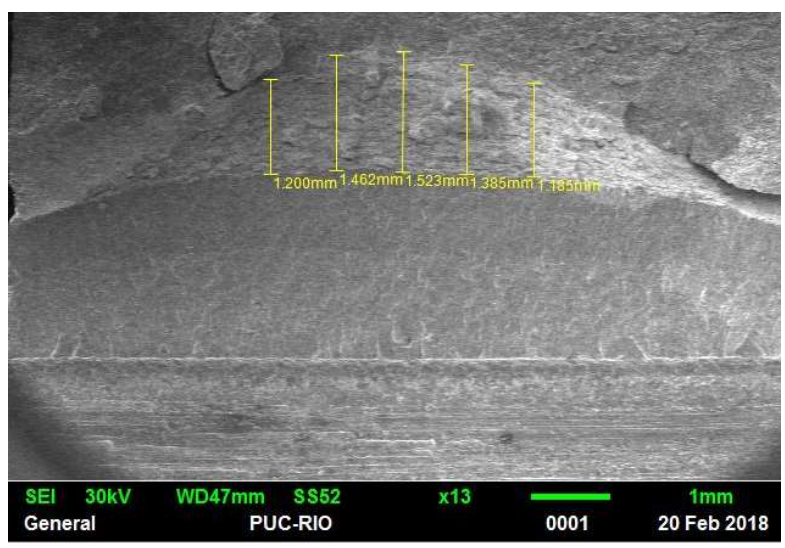

Figura 43 - Medição da extensão dúctil de trinca do CP_D_0.45. 


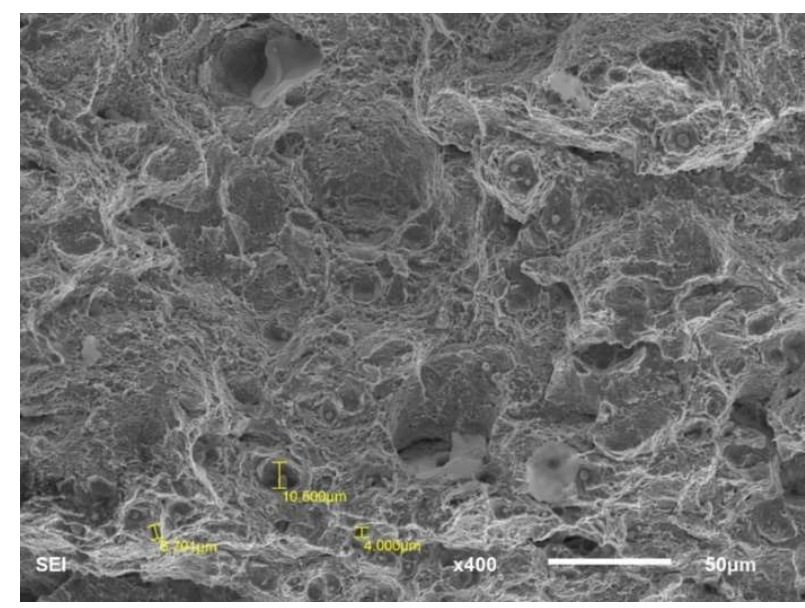

Figura 44 - Microestrutura da região da extensão dúctil.

Quanto ao CP_D_0.6, uma anàlise semelhante à realizada com o CP_D_0.3 teve que ser efetuada. Neste ensaio os valores gerados do compliance, Tabela XXIV, induziu a aquisição de $\mathrm{a}_{(\mathrm{i})} / \mathrm{W}$ menores que o $\mathrm{a}_{\mathrm{M}(\mathrm{i})} / \mathrm{W}$, assim como valor de tamanho de trinca inferior a existente fisicamente, $16,26 \mathrm{~mm}$, ver Tabela XXV.

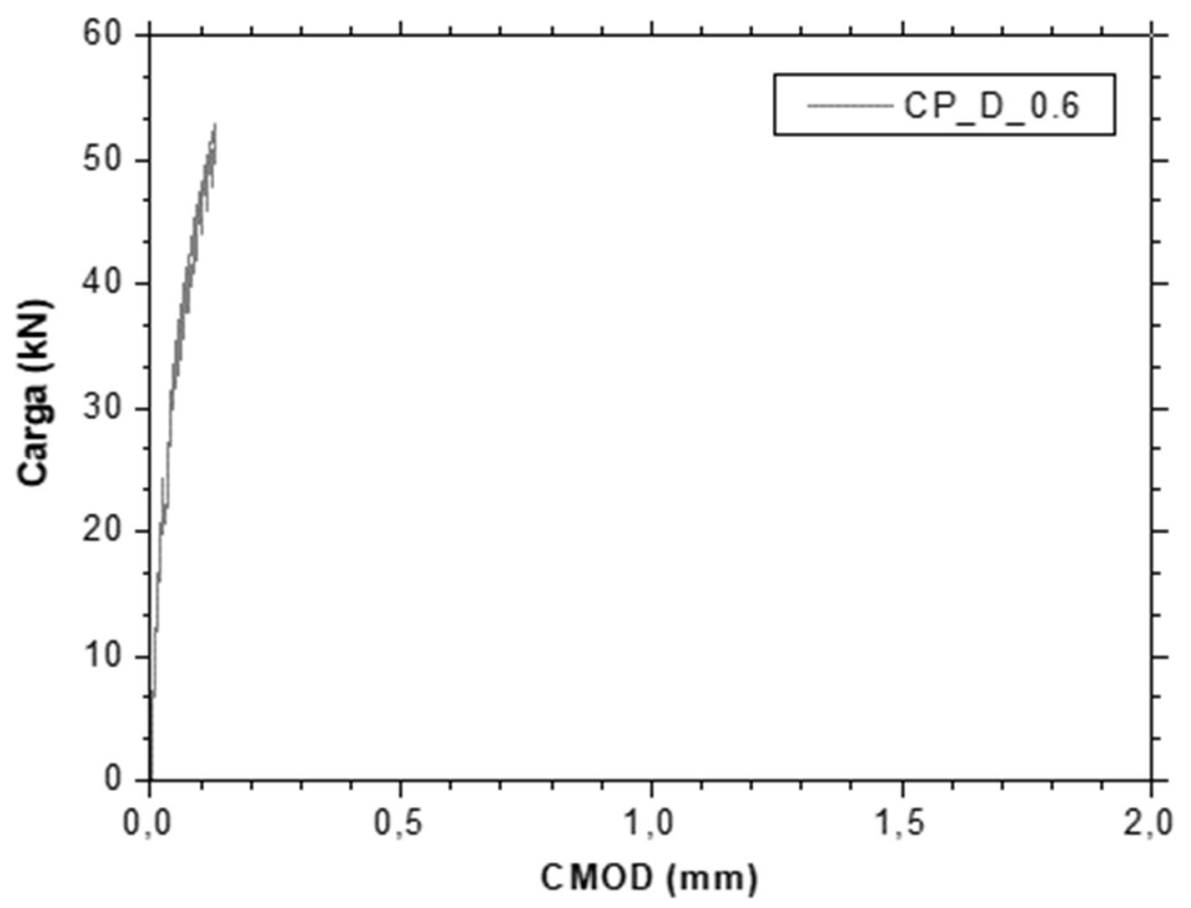

Gráfico 8 - Curva P vs. CMOD referente ao CP_D_0.6

Tabela XXV - Parâmetros do ensaio do CP_D_0.6

\begin{tabular}{|c|c|c|c|c|}
\hline Posição & $\begin{array}{c}\Delta \mathbf{C M O D}_{(\mathbf{i})} \\
(\mathbf{m m})\end{array}$ & $\begin{array}{c}\Delta \mathbf{P}_{(\mathbf{i})} \\
\mathbf{( N )}\end{array}$ & $\begin{array}{c}\text { Compliance } \\
\text { medido }(\mathbf{m m} / \mathbf{N})\end{array}$ & $\boldsymbol{\mu}$ \\
\hline $\mathbf{1}$ & 0,0027 & 3246,3 & $8,41 \mathrm{E}-07$ & $4,20 \mathrm{E}-01$ \\
\hline
\end{tabular}




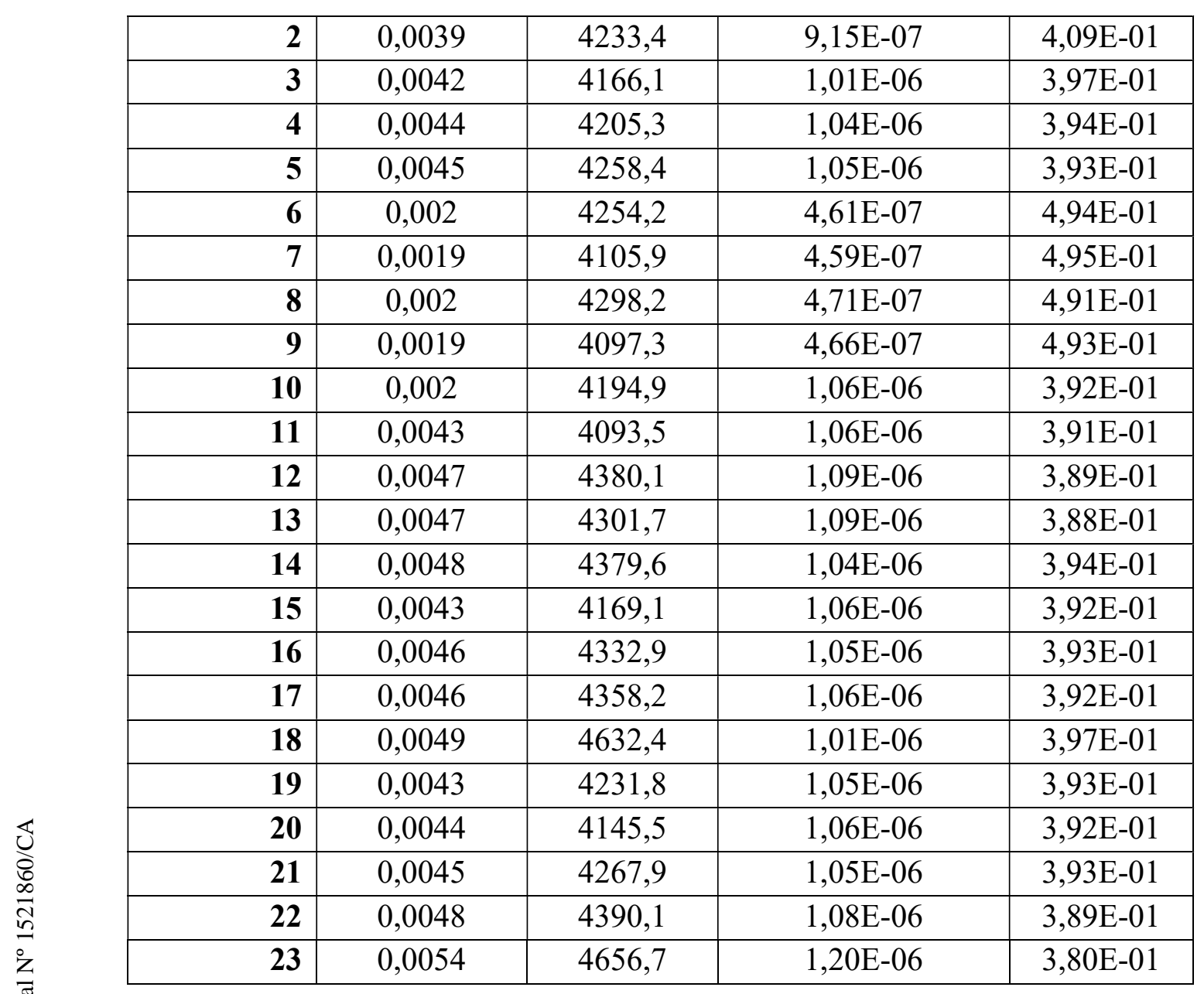

Tabela XXVI - Parâmetros da curva J- $\Delta$ a do CP_D_0.6

\begin{tabular}{|r|c|c|c|c|c|}
\hline Posição & $\begin{array}{c}\mathbf{J} \\
\left(\mathbf{k J} / \mathbf{m}^{\mathbf{2}}\right)\end{array}$ & $\mathbf{a}(\mathbf{i}) / \mathbf{W}$ & $\begin{array}{c}\mathbf{a}(\mathbf{i}) \\
(\mathbf{m m})\end{array}$ & $\begin{array}{c}\Delta \mathbf{a} \\
(\mathbf{m m})\end{array}$ & $\begin{array}{c}\Delta \mathbf{a} \text { TOTAL } \\
(\mathbf{m m})\end{array}$ \\
\hline $\mathbf{1}$ & 0,088286109 & 0,250874395 & 6,3 & $-9,99677$ & $-9,99677$ \\
\hline $\mathbf{2}$ & 0,150399407 & 0,265186531 & 6,6 & 0,35780 & $-9,63896$ \\
\hline $\mathbf{3}$ & 0,242211749 & 0,282511459 & 7,1 & 0,43312 & $-9,20584$ \\
\hline $\mathbf{4}$ & 0,372907326 & 0,288097009 & 7,2 & 0,13964 & $-9,06620$ \\
\hline $\mathbf{5}$ & 0,518407375 & 0,289522433 & 7,2 & 0,03564 & $-9,03056$ \\
\hline $\mathbf{6}$ & 0,394881832 & 0,160499271 & 4,0 & $-3,22558$ & $-12,25614$ \\
\hline $\mathbf{7}$ & 0,479023959 & 0,159865738 & 4,0 & $-0,01584$ & $-12,27198$ \\
\hline $\mathbf{8}$ & 0,594037527 & 0,163087886 & 4,1 & 0,08055 & $-12,19143$ \\
\hline $\mathbf{9}$ & 0,732389738 & 0,161755485 & 4,0 & $-0,03331$ & $-12,22474$ \\
\hline $\mathbf{1 0}$ & 2,883637372 & 0,290914025 & 7,3 & 3,22896 & $-8,99577$ \\
\hline $\mathbf{1 1}$ & 3,254158455 & 0,291693164 & 7,3 & 0,01948 & $-8,97630$ \\
\hline $\mathbf{1 2}$ & 3,587368493 & 0,295451239 & 7,4 & 0,09395 & $-8,88234$ \\
\hline $\mathbf{1 3}$ & 4,137296512 & 0,296192891 & 7,4 & 0,01854 & $-8,86380$ \\
\hline $\mathbf{1 4}$ & 5,186116096 & 0,287277182 & 7,2 & $-0,22289$ & $-9,08670$ \\
\hline $\mathbf{1 5}$ & 6,296308225 & 0,290711358 & 7,3 & 0,08585 & $-9,00084$ \\
\hline $\mathbf{1 6}$ & 7,573425703 & 0,289150766 & 7,2 & $-0,03901$ & $-9,03986$ \\
\hline
\end{tabular}




\begin{tabular}{|r|c|c|c|c|c|}
\hline $\mathbf{1 7}$ & 9,10495681 & 0,291127659 & 7,3 & 0,04942 & $-8,99043$ \\
\hline $\mathbf{1 8}$ & 10,75968696 & 0,282608278 & 7,1 & $-0,21298$ & $-9,20342$ \\
\hline $\mathbf{1 9}$ & 12,31985445 & 0,289661271 & 7,2 & 0,17632 & $-9,02709$ \\
\hline $\mathbf{2 0}$ & 14,29819472 & 0,291240643 & 7,3 & 0,03948 & $-8,98761$ \\
\hline $\mathbf{2 1}$ & 16,71492746 & 0,288700186 & 7,2 & $-0,06351$ & $-9,05112$ \\
\hline $\mathbf{2 2}$ & 19,07056706 & 0,295177277 & 7,4 & 0,16193 & $-8,88919$ \\
\hline $\mathbf{2 3}$ & 21,96597797 & 0,308277311 & 7,7 & 0,32750 & $-8,56169$ \\
\hline
\end{tabular}

A comparação entre os valores mesurados fisicamente e os calculados indiretamente pelo método compliance, constam na Tabela XXVII, constatando-se uma diferença de quase $10 \mathrm{~mm}$ entre os valores.

Tabela XXVII - Comparação entre a dimensão da trinca mensurada com a calculada do CP D 0.6

\begin{tabular}{|l|c|c|c|c|}
\hline \multicolumn{5}{|c|}{ Resultados para o CP_D_0.6 } \\
\hline & Mensurado (mm) & & Compliance $(\mathrm{mm})$ & $\boldsymbol{\Delta}$ \\
\hline $\mathbf{a} \mathbf{M}(\mathbf{i})=$ & 16,2686 & $\mathbf{a 0 q}=$ & 6,6547 & 9,6138 \\
\hline $\mathbf{a}_{\mathbf{p}}=$ & 16,8450 & $\mathbf{a p e s t i m a d o}_{\mathbf{n}}=$ & 7,3794 & 9,4655 \\
\hline $\mathbf{\Delta a}=$ & 0,5764 & $\mathbf{\Delta}$ aprevisto $=$ & 0,7246 & $-0,1483$ \\
\hline
\end{tabular}

Para que o ensaio fosse satisfatório, o resultado do compliance deveria ter sido no mínimo 6,6115E-06, o que resultaria em valores mais acurados de $\mu$, como apresentado na Tabela XXVIII.

Tabela XXVIII - Valor ideal dos parâmetros de ensaio para CP_D_0.6

\begin{tabular}{|c|c|c|c|}
\hline $\begin{array}{c}\text { Compliance } \\
(\mathbf{m m} / \mathbf{N})\end{array}$ & $\mathbf{M}$ & $\mathbf{a}_{(\mathbf{1})} / \mathbf{W}$ & $\begin{array}{c}\mathbf{a}(\mathbf{1}) \\
(\mathbf{m m})\end{array}$ \\
\hline $6,6115 \mathrm{E}-06$ & $2,0456 \mathrm{E}-1$ & 0,65 & 16,3 \\
\hline
\end{tabular}

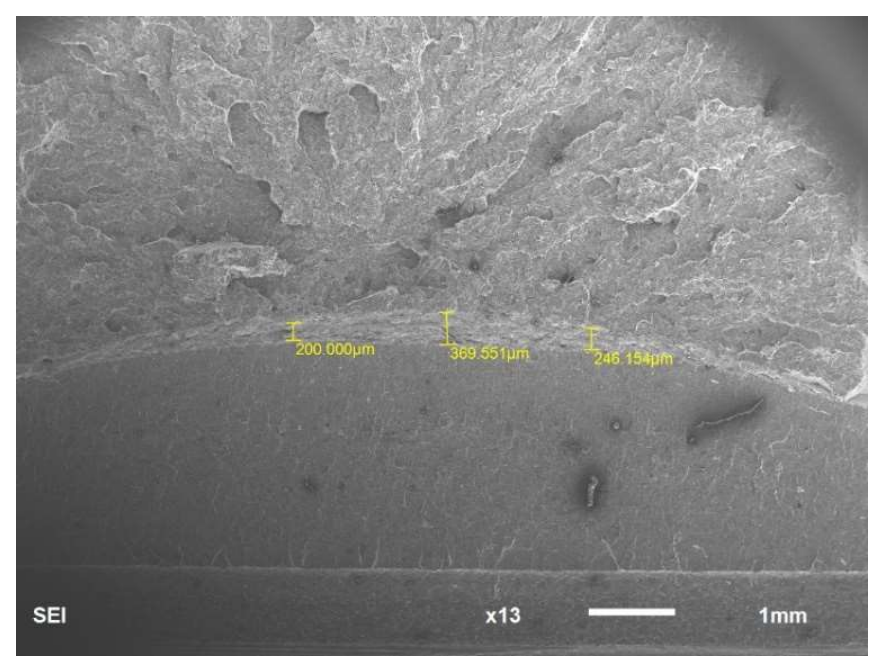

Figura 45 - Determinação dos pontos de medição para determinação da extensão dúctil de trinca 
Tornando agora para análise efetuada para o CP_D_0.7, dados tratados a partir do Gráfico 9 permitiu a apuração de valores constados na Tabela XXIX. Aplicando um descarregamento inicial de $6091 \mathrm{kN}$ o corpo de prova foi a fratura quando atingiu o incremento 15 , com valor aproximado de carga de $34 \mathrm{kN}$. O resultado do compliance no incremento 1 foi encontrado 1,022E-0,5 mm/N chegando a um valor de $1,52 \mathrm{E}-0,5 \mathrm{~mm} / \mathrm{N}$ no incremento final. Como o corpo de prova fraturou enquanto estava sendo ensaiado, apenas os registros dos dados até o incremento 14 foram considerados para desenvolvimento dos cálculos pertinentes e levantamento da curva $\mathrm{J}-\Delta \mathrm{a}$

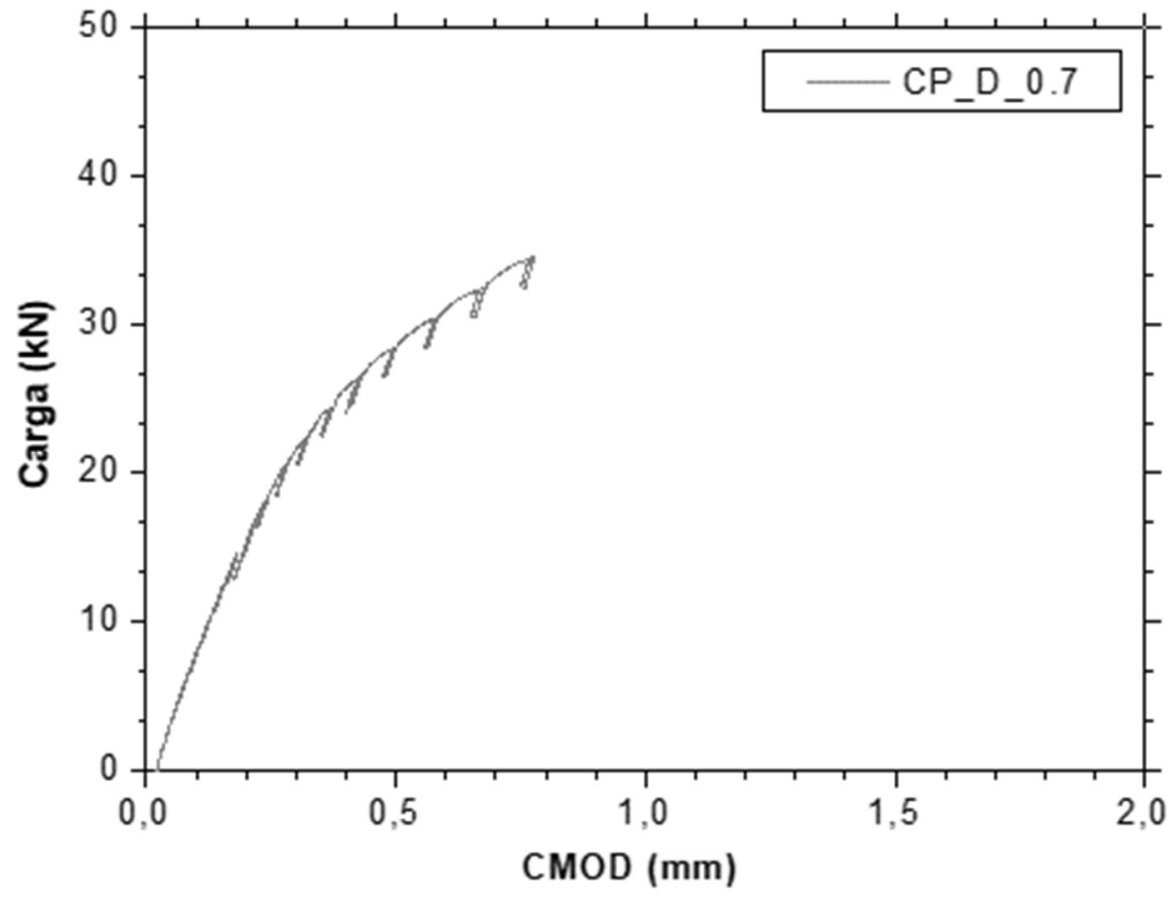

Gráfico 9 - Curva P vs. CMOD referente ao CP_D_0.7

Tabela XXIX - Parâmetros do ensaio do CP_D_0.7

\begin{tabular}{|r|c|c|c|c|}
\hline Posição & $\begin{array}{c}\Delta \mathbf{C M O D}_{(\mathbf{i})} \\
\mathbf{( m m )}\end{array}$ & $\begin{array}{c}\Delta \mathbf{P}_{(\mathbf{i})} \\
\mathbf{( N )}\end{array}$ & $\begin{array}{c}\text { Compliance } \\
\text { medido }(\mathbf{m m} / \mathbf{N})\end{array}$ & $\mathbf{M}$ \\
\hline $\mathbf{1}$ & 0,014625 & 6298,53 & $1,02 \mathrm{E}-05$ & $1,72 \mathrm{E}-01$ \\
\hline $\mathbf{2}$ & 0,016430 & 8358,73 & $1,05 \mathrm{E}-05$ & $1,70 \mathrm{E}-01$ \\
\hline $\mathbf{3}$ & 0,017555 & 10351,75 & $1,05 \mathrm{E}-05$ & $1,70 \mathrm{E}-01$ \\
\hline $\mathbf{4}$ & 0,018640 & 12464,10 & $1,05 \mathrm{E}-05$ & $1,70 \mathrm{E}-01$ \\
\hline $\mathbf{5}$ & 0,024450 & 14565,70 & $1,05 \mathrm{E}-05$ & $1,70 \mathrm{E}-01$ \\
\hline $\mathbf{6}$ & 0,020410 & 16526,14 & $1,06 \mathrm{E}-05$ & $1,69 \mathrm{E}-01$ \\
\hline $\mathbf{7}$ & 0,019875 & 18355,50 & $1,06 \mathrm{E}-05$ & $1,69 \mathrm{E}-01$ \\
\hline $\mathbf{8}$ & 0,021210 & 20392,13 & $1,07 \mathrm{E}-05$ & $1,69 \mathrm{E}-01$ \\
\hline $\mathbf{9}$ & 0,021090 & 22404,80 & $1,08 \mathrm{E}-05$ & $1,68 \mathrm{E}-01$ \\
\hline
\end{tabular}




\begin{tabular}{|r|l|l|l|l|}
\hline $\mathbf{1 0}$ & 0,021385 & 24490,90 & $1,10 \mathrm{E}-05$ & $1,66 \mathrm{E}-01$ \\
\hline $\mathbf{1 1}$ & 0,025850 & 26566,30 & $1,10 \mathrm{E}-05$ & $1,66 \mathrm{E}-01$ \\
\hline $\mathbf{1 2}$ & 0,015755 & 27454,02 & $1,14 \mathrm{E}-05$ & $1,64 \mathrm{E}-01$ \\
\hline $\mathbf{1 3}$ & 0,022935 & 30433,09 & $1,15 \mathrm{E}-05$ & $1,64 \mathrm{E}-01$ \\
\hline $\mathbf{1 4}$ & 0,023180 & 32548,10 & $1,15 \mathrm{E}-05$ & $1,63 \mathrm{E}-01$ \\
\hline
\end{tabular}

Tabela XXX - Parâmetros da curva J- $\Delta$ a do CP_D_0.7

\begin{tabular}{|c|c|c|c|c|c|}
\hline Posição & $\begin{array}{c}\mathbf{J} \\
\left(\mathbf{k J} / \mathbf{m}^{2}\right)\end{array}$ & $\mathbf{a}_{(\mathbf{i})} / \mathbf{W}$ & $\begin{array}{c}\mathbf{a}(\mathbf{i}) \\
(\mathbf{m m})\end{array}$ & $\begin{array}{c}\Delta \mathbf{a} \\
(\mathbf{m m})\end{array}$ & $\begin{array}{c}\Delta \mathbf{a} \text { TOTAL } \\
(\mathbf{m m})\end{array}$ \\
\hline 1 & 0,875789115 & 0,739782892 & 18,49457 & 0,34326 & 0,34326 \\
\hline 2 & 1,607585397 & 0,744828492 & 18,62071 & 0,12614 & 0,46940 \\
\hline 3 & 2,639002256 & 0,745240731 & 18,63102 & 0,01031 & 0,47971 \\
\hline 4 & 4,04168712 & 0,745893893 & 18,64735 & 0,01633 & 0,49603 \\
\hline 5 & 3,775064476 & 0,781306367 & 19,53266 & 0,88531 & 1,38135 \\
\hline 6 & 9,891195723 & 0,737208491 & 18,43021 & $-1,10245$ & 0,27890 \\
\hline 7 & 11,40726789 & 0,747448394 & 18,68621 & 0,25600 & 0,53490 \\
\hline 8 & 15,22032932 & 0,748661412 & 18,71654 & 0,03033 & 0,56522 \\
\hline 9 & 20,36485432 & 0,752000916 & 18,80002 & 0,08349 & 0,64871 \\
\hline 10 & 27,46192903 & 0,755860495 & 18,89651 & 0,09649 & 0,74520 \\
\hline 11 & 37,32793848 & 0,757242894 & 18,93107 & 0,03456 & 0,77976 \\
\hline 12 & 47,10713902 & 0,762680703 & 19,06702 & 0,13595 & 0,91571 \\
\hline 13 & 65,56976127 & 0,764060535 & 19,10151 & 0,03450 & 0,95020 \\
\hline 14 & 87,73117284 & 0,764775896 & 19,11940 & 0,01788 & 0,96808 \\
\hline
\end{tabular}

Com o resultado de $\mathrm{J}$ e $\Delta \mathrm{a}$ TOTAL positivos, foi possível aproveitar todos os pares para plotagem do Gráfico 10 e também determinar a curva de ajuste entre os pontos. O mesmo procedimento de deslocamento do eixo das abscissas efetuado no CP_D_0.2, foi reproduzido no CP_D_0.7, possibilitando a interseção entre a linha de construção e curva de ajuste para se encontrar $\mathrm{J}_{\mathrm{IC}}$, determinado seu valor igual a $3,8 \mathrm{~kJ} / \mathrm{m}^{2}$.

Tabela XXXI - Valor de $\mathrm{J}_{\mathrm{IC}}$ determinado a partir da curva J-R para o CP_D_0.7

\begin{tabular}{|c|c|}
\hline \multicolumn{2}{|c|}{ CP_D_0.7 } \\
\hline $\mathrm{J}_{\mathrm{IC}}\left(\mathrm{kJ} / \mathrm{m}^{2}\right)$ & $\Delta \mathrm{a} \min (\mathrm{mm})$ \\
\hline 3,8 & 0,4605 \\
\hline
\end{tabular}

Pode-se observar assim, que o valor de $\mathrm{J}_{\mathrm{IC}}$ para o CP_D_0.7 é menor que o do CP_D_0.2, mesmo ele tenha atingido valores de $\mathrm{J}$ superiores em cerca de 3 vezes. O que indica que um componente com dimensão de trinca mais profunda requer uma quantidade de energia menor para iniciar a extensão do defeito. 


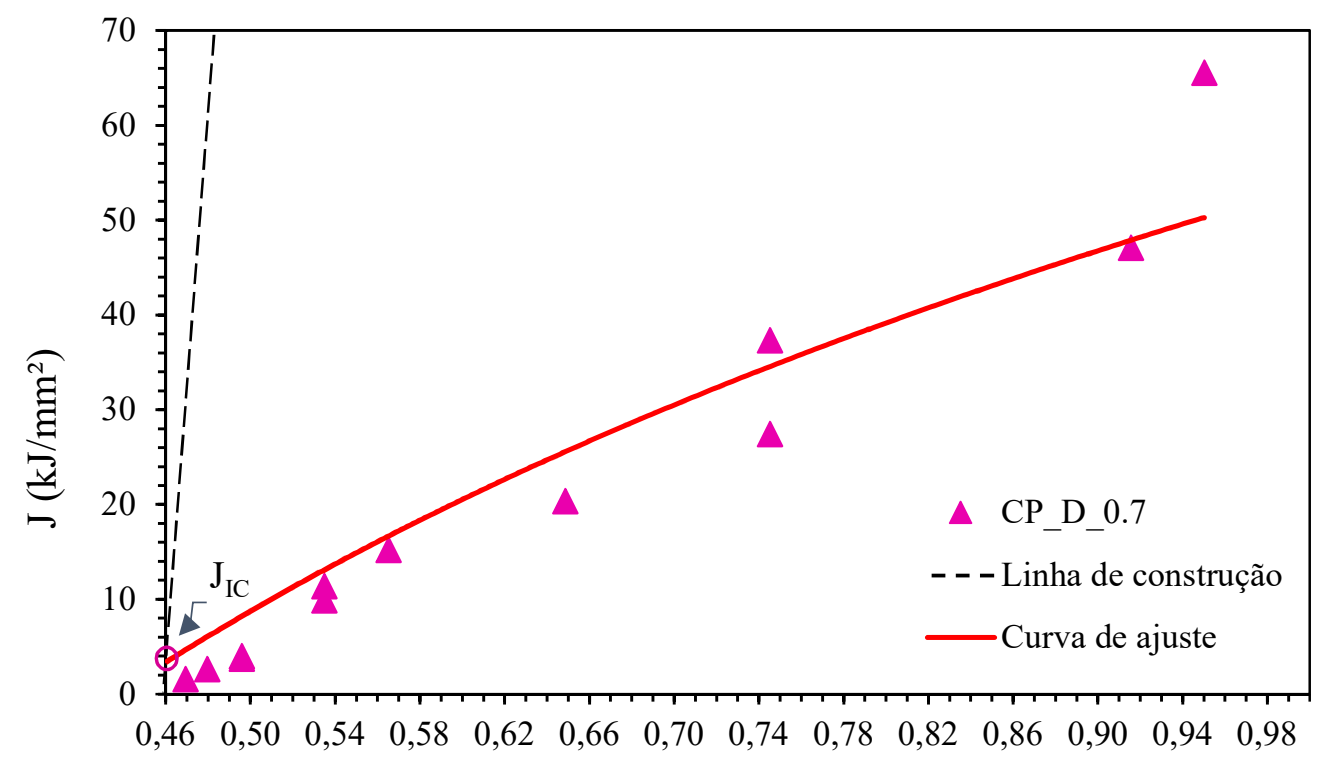

$\Delta \mathrm{a}(\mathrm{mm})$

Gráfico 10 - Plotagem dos pares J e $\Delta \mathrm{a}$ TOTAL para o CP_D_0.7.

Tabela XXXII - Comparação entre a dimensão da trinca mensurada com a calculada do CP_D_0.7

\begin{tabular}{|l|c|c|c|c|}
\hline \multicolumn{5}{|c|}{ Resultados para o CP_D_0.7 } \\
\hline & Mensurado $(\mathrm{mm})$ & & Compliance $(\mathrm{mm})$ & $\boldsymbol{\Delta}$ \\
\hline $\mathbf{a} \mathbf{M}(\mathbf{i})=$ & 18,1513 & $\mathbf{a 0 q}=$ & 18,5821 & $-0,43$ \\
\hline $\mathbf{a}_{\mathbf{p}}=$ & 18,6775 & $\mathbf{a f}=$ & 19,1015 & $-0,42$ \\
\hline$\Delta \mathbf{a}=$ & 0,5262 & $\Delta \mathbf{a p r e v i s t o}=$ & 0,5194 & 0,00678 \\
\hline
\end{tabular}

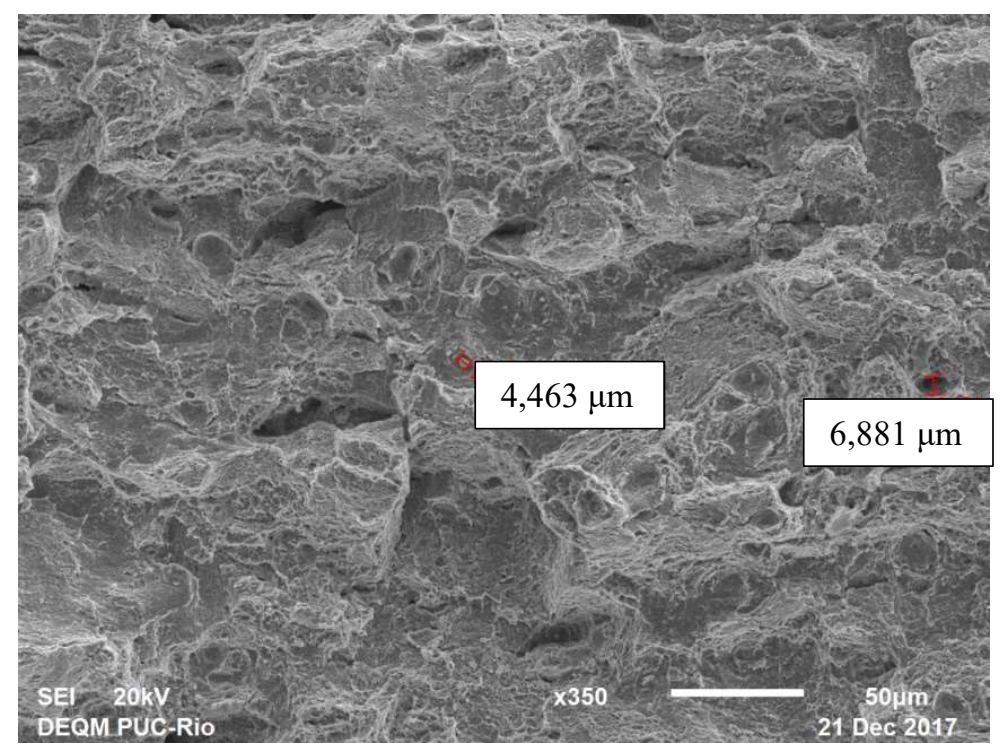

Figura 46 - Imagem micrográfica da extensão de trinca do CP_D_0.7.

O resultado da curva carga vs. CMOD adquirido para o corpo de prova CP_A_06, o qual foi submetido a um descarregamento primário de $1095 \mathrm{kN}$ e 
último descarregamento em torno de $34 \mathrm{kN}$, encontra-se disposta no Gráfico 10 . Para este corpo de prova, foi possível apurar 47 pontos incrementais com resultados dos parâmetros de ensaio apresentados na Tabela XXX. Com os dados adquiridos foi possível realizar o levantamento da curva-R para este material.

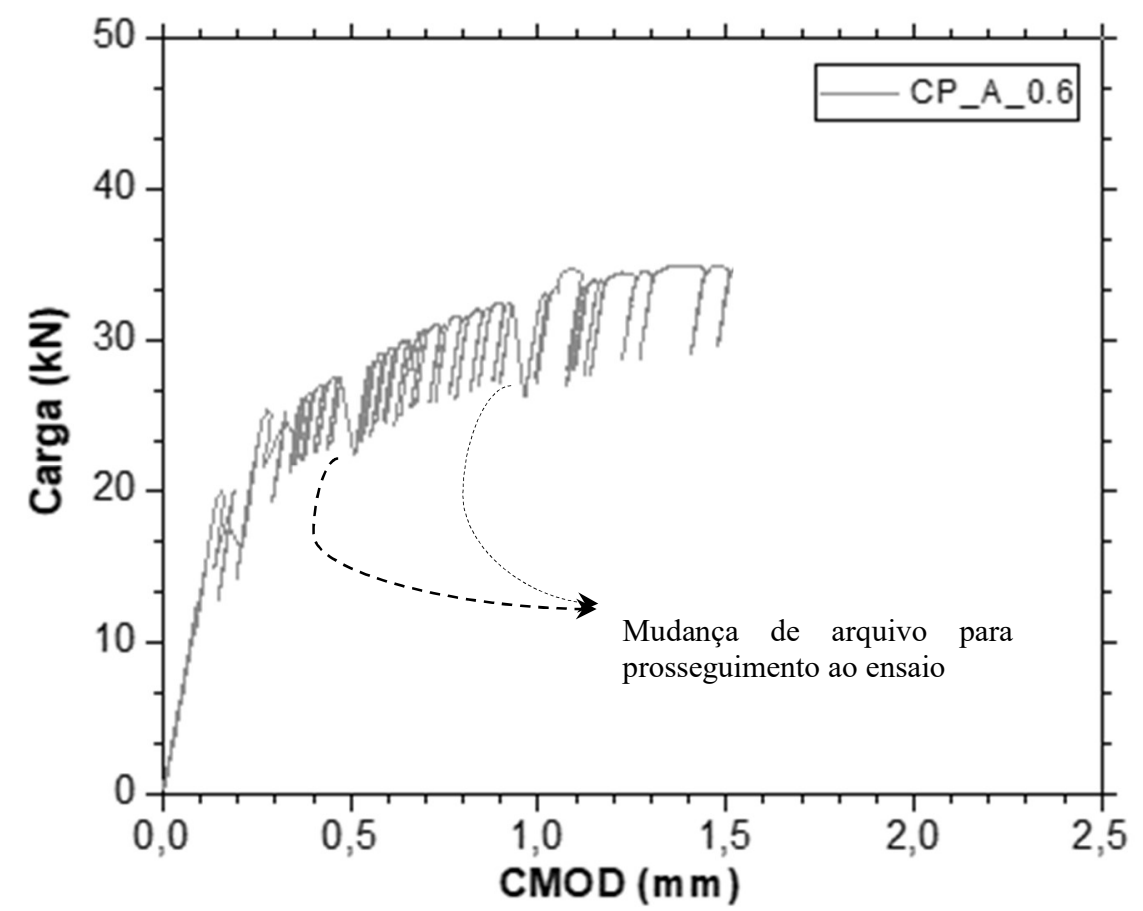

Gráfico 7 - Curva P vs. CMOD referente ao CP_A_0.6

Tabela XXXIII - Parâmetros do ensaio do CP_A_0.6

\begin{tabular}{|r|c|c|c|c|}
\hline \multicolumn{1}{|r|}{ Posição } & $\begin{array}{c}\mathbf{A M O D}_{(\mathbf{i})} \\
\mathbf{( m m}\end{array}$ & $\begin{array}{c}\mathbf{\Delta P}_{(\mathbf{i})} \\
\mathbf{( N )}\end{array}$ & $\begin{array}{c}\text { Compliance } \\
\text { medido }(\mathbf{m m} / \mathbf{N})\end{array}$ & $\boldsymbol{\mu}$ \\
\hline $\mathbf{1}$ & 0,0138 & 2287,3 & $5,90 \mathrm{E}-06$ & $2,14 \mathrm{E}-01$ \\
\hline $\mathbf{2}$ & 0,0142 & 2407,2 & $5,89 \mathrm{E}-06$ & $2,15 \mathrm{E}-01$ \\
\hline $\mathbf{3}$ & 0,0146 & 2482,7 & $6,00 \mathrm{E}-06$ & $2,13 \mathrm{E}-01$ \\
\hline $\mathbf{4}$ & 0,0155 & 2577,4 & $5,87 \mathrm{E}-06$ & $2,15 \mathrm{E}-01$ \\
\hline $\mathbf{5}$ & 0,0154 & 2617,7 & $6,06 \mathrm{E}-06$ & $2,12 \mathrm{E}-01$ \\
\hline $\mathbf{6}$ & 0,0151 & 2498,6 & $5,88 \mathrm{E}-06$ & $2,15 \mathrm{E}-01$ \\
\hline $\mathbf{7}$ & 0,0152 & 2587,6 & $6,02 \mathrm{E}-06$ & $2,13 \mathrm{E}-01$ \\
\hline $\mathbf{8}$ & 0,0159 & 2645,6 & $5,77 \mathrm{E}-06$ & $2,16 \mathrm{E}-01$ \\
\hline $\mathbf{9}$ & 0,0148 & 2563,9 & $5,90 \mathrm{E}-06$ & $2,14 \mathrm{E}-01$ \\
\hline $\mathbf{1 0}$ & 0,0169 & 2865 & $6,08 \mathrm{E}-06$ & $2,12 \mathrm{E}-01$ \\
\hline $\mathbf{1 1}$ & 0,0185 & 3045,6 & $5,87 \mathrm{E}-06$ & $2,15 \mathrm{E}-01$ \\
\hline $\mathbf{1 2}$ & 0,0201 & 3433,1 & $5,86 \mathrm{E}-06$ & $2,15 \mathrm{E}-01$ \\
\hline $\mathbf{1 3}$ & 0,0183 & 3119,8 & $5,92 \mathrm{E}-06$ & $2,14 \mathrm{E}-01$ \\
\hline $\mathbf{1 4}$ & 0,0192 & 3246,2 & $5,82 \mathrm{E}-06$ & $2,16 \mathrm{E}-01$ \\
\hline $\mathbf{1 5}$ & 0,0247 & 4239 & $5,87 \mathrm{E}-06$ & $2,15 \mathrm{E}-01$ \\
\hline
\end{tabular}




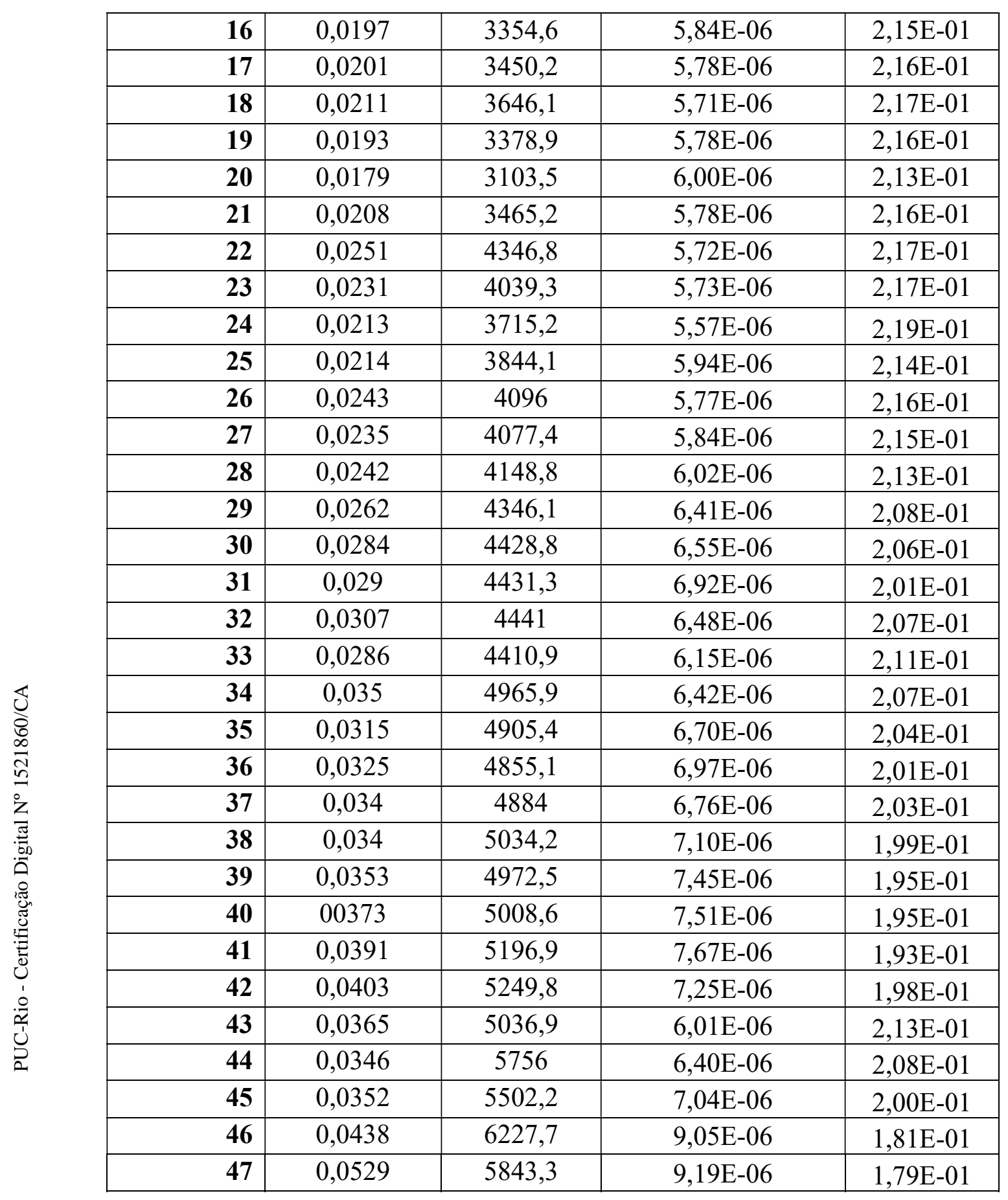

Tabela XXXIV - Parâmetros da curva J- $\Delta$ a do CP_A 0.6

\begin{tabular}{|r|c|c|c|c|c|}
\hline Posição & $\begin{array}{c}\mathbf{J} \\
\left(\mathbf{k J} / \mathbf{m}^{\mathbf{2}}\right)\end{array}$ & $\mathbf{a}(\mathbf{i}) / \mathbf{W}$ & $\begin{array}{c}\mathbf{a}(\mathbf{i}) \\
(\mathbf{m m})\end{array}$ & $\begin{array}{c}\Delta \mathbf{a} \\
(\mathbf{m m})\end{array}$ & $\begin{array}{c}\Delta \mathbf{a} \text { TOTAL } \\
(\mathbf{m m})\end{array}$ \\
\hline $\mathbf{1}$ & 2,296874471 & 0,626451589 & 15,661290 & $-0,00246$ & $-0,00246$ \\
\hline $\mathbf{2}$ & 2,513791861 & 0,626041406 & 15,651035 & $-0,01025$ & $-0,01271$ \\
\hline $\mathbf{3}$ & 2,719816924 & 0,629684751 & 15,742119 & 0,09108 & 0,07837 \\
\hline $\mathbf{4}$ & 2,662094935 & 0,625224299 & 15,630607 & $-0,11151$ & $-0,03314$ \\
\hline $\mathbf{5}$ & 2,95188536 & 0,631780855 & 15,794521 & 0,16391 & 0,13077 \\
\hline $\mathbf{6}$ & 2,776043297 & 0,625625993 & 15,640650 & $-0,15387$ & $-0,02310$ \\
\hline
\end{tabular}




\begin{tabular}{|c|c|c|c|c|c|}
\hline 7 & 3,25568639 & 0,630556965 & 15,763924 & 0,12327 & 0,10017 \\
\hline 8 & 3,080026788 & 0,621845986 & 15,546150 & $-0,21777$ & $-0,11760$ \\
\hline 9 & 3,661778341 & 0,626310014 & 15,657750 & 0,11160 & $-0,00600$ \\
\hline 10 & 9,561160294 & 0,632449574 & 15,811239 & 0,15349 & 0,14749 \\
\hline 11 & 9,32690732 & 0,625195186 & 15,629880 & $-0,18136$ & $-0,03387$ \\
\hline 12 & 10,10539734 & 0,625096578 & 15,627414 & $-0,00247$ & $-0,03634$ \\
\hline 13 & 10,30269182 & 0,626976888 & 15,674422 & 0,04701 & 0,01067 \\
\hline 14 & 10,26788411 & 0,623520214 & 15,588005 & $-0,08642$ & $-0,07574$ \\
\hline 15 & 16,95489711 & 0,625149553 & 15,628739 & 0,04073 & $-0,03501$ \\
\hline 16 & 16,74521512 & 0,624177996 & 15,604450 & $-0,02429$ & $-0,05930$ \\
\hline 17 & 17,05324215 & 0,62223621 & 15,555905 & $-0,04854$ & $-0,10784$ \\
\hline 18 & 17,38706787 & 0,619583378 & 15,489584 & $-0,06632$ & $-0,17417$ \\
\hline 19 & 17,59803189 & 0,622037183 & 15,550930 & 0,06135 & $-0,11282$ \\
\hline 20 & 18,65549753 & 0,629633136 & 15,740828 & 0,18990 & 0,07708 \\
\hline 21 & 18,07969958 & 0,622009159 & 15,550229 & $-0,19060$ & $-0,11352$ \\
\hline 22 & 19,24423788 & 0,619993152 & 15,499829 & $-0,05040$ & $-0,16392$ \\
\hline 23 & 19,77479226 & 0,620413494 & 15,510337 & 0,01051 & $-0,15341$ \\
\hline 24 & 31,16254488 & 0,614751974 & 15,368799 & $-0,14154$ & $-0,29495$ \\
\hline 25 & 32,33023587 & 0,627767167 & 15,694179 & 0,32538 & 0,03043 \\
\hline 26 & 31,07894366 & 0,621927834 & 15,548196 & $-0,14598$ & $-0,11555$ \\
\hline 27 & 32,26780869 & 0,624128981 & 15,603225 & 0,05503 & $-0,06053$ \\
\hline 28 & 32,80514911 & 0,630504833 & 15,762621 & 0,15940 & 0,09887 \\
\hline 29 & 39,69043822 & 0,643158923 & 16,078973 & 0,31635 & 0,41522 \\
\hline 30 & 40,97474318 & 0,647669039 & 16,191726 & 0,11275 & 0,52798 \\
\hline 31 & 45,56567433 & 0,658980949 & 16,474524 & 0,28280 & 0,81077 \\
\hline 32 & 50,1038246 & 0,645569966 & 16,139249 & $-0,33527$ & 0,47550 \\
\hline 33 & 59,83815804 & 0,634784764 & 15,869619 & $-0,26963$ & 0,20587 \\
\hline 34 & 80,27959745 & 0,64342332 & 16,085583 & 0,21596 & 0,42183 \\
\hline 35 & 81,39748516 & 0,652271454 & 16,306786 & 0,22120 & 0,64304 \\
\hline 36 & 86,09605291 & 0,66033611 & 16,508403 & 0,20162 & 0,84465 \\
\hline 37 & 91,07978333 & 0,654045691 & 16,351142 & $-0,15726$ & 0,68739 \\
\hline 38 & 101,7877234 & 0,664331391 & 16,608285 & 0,25714 & 0,94453 \\
\hline 39 & 110,8805621 & 0,674077332 & 16,851933 & 0,24365 & 1,18818 \\
\hline 40 & 121,7875781 & 0,675914137 & 16,897853 & 0,04592 & 1,23410 \\
\hline 41 & 136,1790665 & 0,680188027 & 17,004701 & 0,10685 & 1,34095 \\
\hline 42 & 150,2047062 & 0,668549998 & 16,713750 & $-0,29095$ & 1,05000 \\
\hline 43 & 165,7575678 & 0,630199406 & 15,754985 & $-0,95876$ & 0,09124 \\
\hline 44 & 223,9068653 & 0,642926809 & 16,073170 & 0,31819 & 0,40942 \\
\hline 45 & 226,2428736 & 0,66250383 & 16,562596 & 0,48943 & 0,89885 \\
\hline 46 & 238,9611279 & 0,714501284 & 17,862532 & 1,29994 & 2,19878 \\
\hline 47 & 261,3782149 & 0,717637457 & 17,940936 & 0,07840 & 2,27719 \\
\hline
\end{tabular}




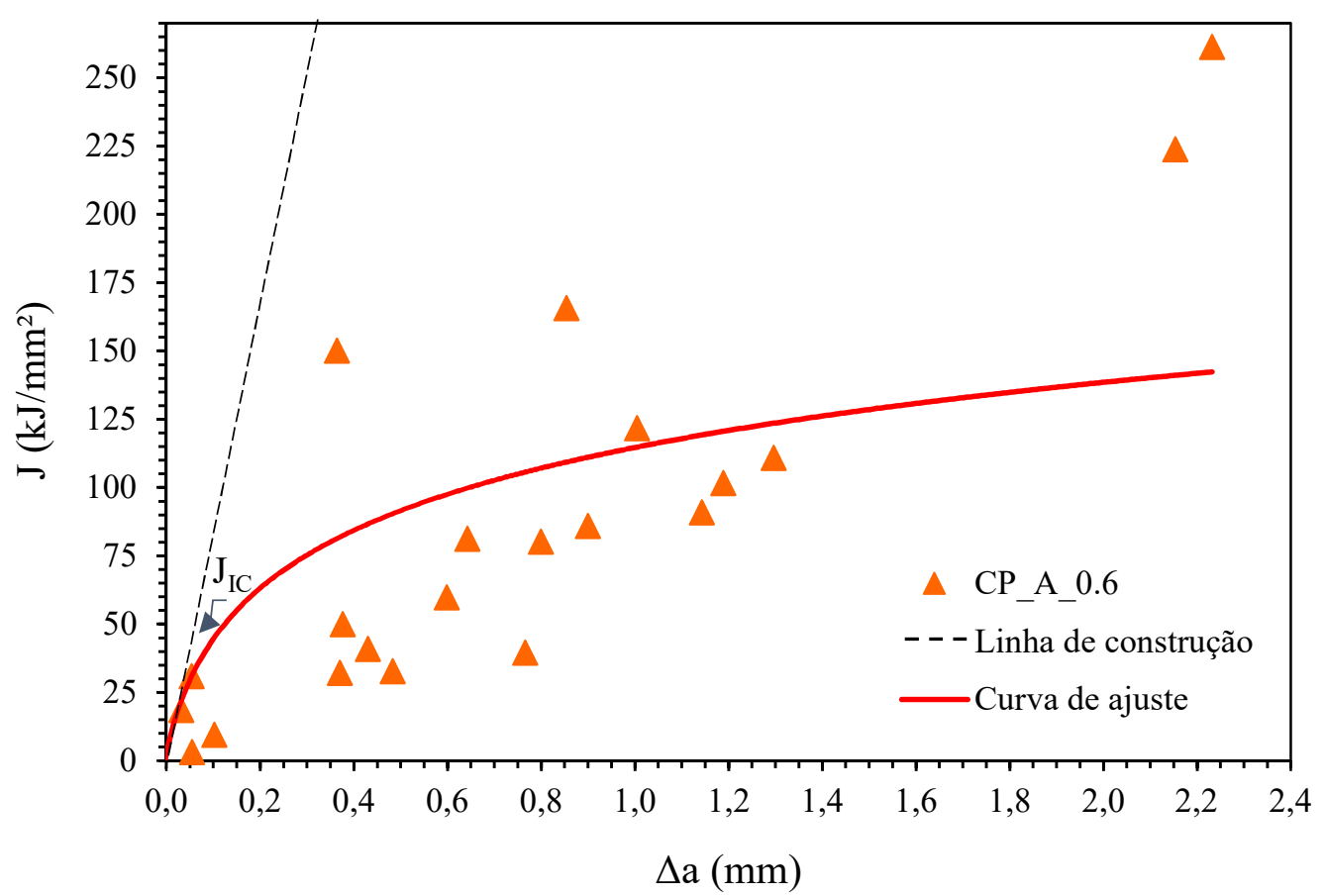

Gráfico 12 - Plotagem dos pares J e $\Delta$ a para CP_A_0.6

Tabela XXXV - Valor de JIC determinado a partir da curva J-R para o CP_A_0.6

\begin{tabular}{|c|c|}
\hline \multicolumn{2}{|c|}{ CP_A_0.6 } \\
\hline $\mathrm{J}_{\mathrm{IC}}\left(\mathrm{kJ} / \mathrm{m}^{2}\right)$ & $\Delta \mathrm{a} \min (\mathrm{mm})$ \\
\hline 35 & 0,1 \\
\hline
\end{tabular}

Observou-se que ambos os lados da superfície externa do corpo de prova deformaram-se à medida que ocorria o ensaio. Na pesquisa realizada por Francisco [26], mesmo que tenha sido ensaiado materiais distintos, também foi encontrado esta ocorrência, tendo em conhecimento que o corpo de prova SENT adotado por ele possuía valor de espessura de 12,8 mm e largura de $32 \mathrm{~mm}$ com uma razão de a/W equivalente a 0,5 . Acredita-se então que mesmo que o corpo de prova possua side-groove, não tem como garantir um estado plano de deformação durante o ensaio, fazendo com que ele apresente essa deformação na superfície do corpo de prova e propagação de trinca mais extensa próximo a raiz do side-groove. Outra observação levantada sobre a fractografia disposta na Figura 48, é que como a nucleação da pré-trinca de fadiga foi procedida após a usinagem do side-groove sua extensão também se caracterizou com dimensão maiores nas extremidades assim como a extensão dúctil de trinca. 

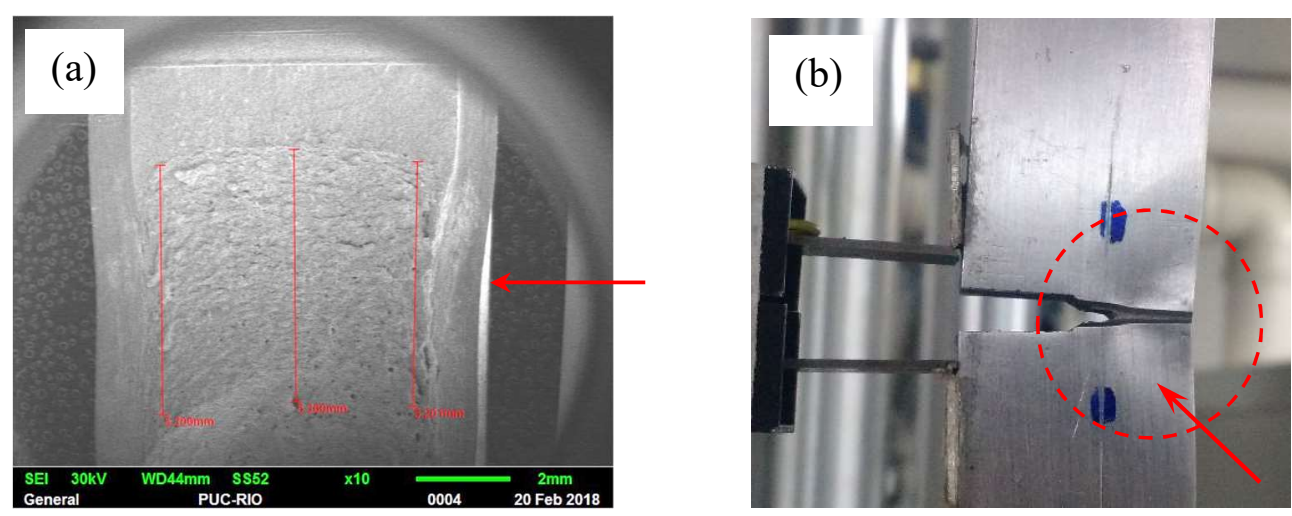

Figura 47 - Fractografia do CP_A_0.6. (a) Presença de tensão plana em um corpo de prova com side-groove; (b) superfície lateral do corpo de prova deformada.

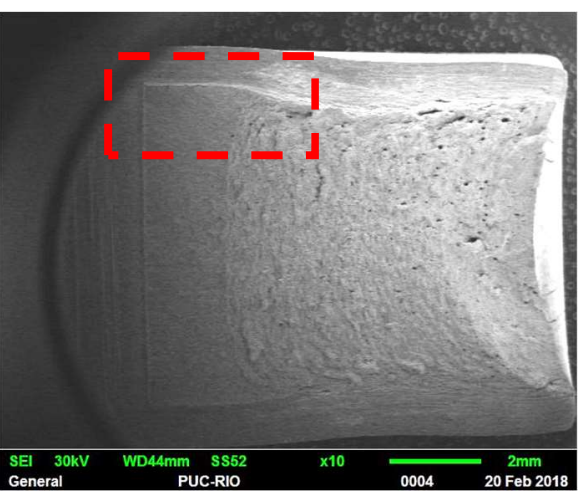

Figura 48 - Evidencia de estado plano de tensão na propagação da pré-trinca de fadiga

Em relevância pode-se dizer que os efeitos da plasticidade característica dos metais com boa ductilidade podem ser considerados uma das limitações quanto ao uso do método compliance, pois pode causar uma superestimativa de $\mathrm{J}$ ou a subestimativa dos valores de propagação dúctil de trinca ( $\Delta \mathrm{a}$ previsto), o que foi encontrado para o CP_A_0.6, como apresentado na Tabela XXXVI

Tabela XXXVI - Comparação entre a dimensão da trinca mensurada com a calculada do CP_A_0.6

\begin{tabular}{|l|c|c|c|c|}
\hline \multicolumn{5}{|c|}{ Resultados para o CP_A_0,6 } \\
\hline & Mensurado (mm) & & Compliance $(\mathrm{mm})$ & $\boldsymbol{\Delta}$ \\
\hline $\mathbf{a} \mathbf{M}(\mathbf{i})=$ & 15,66 & $\mathbf{a} 0 \mathbf{q}=$ & 15,68 & 0,00246 \\
\hline $\mathbf{a p}=$ & 22,09 & $\mathbf{a f}=$ & 17,95 & 4,1565 \\
\hline$\Delta \mathbf{a}=$ & 6,43 & $\Delta \mathbf{a}_{\text {previsto }}=$ & 2,28 & \\
\hline
\end{tabular}




\section{CONCLUSÕES}

Conforme dissertado, este trabalho apresentou um estudo de dois materiais

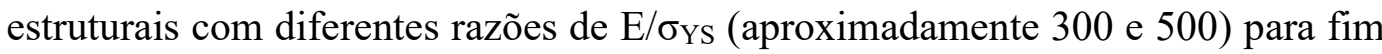
de comparação das curvas-R adotando-se corpos de prova do tipo SENT. Esta geometria é geralmente empregada quando utilizado materiais da série API com diferentes propriedades mecânicas. Como conclusões, tem-se:

1) Mesmo com a/W diferente daqueles indicados por normas para levantamento da curva- $R$, consegue-se obter tal curva para a/W $=0,2$

2) Para se conseguir obter uma curva J-R considerando todos os pontos experimentais adotando o método compliance, o primeiro valor do compliance medido precisa atingir um valor mínimo e ainda respeitar um valor mínimo incremental de $\Delta \mathrm{a}$

3) Existe uma limitação em aplicar a geometria SENT em materiais que não possuem extensa ductilidade 


\section{SUGESTÕES PARA TRABALHOS FUTUROS}

Uma alternativa para trabalhos futuros é empregar o estudo de materiais da série API para levantamento da curva- $\mathrm{R}$ utilizando o método compliance em geometria SENT com diferentes razões a/W, dando prioridade para as trincas mais rasas. Além de comparar o resultado do ensaio quando adotada a medição do deslocamento por intermédio do CMOD e do LLD. Em adição, uma comparação entre o método compliancce aplicando descarregamentos parciais de controle por carga e por controle por CMOD pode vir a ser realizada, não limitando a determinação apenas da integral-J, como também o trabalho desenvolveria a determinação do CTOD. 


\section{REFERÊNCIAS BIBLIOGRÁFICAS}

[1] AMERICAN SOCIETY FOR TESTING AND MATERIALS. ASTM E1820: standard test method for measurement of fracture toughness. Estados Unidos, 2017.

[2] AMERICAN SOCIETY FOR TESTING AND MATERIALS. ASTM E1290: standard test method for crack-tip opening displacement (ctod) fracture toughness measurement. Estados Unidos,2008.

[3] BRITISH STANDARD. BS 7448: fracture mechanics toughness tests. 2002

[4] J.P TAN; G.Z WANG; F.Z. XUAN; S.T. TU. Correlation of creep crack-tip constraint between axially cracked pipelines and test specimens. International Journal of Pressure Vessels and Piping, v.98, p.16-25, 2012.

[5] SEBASTIAN CRAVERO; CLAUDIO RUGGIERI. Correlation of fracture behavior in high pressure pipelines with axial flaws using constraint designed test specimens - Part I: plane-strain analyses. Engineering Fracture Mechanics, v. 72, p. $1344-1360$, 2005.

[6] X.-K.ZHU. Advances In Fracture Toughness Test Methods For Ductile Materials In Low Constraint Conditions. In. 14th INTERNATIONAL CONFERENCE ON PRESSURE VESSEL TECHNOLOGY. PROCEDIA ENGINEERING. Edison Welding Institute, 2015, p. $784-802$.

[7] R. WINSTON REVIE. Oil and gas pipelines integrity and safety handbook. 1.ed. New Jersey, 2015. 855p.

[8] HENRYK G PISARSKI. Determination of pipe girth weld fracture toughness using SENT specimens. In: PROCEEDINGS OF THE 8th 
INTERNATIONAL PIPELINE CONFERENCE. Calgary-Canada, 2010

[9] LENIN MARCELO PAREDE TOBAR; CLAUDIO RUGGIERI. Estimation Procedure of $J$ and CTOD fracture parameters for SE(T) fracture specimens based on the $\eta$ method. In. 20th INTERNATIONAL CONGRESS OF MECHANICAL ENGINEERING. Proceedings of COBEM 2009. Gramado - RS, 2009.

[10] GUOWU SHEN; JAMES A, GIANETTO; WILLIAN R. TYSON. Measurement of J-R curves using single-specimen technique on clamped SE(T) specimens. In: 19th INTERNATIONAL OFFSHORE AND POLAR ENGINEERING CONFERENCE. Osaka-Japão, 2009.

[11] CLAUDIO RUGGIERI. Further results in $\mathbf{J}$ and CTOD estimation procedures for $\mathrm{SE}(\mathrm{T})$ fracture specimens - Part I: homogeneous materials. Engineering Fracture Mechanics, v. 79, p. 245-265.

[12] DET NORSKE VERITAS. DNV-RP-F108: fracture control for pipeline installation methods introducing cyclic plastic strain. Noruega, 2006.

[13] B. TYSON; P.DING; X.WANG. Elastic compliance of single-edgenotched SE(T) (or SENT) specimens. Frattura Ed Integrità Strutturale. 2014, v. 30, p. 95 - 100.

[14] ExxonMobil. Measurement of crack-tip opening displacement (CTOD) - fracture resistance curves using single-edge notched tension (SENT) specimens. ExxonMobil Upstream Research Company, Houston, 2010.

[15] BRITISH STANDARD. BS 8571: Method od test for determination of fracture toughness in metallic materials using single edge notched tension (SENT) specimens. 2014

[16] AMERICAN SOCIETY FOR TESTING AND MATERIALS. ASTM E2472: standard test method for determination of resistance to stable crack extension under low-constraint conditions. Estados Unidos, 2012. 
[17] AGÊNCIA NACIONAL DE PETRÓLEO. Anuário estatístico brasileiro do petróleo gás natural e biocombustíveis. 2016

[18] AGÊNCIA NACIONAL DE PETRÓLEO. Boletim da produção de petróleo e gás natural. Março/2017

[19] DODDS, R. H. Jr.; SHIH, C. F.; ANDERSON, T. L. Continuum and micromechanics treatment of constraint in fracture. International Journal of Fracture. v. 64, p. 101-133, 1993.

[20] FBTS. Curso de Inspetor de Soldagem (CIS). Nível 1. v. 1. 16 ed. Rio de Janeiro, 2009. (Apostila)

[21] ULRICH KRUPP. Fatigue crack propagation in metals and alloys: microstructural aspects and modelling concepts. 1 ed. Weinheim, 2007. 312p

[22] HIBBELER, RUSSEL CHARLES. Resistência dos materiais. 7 ed. Pearson, São Paulo, 2010. 659p.

[23] ANDERSON, T. L. Fracture Mechanics: fundamentals and applications. 3 ed. Boca Raton, Florida: CRC Press, 2005. 640p.

[24] XIAN-KUI ZHU; JAMES A. JOYCE. Review of fracture toughness (G, K, J, CTOD, CTOA) testing and standardization. Engineering Fracture Mechanics, v. 85, p. 1-46, 2012.

[25] WILLIAM D. CALLISTER, JR. Ciência e engenharia de materiais: uma introdução. 8 ed. LTC, Rio de Janeiro, 2012. 817p.

[26] FRANCISCO, J.C.S, Avaliação da tenacidade à fratura de aço API 5I X70 utilizado na fabricação de dutos transportadores de gás e petróleo, Dissertação, 2009, USP-São Carlos

[27] INGLIS, C. E. Stresses in a plate due to the presence of cracks and sharp corners. Transactions of the Institute of Naval Architects, v. 55, p. $219-241,1913$

[28] GRIFFITH, A. A. The phenomena of rupture and flow in solids. Philosophical Transactions of the Royal Society, London, v. 221, p. 163-198. 
[29] IRWIN. Analyses of stresses and strains near the end of a crack traversing a plate. Journal of Applied Mechanics. p. 361-364, 1957.

[30] H. P. ROSSMANITH. Teaching and education in fracture and fatigue. Vol. 1. Viena, 1996. 336p.

[31] JAGANNDHAM, K; MARCINKOWSKI, M. J. Unified theory of fracture. $795 p$

[33] HERTZBERG, RICHARD W. Deformation and fracture mechanics of engineering materials. 5 ed. 2013. 755p.

[34] BROEK, DAVID. The practical use of fracture mechanics.1988, $588 p$.

[35] WELLS, A. A.. Unstable crack propagation in metals: cleavage and fast fracture. In: Synposium on crack propagation, 1961, Cranfiels. Proceedings. Cranfield: [s.n.]. v. 1; p.210-230

[36] J. R. RICE. A path independente integral and the approximate analysis of strain concentration by notches and cracks. Journal of Applied Mechanics, v. 35, p. 379-386, 1968.

[37] TADA, H.; PARIS, P.C; IRWIN, G.R. The stress analysis of crack handbook. St. Louis: Paris Production.

[38] CICERO, SERGIO; GUTIÉRREZ-SOLANA, F.; ÁLVAREZ, J.A. Structural integrity assessment of componentes subjected to low constraint condictions. Engineering Fracture Mechanics, v. 75, p. 3038-3059, 2008.

[39] TKACH, Y; BURDEKIN, F.M. A three-dimensional analysis of fracture mechanics test pieces of diferente geometries - Part 2 constraint and material variations. International Journal of Pressure Vessels and Piping. v. 93-94, p. 51-56, 2012.

[40] CHIESA, M; NYHUS, B. Efficcient fracture assessment of pipelines. A constraint-corrected SENT specimen approach. Engineering Fracture Mechanics. v. 68, p 527-547, 2001. 
[41] CLARKE, G. A.; LANDES, J. D. Evaluation of the J-integral for the compact specimen. Journal of Testing and Evaluation. v. 7 (5), p. 264-269, 1979.

[42] JOYCE, J. Manual on elastic-plastic fracture: Laboratory test procedures. Pensilvânia: ASTM manual series-MNL 27,1966

[43] M. SULLIVAN, New specimen design for plane-strain fracture toughness tests. Mat. Res. Standard. v. 4, p. 20-24, 1964.

[44] J.E. SRAWLEY, M.H. JONES, B. GROSS, Experimental determination of the dependence of crack extension force on crack length for a single-edge-notch specimen. NASA TN-D2396, 1964

[45] J.E. SRAWLEY, M.H. JONES, B. GROSS, Fracture toughness testing, NASA TN-D-2599, 1965

[46] TADA, P. C PARIS, G. R. IRWIN, The stress analysis of cracks handbook, Del Research Corporation, Hellertown, PA, USA, 1973.

[47] X.-K. ZHU, Advances in fracture toughness test methods for ductile materials in low-constraint conditions. In. 14th INTERNATIONAL CONFERENCE ON PRESSURE VESSEL TECHNOLOGY. Procedia Engineering, v.130, p. 784-802,2015

[48] JOYCE, J. A; LINK, R. E. Effects of constraint on upper shelf fracture toughness. Fracture Mechanics 26th Volume. ASTM STP 1256, ASTM, 1995.

[49] ZHU, XIAN-KUI. J-integral resistance curve testing and evaluation. Journal of Zhejiang University Science A. v. 10, p. 15411560, 2009.

[50] ZHU, XIAN-KUI. Full-range stress intesity fator solutions for clamped SENT specimens. International Journal of Pressure Vessels and Piping. v. 149, p. 1-13, 2017.

[51] CRAVERO,S. Desenvolvimento de procedimentos para avaliação de curvas $\mathrm{J}-\mathrm{R}$ em espécimes à fratura $\mathrm{SE}(\mathrm{T})$ utilizando o método de flexibilidade, Tese, 2007, USP. 
[52] RUGGIERI, C; CRAVERO, S. Estimation of J-resistance curves for $\mathrm{SE}(\mathrm{T})$ fracture specimens using unloading compliance. Engineering Fracture Mechanics. v. 74, p. 2735-2757, 2007.

[53] BLATT, D; JOHN, R; COKER, D. Stress intensity factor and compliance solutions for a single edge notched specimen with clamped ends. Engineering Fracture Mechanics. v. 47, p. 521-532, 1994.

[54] JOHN, R. Stress intensity factor and compliance solutions for a eccentrically loaded single edge cracked geometry. Engineering Fracture Mechanics. v. 58, p. 87-96, 1997.

[55] JOHN, R; RIGLING,B. Effect of height to width ratio on $\mathrm{K}$ and CMOD solutions for a single edge cracked geometry with clamped ends. Engineering Fracture Mechanics. v. 60, p. 147-156, 1998.

[56] ARCELORMITTAL. Barra Chata. Ordem de venda 6176511. Rio de Janeiro: ANOX, 2015. Certificado de Qualidade ASTM A36

[57] RIPLING, E.J.; MULHERIN, J. H.; CROSLEY, P.B. Crack arrest toughness of two high strength steels (AISI 4140 and AISI 4340). Metallurgical Transaction A. v. 13A, p. 657-664, 1982.

[58] AMERICAN SOCIETY FOR TESTING AND MATERIALS. ASTM E8M - 16a: Standard test methods for tension testing of metallic materials. West Conshohocken. 2016 